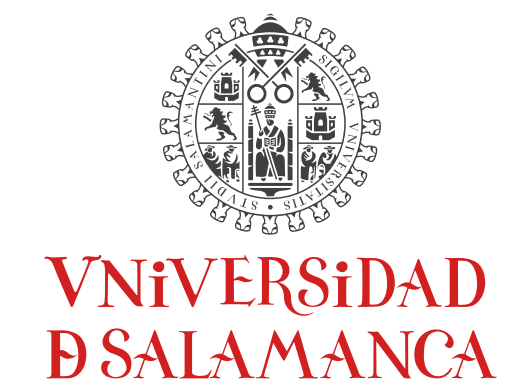

CAMPUS OF INTERNATIONAL EXCELLENCE

Doctoral Dissertation

\title{
Characterization by Next Generation Sequencing of mutations of spliceosome genes and bone marrow mesenchymal cells in patients with myelodysplastic syndromes
}

\author{
With the approval of Salamanca University, Department of \\ Medicine, this thesis will be defended on $24^{\text {th }}$ July 2019 , in the \\ Lecture Hall, Centro de Investigación del Cáncer-IBMCC, \\ Salamanca. \\ Supervisors:
}

Prof. Dr. Jesús M. Hernández Rivas

Dra. María Diez Campelo

Dra. María Abáigar Alvarado

Kamila Janusz

2019

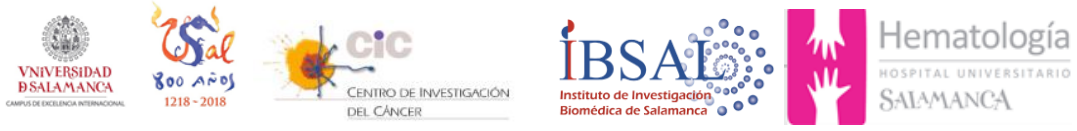


$\begin{array}{lr}\text { Introduction } & 7\end{array}$

1. MYELODYSPLASTIC SYNDROMES - OVERVIEW 9

1.1. Epidemiology 9

1.2. Etiology 9

1.3. Diagnosis 9

$\begin{array}{ll}\text { 1.4. Classification } & 10\end{array}$

$\begin{array}{ll}\text { 1.4.1.Risk stratification systems } & 13\end{array}$

2. MDS: GENOMIC ABNORMALITIES

2.1. Cytogenetics in MDS patients $\quad 14$

2.2. Overview of gene mutations in MDS $\quad 15$

2.2.1.Mutations in the RNA Splicing machinery components $\quad \mathbf{1 7}$

3. MDS: MICROENVIRONMENT 19

3.1. Healthy mesenchymal stromal cells $\quad 20$

3.2. MDS mesenchymal stromal cells $\quad 21$

3.2.1.3.2.1MSC: Cytogenetics $\quad 21$

3.2.2.MSC: Molecular profile of MSC in MDS $\quad 21$

4. APPLICATIONS OF NEXT GENERATION SEQUENCING IN MDS STUDY 22

$\begin{array}{lr}\text { Hypothesis } & \mathbf{2 7}\end{array}$

$\begin{array}{ll}\text { Aims } & 31\end{array}$

$\begin{array}{ll}\text { Results } & 35\end{array}$

Chapter 1: A two-step approach for sequencing spliceosome-related genes as a complementary diagnostic assay in MDS patients with ringed sideroblasts

Chapter 2: Clincal, biological and prognostic implication of SF3B1 co-occurrence mutations in very low/low and intermediate-risk MDS patients

Chapter 3: Mutational status of mesenchymal stromal cells in myelodysplastic syndromes patients

$\begin{array}{ll}\text { General discussion } & \mathbf{8 1}\end{array}$

$\begin{array}{lr}\text { Concluding remarks } & 89\end{array}$

$\begin{array}{ll}\text { References } & 93\end{array}$ 
List of Tables and Figures

Abbreviations

121 
Introduction 


\section{Myelodysplastic Syndromes - Overview}

Myelodysplastic syndromes (MDS) are clonal disorders of hematopoietic progenitor cells [1]. They are characterized by ineffective hematopoiesis, dysplasia of at least one hematopoietic lineage, hypercellular bone marrow (BM), and peripheral blood (PB) cytopenias, with an increased risk of leukemic transformation [2-6].

\subsection{Epidemiology}

MDS are a group of diseases of elderly with predominance in men [7]. The median age of patients at diagnosis is 70 years, among the different nationalities, except for Asian population, with the lowest median age of 49 [8-11]. The age-adjusted incidence is 4.9 per 100,000 cases per year and it increases with age, being up to 30 in patients above 70 years old $[1,12]$.

\subsection{Etiology}

Different risk factors can contribute to the development of primary MDS. The main ones include: advanced age, male gender, and environmental agents such as benzene, ionizing radiation, excess alcohol and tobacco smoking [13, 14]. Furthermore, exposure to radiation or chemotherapy may be the cause of secondary or therapy related-MDS [3]. By contrast, the MDS in younger patients is more related to from bone marrow failure syndromes such as Fanconi Anemia, dyskeratosis congenita or Schwachman-Diamond syndrome $[1,15]$.

\subsection{Diagnostics}

MDS are very heterogeneous group of diseases, thereby the diagnosis is often very challenging. However, usually the suspicion of MDS diagnosis is based on the presence of cytopenia in a routine analysis of peripheral blood [16]. The WHO recommended threshold levels of cytopenias came from those previously reported in the International Prognostic Scoring System (IPSS) considering anemia when $\mathrm{Hb}$ is low than $10 \mathrm{~g} / \mathrm{dL}$, 
thrombocytopenia when platelet count $<100 \times 10^{9} / \mathrm{L}$ and neutropenia when absolute neutrophil count $(\mathrm{ANC})<1.8100 \times 10^{9} / \mathrm{L}$ [17]. Furthermore in order to confirm MDS diagnosis, morphological evaluation of peripheral blood smear and bone marrow aspirate is performed [18]. The BM in MDS is usually hypercellular with dysplasia in one or more lineages (erythroid, granulocytic, megakaryocytic) [19-22]. The recommended requisite percentage of cells manifesting dysplasia to qualify as significant is $\geq 10 \%$ [23]. In patients where cytopenias are moderate and marrow dysplasia is mild, detection of a chromosomal abnormality (karyotype and/or FISH), flow cytometry analysis, as well as mutational analysis are considered to better define MDS subtypes and prognosis of these patients [16, 24-26]. The proportion of blasts in the BM must also be assessed to provide a correct classification [27].

\subsection{Classifications}

There are two classification systems for MDS patients. The French-American-British (FAB) classification scheme for MDS was described in 1982 and has become the reference standard for subsequent MDS classification schemes [28]. Five subgroups with significantly different prognoses were established, taking into account PB and BM percentage of blasts, number of monocytes in PB and percentage of ringed sideroblasts.[28, 29]. In 2001, the World Health Organization (WHO) published a new classification for hematopoietic and lymphoid neoplasms. Therefore apart of previously considered morphologic findings, WHO added available information including genetic, immunophenotypic, biologic and clinical features making a main changes to the $F A B$ division [30]:

- A new subtypes $5 q$ syndrome as well as refractory cytopenia with multilineage dysplasia without and with ring sideroblasts (RCMD, RCMD-RS) were defined.

- RAEB-t was considered as acute myeloid leukemia (AML).

- RAEB was split into two different subtypes: RAEB-1 and RAEB-2 based on blasts percentage.

- $\mathrm{CMML}$ was included into the myelodysplastic/myeloproliferative syndromes group. 
The growing number of research studies that have been performed since then contributed to the update in 2008 of the WHO classification, which redifined diagnostic criteria and introduced newly recognized disease entities which are shown in Table 1 [31].

Table 1. WHO 2008 classification of MDS (Adapted from Vardiman et. al, 2009, Blood)[31].

\begin{tabular}{|c|c|c|c|c|}
\hline \multirow{2}{*}{ MDS subtype } & \multicolumn{2}{|c|}{ Blood findings } & \multicolumn{2}{|c|}{ Bone marrow findings } \\
\hline & Cytopenia & Blasts & Dysplasia & Blasts \\
\hline $\begin{array}{l}\text { RCUD } \\
\text { (RA, RN, RT) }\end{array}$ & $\begin{array}{l}\text { Unicytopenia/ } \\
\text { bicytopenia }\end{array}$ & $\begin{array}{l}\text { No or rare blasts } \\
(<1 \%)\end{array}$ & $\begin{array}{l}\text { Unilineage } \\
\text { dysplasia: } \geq 10 \% \\
\text { of the cells in one } \\
\text { myeloid lineage }\end{array}$ & $\begin{array}{l}<5 \% \text { blasts } \\
<15 \% \text { ringed } \\
\text { sideroblasts }\end{array}$ \\
\hline RARS & Anemia & No blasts & Erythroid & $\begin{array}{l}<5 \% \text { blasts } \\
\geq 15 \% \text { ringed } \\
\text { sideroblasts }\end{array}$ \\
\hline RCMD & Cytopenia & $\begin{array}{l}\text { No or rare blasts } \\
(<1 \%) \\
\text { No Auer rods }\end{array}$ & $\begin{array}{l}\geq 10 \% \text { of cells in } 2 \\
\text { or more myeloid } \\
\text { cell lineages }\end{array}$ & $\begin{array}{l}<5 \% \text { blasts } \\
\pm 15 \% \text { ringed } \\
\text { sideroblasts No } \\
\text { Auer rods }\end{array}$ \\
\hline RAEB-1 & Cytopenia(s) & $\begin{array}{l}<5 \% \text { blasts } \\
\text { No Auer rods }\end{array}$ & $\begin{array}{l}\text { Unilineage/ } \\
\text { multilineage }\end{array}$ & $\begin{array}{l}5-9 \% \text { blasts No } \\
\text { Auer rods }\end{array}$ \\
\hline RAEB-2 & Cytopenia(s) & $\begin{array}{l}5-19 \% \text { blasts } \\
\text { Auer rods } \pm\end{array}$ & $\begin{array}{l}\text { Unilineage/multi } \\
\text { lineage }\end{array}$ & $\begin{array}{l}10-19 \% \text { blasts } \\
\text { Auer rods } \pm\end{array}$ \\
\hline MDS-U & Cytopenias & $<1 \%$ blasts & $\begin{array}{l}<10 \% \text { of cells in } 1 \\
\text { or more myeloid } \\
\text { lineages }+ \\
\text { cytogenic } \\
\text { abnormality }\end{array}$ & $<5 \%$ blasts \\
\hline $\begin{array}{l}\text { MDS associated } \\
\text { with isolated } \\
\text { del(5q) }\end{array}$ & Anemia & $\begin{array}{l}\text { No or rare blasts } \\
(<1 \%)\end{array}$ & & $\begin{array}{l}<5 \% \text { blasts } \\
\text { Isolated del }(5 q) \\
\text { No Auer rods }\end{array}$ \\
\hline
\end{tabular}

RCUD: refractory cytopenia with unilineage dysplasia; RA: refractory anemia; RN: refractory neutropenia; RT: refractory thrombocytopenia; RARS: refractory anemia with ringed sideroblasts; RCMD: refractory cytopenia with multilineage dysplasia; RAEB-1: refractory anemia with excess blasts-1; RAEB-2: refractory anemia with excess blasts-2; MDS-U: myelodysplastic syndromeunclassified.

A novel MDS WHO classification system was published in 2016, which allows a more accurate diagnosis and risk assessment. This new classification system is based, as before, on clinical features, morphology and cytogenetics, and includes for the first time information from mutational analysis. Among the wide spectrum of molecular data that are available for myeloid neoplasms, SF3B1 mutational status has been included and recognized to define MDS with ring sideroblasts (MDS-RS) (Table 2) [32]. 
Table 2. WHO 2016 classification of MDS (Adapted from Arber et. al, 2016, Blood)[32].

MDS-SLD: MDS with single lineage dysplasia; MDS-MLD: MDS with multilineage dysplasia; MDS-RS: MDS with ring sideroblasts; MDSRS-SLD: MDS-RS with single lineage dysplasia; MDS-RS-MLD: MDS-RS with multilineage dysplasia; MDS-EB: MDS with excess blasts; MDS-U: MDS unclassifiable.

The patients included in this Ph.D. thesis were classified according to WHO 2008 and 2016 criteria, with the exception of cases with RCMD-RS, which were maintained as a separate category according to WHO 2001, due to the distinctive characteristic of presenting ring sideroblasts and multilineage dysplasia. 


\subsubsection{Risk stratification systems}

MDS include several different entities. Therefore it is necessary to have systems that help to establish the prognosis of each patient in order to assess the need and the type of treatment they should receive. The most commonly used system is the International Prognostic Scoring System (IPSS) established in 1997 by Greenberg P. and his colleagues [33]. The prognostic score includes blasts percentage, number of cytopenias and chromosomal abnormalities, stratified over different cytogenetic risk groups [28]. However, over time, IPSS has been noted as not very precise predictor of prognosis in lower-risk patients [34]. Therefore the IPSS has been revised (IPSS-R) in order to capture more inclusive cytogenetic characterization, more stringent blast description, and more detailed cytopenia assignments, making it becomes reliably tool for estimate survival and risk of transformation to AML in all MDS patients [35]. Table 3 represent description of both prognostic scoring system (IPSS, IPSS-R) including stratification of chromosomal abnormalities into various cytogenetic risk group, score values of prognostic variables and the risk score corresponding to different risk group.

The beginning of XXI century has been significantly ifluenced by the results from the Human Genome Project (HGP), and conseuqently by the discovery and wide use of next generation sequencing (NGS). Huge amounts of molecular data were initially generated by the HGP, and afterwards by a wide spectrum of research studies conducted on large cohorts of patients suffering from different hematological malignancies, providing significant knowledge about the pathogenesis of these disorders [36-39]. Among these studies it has been demostrated that some gene mutations have a significant influence in the prognosis of the patients [40-46]. For this reason, a proposal to include this molecular knowledge into the IPSS-R stratification system is being carried out. In fact, mutations of $C B L, I D H 2, A S X L 1, D N M T 3 A$ and TP53 has been independently associated with shorter survival [46]. Each IPSS-R group or 2016 WHO MDS subtype could be divided into 2 risk subgroups based on the molecular status of this five genes, demostrating the utility and importance of considering the previous acquired wide molecular knowledge [46]. 
Table 3. A comparison between the International Prognostic Scoring System (IPSS) and the Revised International Prognostic Scoring System (IPSS-R) (adapted from Greenberg et al., 1997, Blood; Greenberg et al., 2012, Blood) [33, 35].

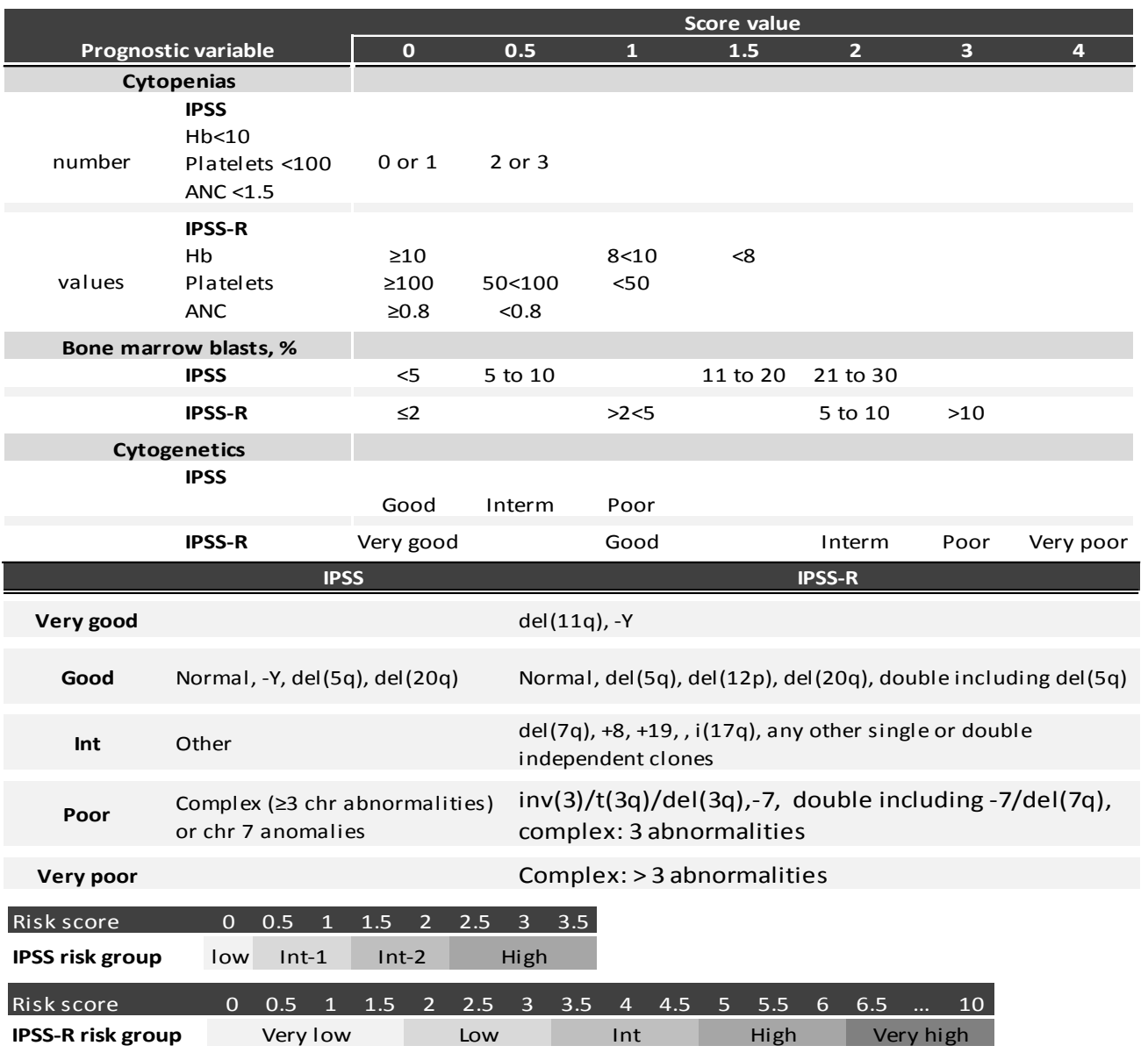

\section{MDS: Genomic abnormalities}

\subsection{Cytogenetics in MDS patients}

One of the most common characteristics of MDS patients is the presence of chromosomal alterations affecting BM cells. Acquired cytogenetic abnormalities are found in $40-50 \%$ of cases with MDS and their analysis play a fundamental role in disease classification, evolution, drug response and overall survival [47-49]. Among cytogenetic changes, deletions of the long arm of chromosome 5 , del( $5 q)$, are the most frequently chromosomal abnormality found in MDS patients, affecting up to $15 \%$ of diagnosed cases $[48,50]$. MDS with isolated del(5q) is the only cytogenetics-based defined MDS subtype [51]. Patients with del(5q) as unique alteration, often have a good prognosis. Nevertheless, when additional chromosomal aberrations are present, prognosis becomes unfavorable. The $5 q 31$ is the most frequent commonly deleted region $[47,52]$. Trisomy of 
chromosome 8 , del(20q), del(7q) and monosomy 7 are other common chromosomal lesions in MDS. The recurrent chromosomal abnormalities and the incidence in MDS are shown in Figure $1[49,53]$.

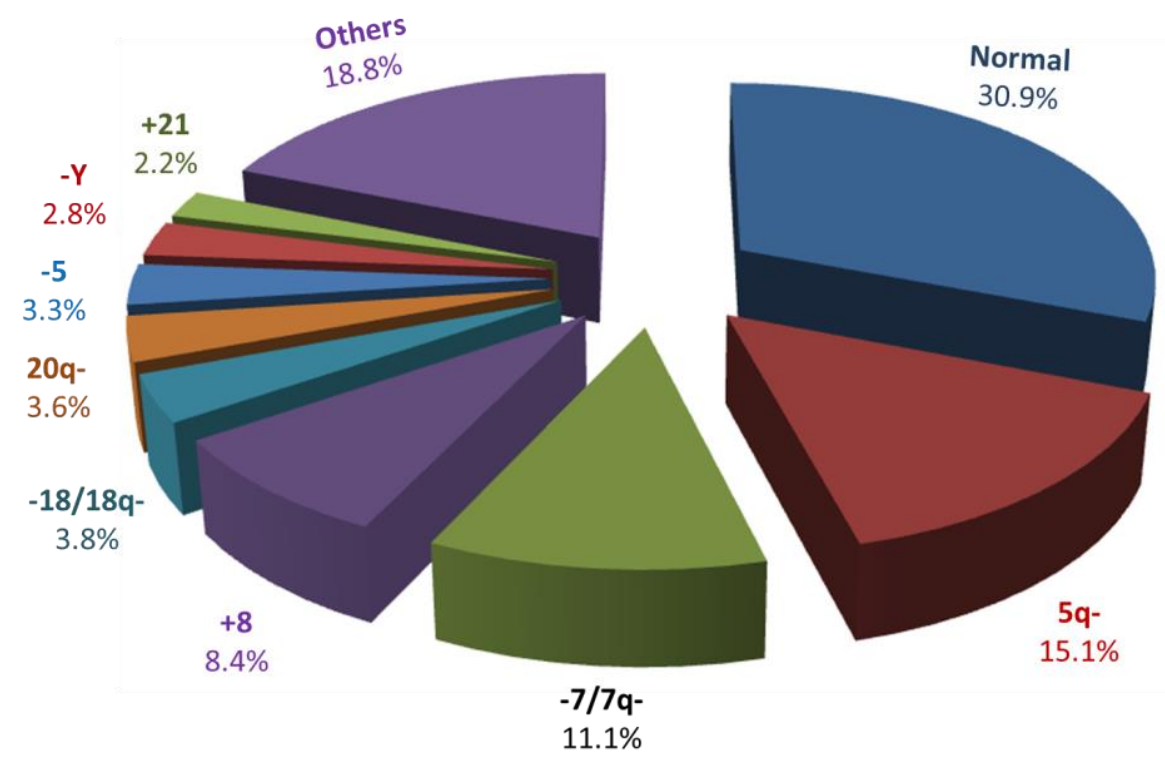

Figure 1. Incidence of chromosome abnormalities in MDS (adapted from Haase D., 2008, Ann Hematol)[54].

The cytogenetic alterations are one of the most important factors associated with the outcome in MDS. Therefore cytogenetics must be analyzed in these patients to assess the IPSS and the IPSS-R (Table 3$)[55,56]$.

\subsection{0verview of gene mutations in MDS}

The use of massive parallel deep-sequencing techniques (whole genome, whole exome and targeted gene sequencing) in a large number of patients with various hematological malignances, led to the identification of new sets of recurrent mutations, hereby providing new insights into the pathophysiology of MDS. Mutations affect the majority of newly diagnosed cases of MDS (covering approximately $90 \%$ of patients with MDS) even with a normal karyotype. The high number of driver genes affected in MDS patients can be classified into different cellular processes: epigenetic regulators (TET2, DNMT3A, IDH1, IDH2, ASXL1, EZH2), transcription factors (ETV6, RUNX1, TP53), cohesins (STAG2, RAD21), signal transduction proteins ( $C B L, J A K 2, K R A S, N R A S)$, and genes related to the RNA 
splicing machinery (SF3B1, SRSF2, U2AF1, ZRSR2) [25, 37, 57-59]. The frequency of driver mutations, considering the MDS subtype is shown in Figure 2.

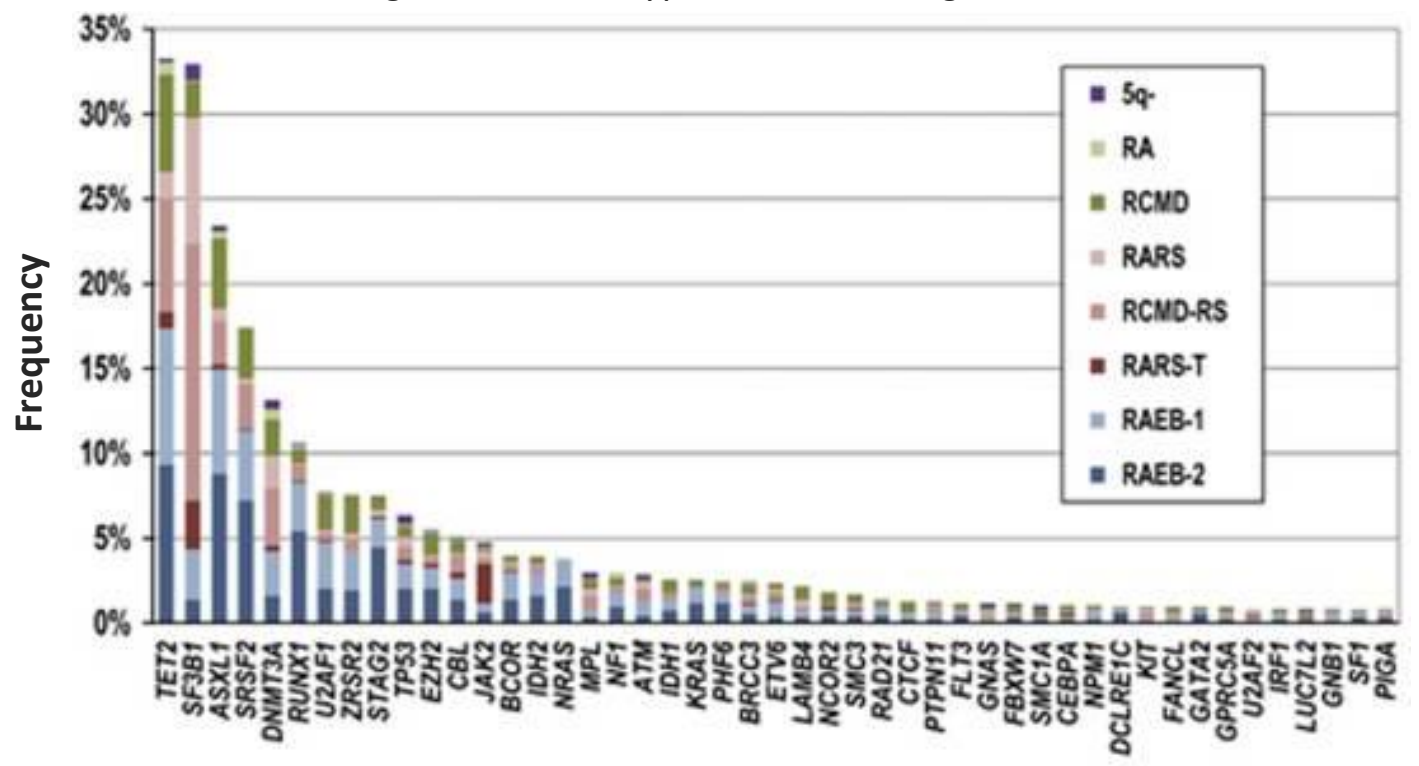

Figure 2. Frequency of driven mutations according to the MDS subtype (Haferlach et al., 2014, Leukemia)[38].

It has been shown that approximately $40 \%$ of patients carried 2 or 3 mutated genes, while $10 \%$ of cases presented from 4 to 8 oncogenic point mutations [38]. In this scenario where multiple gene mutations may be present in one single patient, gene-gene interactions are of great interest, and can be of either co-occurrence or mutually exclusivity. Mutually exclusive relationship has been reported between SRSF2 mutations and mutations/deletions of DNMT3A, EZH2, and IRF1, and also between ASXL1 and DNMT3A. Similarly, no affinity of SF3B1 with common mutational targets, other than DNMT3A and JAK2, has been found. By contrast, the co-occurrence among mutations/deletions in STAG2, IDH1, ASXL1, RUNX1 and BCOR genes has been reported $[37,38]$.

Some of these gene mutations are associated with clinical features such as complex karyotypes (TP53), excess BM blast proportion (RUNX1,NRAS), and the presence of ring sideroblasts (SF3B1) [40,60]. Furthermore, mutations in TP53, EZH2, ETV6, RUNX1 as well ASXL1 have been described as predictors of poor overall survival, unlike SF3B1 with a better outcome for the MDS patients $[58,61]$. 


\subsubsection{Mutations in in the RNA splicing machinery components}

Splicing process represents the key link between transcription and translation, that allows the production of multiple mRNA isoforms of more than $90 \%$ of human protein-coding genes [62]. This process consists in removing introns and joining exons together in order to produce a mature mRNA molecule [63]. This process is catalyzed by the spliceosome, a protein complex comprised of a core of five small nuclear ribonucleoproteins (snRNP) U1, $\mathrm{U} 2, \mathrm{U} 4, \mathrm{U} 5$ and $\mathrm{U} 6$ what is represented in Figure $3[64,65]$.

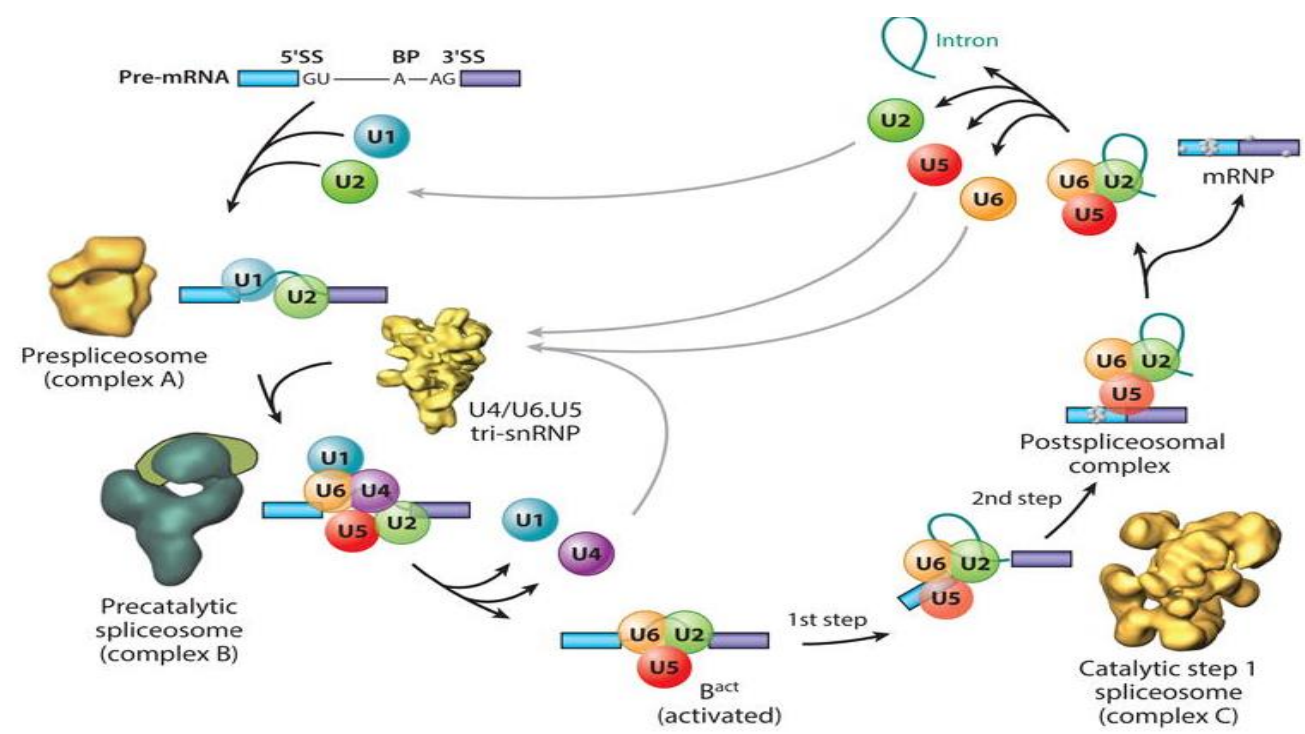

Figure 3. Representation of the spliceosome and splicing process, including the implication of the different snRNP in order to produce a mature mRNA (Lee et.al, 2015, Annu Rev Biochem)[65].

As mentioned above, NGS analysis led to the identification of mutations in genes of the RNA splicing machinery, such as SF3B1, SRSF2, U2AF1 and ZRSR2, in different myeloid malignancies, being highly prevalent and recurrent in MDS and affecting more than $50 \%$ of cases [66]. The high prevalence of these mutations and their early appearance in the disease suggest that they may be key drivers of MDS [67].

\section{SF3B1}

The splicing factor $3 b$, subunit 1 (SF3B1) also known as SF3b155 or SAP155 gene is located on the long arm of chromosome 2 (2q33). It is one of the elements that comprise the SF3b component of the U2 snRNP $[68,69]$. Next generation sequencing studies have revealed that approximately $30 \%$ of MDS patients have mutations in SF3B1 gene, with a 
particularly high prevalence in RARS subtype which is reflected in the new 2016 WHO classification (>80\%) $[32,40,61]$. Furthermore, SF3B1 mutations in low risk MDS patients were associated with good prognostic parameters [40]. The majority of SF3B1 mutations are missense substitutions located in the middle of 4 contiguous HEAT domains from a total of 22, as shown in Figure $4[70,71]$.

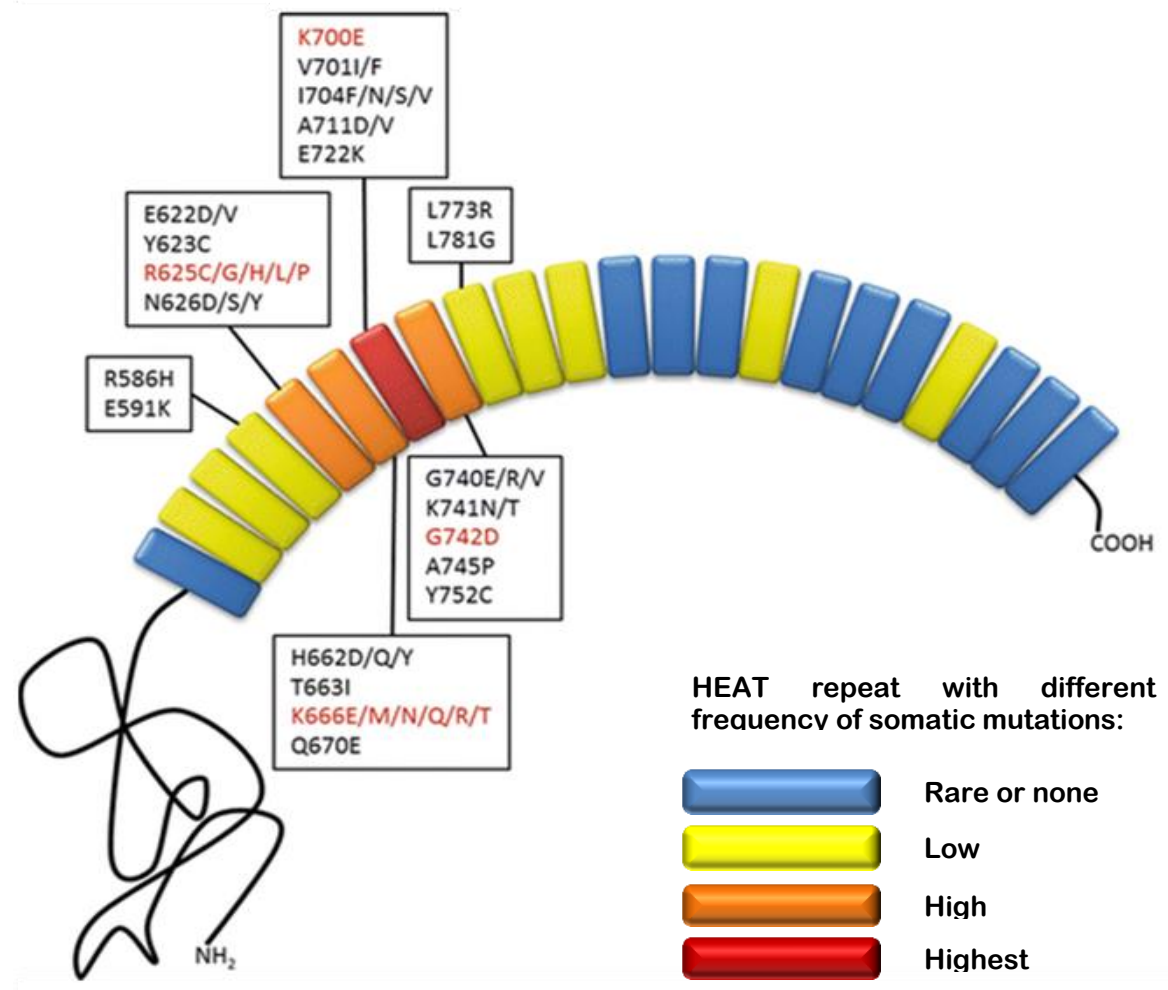

Figure 4. Distribution of SF3B1 mutations. Each rectangle represents a HEAT domain, which has been colored depending on the frequency of recurrent somatic mutations. (Bejar et.al, 2016, Adv Exp Med Biol.)[70].

Among the different hotspot codons $(622,625,662,666$ and 700), missense substitutions at codon 700 (p.K700E), are the most frequent point mutation [72, 73]. All these mutations led to a gain of function [62].Hotspot mutations in this gene result in an out-offrame splicing event for a subset of transcripts $[62,70,74]$.

\section{U2AF1}

The U2-complex auxiliary factor 1 (U2AF1) also known as U2AF35, is another gene frequently mutated in MDS patients. It is located on the long arm of chromosome 21 (21q22.3). U2AF1 mutations appear approximately in 10\% of MDS patients [75]. No effect on overall survival was detected, however trend toward a more rapid transformation to 
AML was seen [76]. Missense mutations occur mostly in two hotspot codons (S34 and Q157), which are adjacent to RNA-binding zinc-finger domains, and are associated with altered splicing of $\sim 5 \%$ of gene transcripts $[70,74]$. Recognition of the terminal 3' AG dinucleotide in pre-mRNA introns by U2AF1 is disrupted by mutations and result in exon inclusion or exclusion in a sequence-specific manner $[70,74]$.

\section{SRSF2}

The serine/arginine-rich splicing factor 2 gene (SRSF2) is another important member of the spliceosome complex. It is located in the long arm of chromosome 17 (17q25.1). It has been shown that mutations in this gene affected $15 \%$ of MDS cases, and have been found to have an adverse effect on overall survival in these patients [70, 77]. P95 is the most frequently mutated codon, where proline $(P)$ is more often substituted by histidine $(H)$, and less frequently by arginine (R) or leucine (L) [77]. Its different functions, such as spliceosome assembly of the U1 snRNP to the 5' splice site or U2 snRNP binding at the branch point and mRNA stabilization, are altered by this hotspot mutation, leading to changes in exon inclusion $[70,78]$.

\section{ZRSR2}

The zinc finger (CCCH type), RNA-binding motif and serine/arginine rich 2 gene (ZRSR2) represent another splicing factor frequently mutated in MDS patients (5\%). In contrast to the rest of the splicing genes described above, it is located in the short arm of the $X$ chromosome (Xp22.2), meaning that men only carry a single copy of this gene. ZRSR2 is an essential component of U12 minor spliceosome. Besides missense mutations, out-offrame insertions/deletions, splice-site and nonsense mutations are also present. Loss-offunction is caused as a consequence of ZRSR2 alteration. With regard to the splicing process, abnormal function leads to introns retention $[67,70]$.

\section{MDS: Microenvironment}

Every day our body produces more than 100 billion of blood cells. To make the process feasible, appropriately environment with special protection and signals is needed. Such a place in bone marrow is hematopoietic stem cell niche [79]. For the first time "niche" was defined by Schofield in 1978, who observed that HSC growth was not supported in the 
spleen in the same manner as in the BM [80]. It has been seen that is a unique composition of different non-mesenchymal and mesenchymal-origin cells (mesenchymal stem cells, osteoblasts, osteoclasts, endothelial cells, fibroblasts, adipocytes and chondrocytes), located in the endosteal and perivascular sites of the bone marrow (BM) cavity (Figure 5). It makes possible hematopoiesis process via paracrine regulation, cellcell contact and extracellular matrix deposition (ECM) [81, 82].

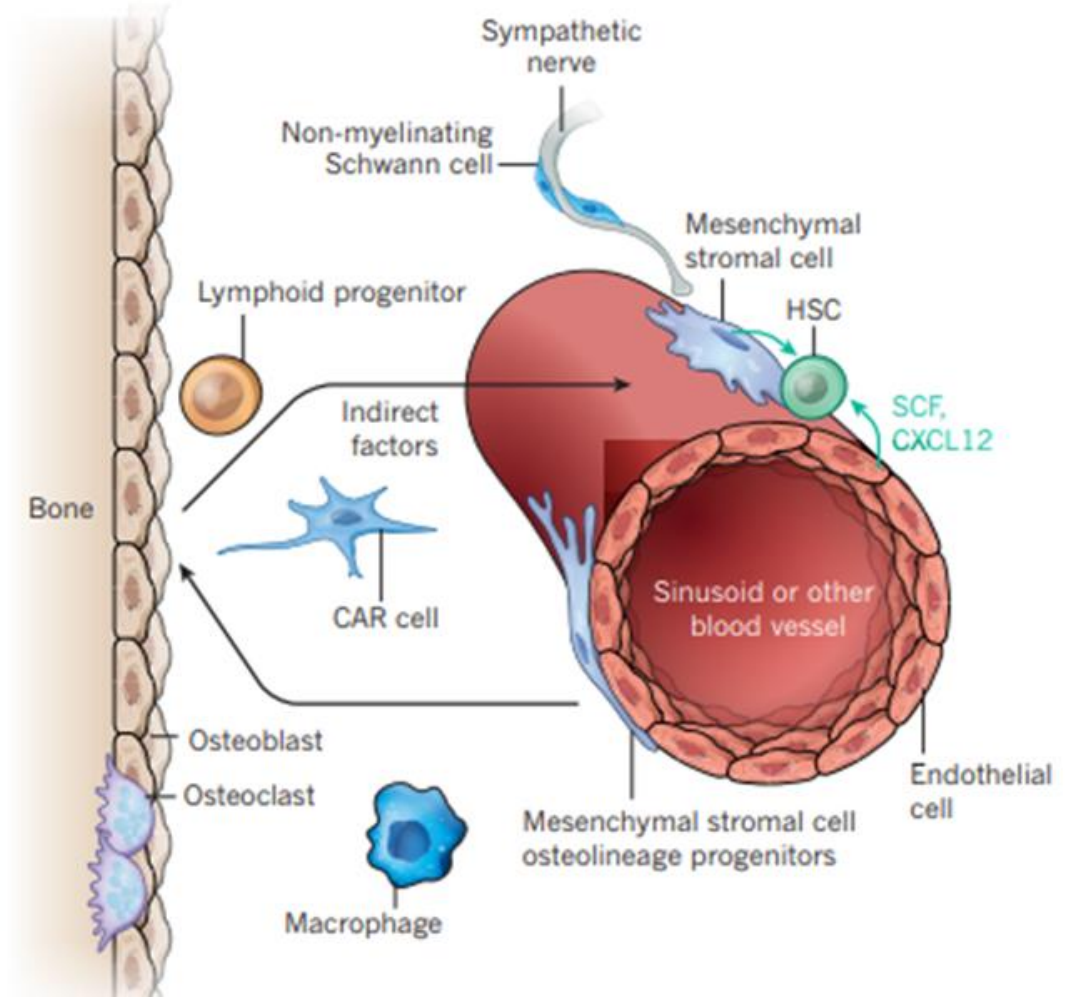

Figure 5. Mesenchymal stromal and hematopoietic cells, and their niche (Morrison and Scadden, 2014, Nature)[83].

\subsection{Healthy mesenchymal stromal cells}

The mesenchymal stromal cells (MSC) are a key element of niche, with the characteristic elongated spindle-shaped and fibroblast appearance. Friedenstein was a first who identified this multipotent cells, which are able to self-renewal and differentiate in different cell lineages including adipocytes, osteocytes and chondrocytes [84-87]. According to the minimal criteria proposed by the International Society for Cellular Therapy, MSC are characterized by the expression of CD73, CD90 and CD105, and they must lack expression of CD34, CD45 and CD14 [88]. Despite they are very rare in the BM (0.001-0.01\%), they are essential for the regulation of the hematopoietic stem cells (HSC) 
[89]. Through the interaction with HSC, MSC are coordinating the balance of HSC selfrenewal and differentiation, ensuring continuous production of blood cells. Furthermore they display immunoregulatory properties $[90,91]$.

\subsection{MDS mesenchymal stromal cells}

\subsubsection{MSC: Cytogenetics}

Despite a large amount of studies, MDS pathogenesis remains still not fully understood. Most of these studies indicate HSC changes as an MDS initiation process. However several studies suggest that alterations present in MDS are not restricted just to bone marrow and peripheral blood hematopoietic cells, but may affect the BM microenvironment [92, 93]. For this reason the interest in MSC investigation has increased significantly in the last few years. Several studies focused on MSC analysis have been published describing qualitative and functional disorders of these cells [84, 86, 90, 94-96]. However still some results of MSC alterations, are a matter of controversy. Thus cytogenetic analysis has shown normal cytogenetic profile of MSC in MDS patients; these studies used FISH to analyze specific chromosomal abnormalities discovered in their hematopoietic counterparts $[97,98]$. Meanwhile, other groups have found the presence of cytogenetic alterations in MSC of MDS patients and these cytogenetic alterations in MSC of MDS patients that could modify their correct function $[84,99]$. Karyotype aberrations in MSC were found in patients with normal hematopoietic cells but as well in cases that showed cytogenetic changes in hematopoietic cells, and they were different to their MSC counterpart. [84, 99]. Among the irregularities, a loss of chromosomal material and structural aberration occur more often than gains of genetic material $[84,85,99,100]$. There are no recurrent MSC cytogenetic changes and changes described so far, have been shown located in different chromosomes $[85,86]$.

\subsubsection{Molecular profile of MSC in MDS}

A greater number of mutational analysis in MSC of MDS patients could significantly help to better know about MSC role in MDS diseases. To date, mainly mouse models have elucidated certain molecular alteration in niche that could contribute to the 
hematopoietic malignancy. Thus Raaijmakers and colleagues demonstrated that osteoblastic deletion of gene DICER1 contributed to the induction of MDS and AML in mice [101]. Similarly, in a study of the Kode et al, an activating mutation in $\beta$-catenin in osteoblasts resulted in the development of MDS and secondary AML in mice [102]. Recently the WNT signaling has been also seen as a one of possible factors that may induce some myeloid mouse disorders [103]. With regards to the mutational status of MSC in MDS patients, very few mutation studies have been implemented so far. Blau with the colleagues analyzed the presence of FLT3 and NPM1 mutations in MSC and bone marrow blast in MDS and AML patients, showing that MSC do not harbor mutations in analyzed genes, presented in their hematopoietic counterparts [85]. Moreover a focused study in 8 genes in 7 MDS patients failed to demonstrate MSC mutations [104]. By contrast, an additional study, carried out in only five MDS patients, showed some mutations in the MSC [105]. Therefore new studies in large series of patients are needed to define the genetic abnormalities of MSC in MDS patients.

\section{Applications of next generation sequencing in MDS study}

The expansion of NGS has been adjusted to the last decade. However over a century ago several researchers, like as Robert Holley, Fred Sanger or Walter Fiers and their groups, made the first efforts of DNA "reading" [106-109]. The further improvement, contributed to creation of two sequencing protocols by Fred Sanger with Alan Coulson, and by Allan Maxam with Walter Gilbert that became widely adopted and considered as a birth of "first-generation" sequencing $[110,111]$. The continuous upgrading of DNA "reading" techniques allowed for creation of a revolution for the human genetics, The International Human Genome Project. During 13 years, the project aimed to know the sequence of the entire human genome. Finished in 2003, this has shed a new light in understanding the genetic changes of different diseases, mainly cancers [36, 112]. Since then, Next Generation Sequencing techniques (Whole Genome Sequencing-WGS, Whole Exome Sequencing-WES and applied in this thesis Target sequencing), became an essential part of many haematological but not only, research projects [113-119]. All of these technologies apply different target enrichment strategies and clonal amplification of the 
DNA that allow to sequence millions of DNA strands in parallel. This massively parallel sequencing facilitates high-throughput sequencing with a significant reduction in costs [120]. NGS platforms have been typically represented by Genome Analyzer/HiSeq, NextSeq 500, 2000/MiSeq from Illumina (http://illumina.com), GS FLX Titanium/GS Junior from Roche (http://sequencing.roche.com) and SOLiD/Ion Torrent PGM from Life Sciences (www.appliedbiosystems.com) [121-123].

In order to explore selected regions of the genome with NGS there are essentially two approaches. The first is amplicon-based next generation deep sequencing, based on PCR reaction, and purification of regions of interest using highly multiplexed oligo sets (recommended for a panel of a few genes) [124]. In the first part of this thesis (Results: Chapter 1), the amplicon-based deep sequencing workflow was followed using Roche/454 FLX platform (Figure 6) [125]. This platform is based on pyrosequencing in which the incorporation of nucleotides complementary to the template strand triggers an enzymatic cascade, which in turn produces a chemiluminescent signal (Figure 6)[126, 127]. 


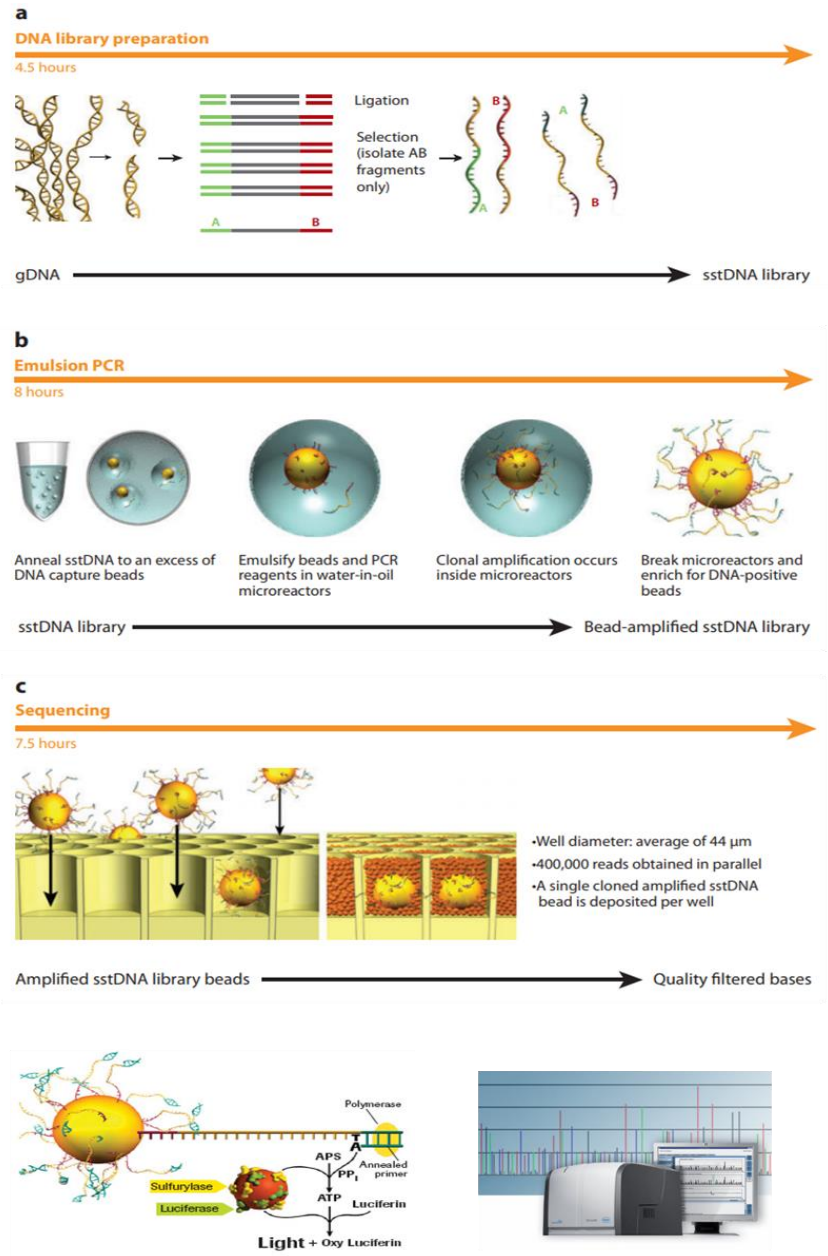

Figure 6. Workflow of amplicon-based NGS by 454 system (adapted from Mardis et al., 2008, Annu Rev Genomics Hum Genet). Amplicon library preparation (a); Emulsion PCR (b), Sequencing and data analysis (c).[125].

The second type of NGS strategy involves hybrid capture. The hybrid capture workflow was applied using the NextSeq 500 and 2000/MiSeq from Illumina in the second and third part of this thesis (Results: Chapter 2\&3). The hybrid capture takes advantage of the hybridization of DNA fragments from a whole-genome library to complementary sequences that were synthesized and combined into a mixture of probes designed with high specificity for the matching regions in the genome. These probes typically have covalently linked biotin moieties, enabling a secondary "capture" by mixing the probe: library complexes with streptavidin-coated magnetic beads. Hence, the targeted regions of the genome can be selectively captured from solution by applying a magnetic field, whereas most of the remainder of the genome is washed away in the supernatant. Subsequent denaturation releases the captured library fragments from the beads into solution, ready for postcapture amplification, quantitation, and sequencing [128]. Among 
the sequencing process a layer of oligonucleotides, complementary to the adapters P5 and P7 added during the preparation of the library, are covalently linked to the sequencing plate, so that the DNA fragments are joined by complementarity and are copied by extension $5^{\prime}->3^{\prime}$ using a high-fidelity DNA polymerase to avoid incorporation errors. Next, the original DNA fragments are denatured leaving the copies immobilized on the surface of the sequencing plate where they are amplified in bridge. Briefly, this amplification shows that these immobilized DNA molecules hybridize with the adjacent oligonucleotides, so that the DNA polymerase, using this adjacent oligonucleotide as a primer, copies them by forming double-stranded DNA bridges. This step of denaturationamplification is repeated until millions of clusters or individual clusters are created with thousands of molecules equal to each other (Figure 7A). Each cluster of double-stranded DNA is denatured and the reverse strands are removed by excision of specific bases, so that, after a wash, only the forward strands are left. Then, the 3 '-ends of the DNA strands and the oligonucleotides attached to the sequencing plate are blocked to avoid interference with the sequencing reaction. Finally, the sequencing primers hybridize with the complementary sequences of the Read 1 adapters at the ends not bound to the sequencing plate. Thus, at this time, the sequencing plate contains more than 200 million clusters with about 1,000 molecules per cluster ready for sequencing by synthesis (Figure 7B). The DNA molecules are sequenced base by base simultaneously in all the clusters, using the 4 nucleotides ( $A, C, G$ and $T$ ) marked with fluorophores and designed with a reversible terminator. In each cycle, the DNA polymerase incorporates a nucleotide by base complementarity, and, after each stage of synthesis, the clusters are excited by a laser that causes fluorescence in the last incorporated nucleotide. Then, fluorescence labels and blocking groups are removed allowing the addition of the next nucleotide. The fluorescence signal emitted after each incorporation is captured by an incorporated camera producing images of the sequencing plate, so that any signal above the background identifies the physical location of the cluster and the nucleotide incorporated in that position. The final result is a very precise base-based sequencing carried out sequentially from both ends for 151 cycles each, plus 8 additional cycles to read each label, which provides robustness even in regions of repetitive sequences and homopolymers (Figure 7C) (www.illumina.com). 
A

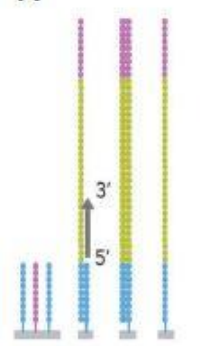

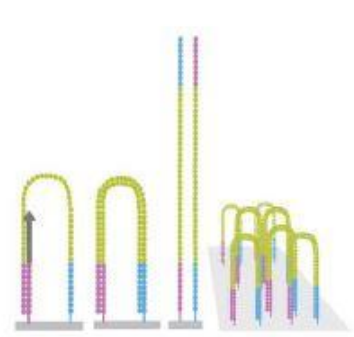

B

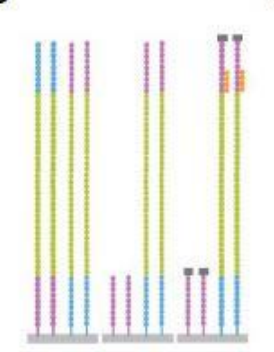

C

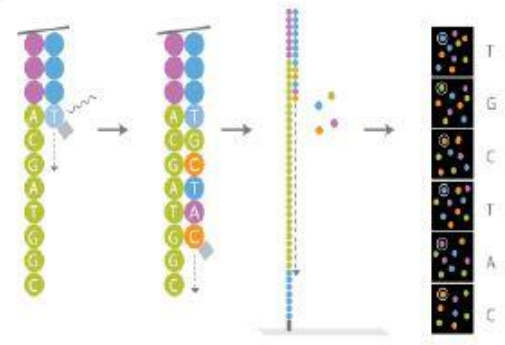

Figure 7. Generation of DNA cluster by bridge amplification and sequencing by synthesis with the Miseq platform of Illumina. (A) The DNA fragments hybridize with the oligonucleotides of the sequencing plate. They are copied and, through the formation of bridges, are amplified forming millions of clusters. (B) The reverse molecules are eliminated and the ends of the forward chains are blocked. Finally, the sequencing primers hybridize with the complementary sequences of the adapters, and everything is ready for sequencing. (C) Sequencing by synthesis. The DNA polymerase incorporates nucleotides marked with fluorophores and these are excited, so that the last incorporated nucleotide emits a specific fluorescence (www.illumina.com).

Over the past years, the NGS analysis have been included in a big amount of MDS studies $[117,129-132]$. The discovery of the mutational landscape in MDS patients allowed to better characterization of this patients, providing the knowledge about the MDS pathogenesis $[32,37,38]$. Application of NGS in analysis of MDS patients discovered as well of the impact of several mutations on clinical features that became crucial for better prognosis estimation, and more adequate chose of treatment $[45,58,133]$. Moreover it has been shown the importance of application of NGS in monitoring of healthy individuals in order to prevent the cancer development [134]. Continuing molecular researches are needed to provide new molecular knowledge which helps to better understand and treat MDS disease. 
Hypothesis 
The application in last years of Next Generation Sequencing (NGS) into MDS studies allowed to define the mutational landscape of these patients. Mutations in genes related to the splicing have been recognized as involved in MDS being SF3B1 the most frequently mutated gene in low-risk MDS [37, 38]. The high prevalence of SF3B1 mutations in MDS with ring sideroblasts (MDS-RS) patients demonstrated the strong relationship between mutations in this gene and the presence of ringed sideroblasts [135]. Therefore the 2016 WHO classification incorporated the presence of SF3B1 mutations as one of the criteria for MDS-RS with the percentage of ringed sideroblasts between 5 and 15 [32]. Most of the SF3B1 mutations are usually located on hot-spot locations on exons 14 and 15, and they can easily find by means of conventional Sanger sequencing [73]. However, not all MDS-RS patients displayed SF3B1 mutations by conventional sequencing. On the other hand, the massive sequencing represent a type of technique which allows to detect mutations in a broad set of patients and genes with mutations that occur in a very low frequency [125]. Furthermore, although a very high prevalence of SF3B1 mutations in MDS patients has been observed, still a remaining part of MDS-RS patients where the SF3B1 mutations do not appear and could carry alterations in other splicing related genes could be present [132]. My hypothesis will be whether the combination of the traditional sequencing methodologies with the new NGS will increase the detection of mutations in SF3B1 and other splicing-related genes. This approach will refine the prognosis of patients with MDS-RS.

In line with the previous hypothesis I will use NGS to explore the concurrence of mutations in MDS patients. Multiple groups are studying the prognostic role of somatic mutations in MDS. The favorable or unfavorable prognostic impact of several mutations when solely presented (such as SF3B1 or TP53, displaying a favorable or unfavorable prognosis, respectively) has been demonstrated. However the prognosis of the presence of more than one mutation remains unclear $[46,136]$. The availability of using NGS in the characterization of MDS patients is providing additional data confirming the presence of additional mutations in MDS. Nevertheless only few studies analyzed the potential implication in the prognosis of the presence of these mutations [38]. In the particular case of the SF3B1 mutation this is especially relevant, being associated with a specific clinical subtype of relative good long-term prognosis. Moreover some studies have already 
shown that in a specific subtype of patients (RARS) the presence of mutations in SF3B1 and DNMT3A was associated with worse results in transfusion requirements, overall survival and AML transformation. Therefore it is necessary to study in depth the mutations of this gene in the rest of SMD subtypes incorporating NGS techniques with a large gene panel [137]. My hypothesis will be that the SF3B1 concurrence with other mutations could influence the clinical characteristics of the very low/low/intermediaterisk MDS patients.

Furthermore, it is demonstrated that not only the hematopoietic cells but also the BM microenvironment is abnormal in MSD patients [86, 138-140]. The mesenchymal stromal cells (MSC) represent a key component of the microenvironment. Despite their low frequency in bone marrow, they are involved in all the mechanisms related to the proliferation and differentiation of hematopoietic cells, caring for its functioning in order to correctly support the process of hematopoiesis $[141,142]$. Despite several studies on its possible role in the pathology of MDS, the role in the development of the disease is unclear and brings some controversy [143-146]. However, all of the changes that have been observed so far in MSC of MDS patients, suggest that they could be involved in the pathophysiology of the disease. Moreover, previous studies demonstrated that MSC don't show the same genetic abnormalities that BM cells [85]. The possibility to confirm these data by using the new genetic tools, such as NGS, will shed a new light on the microenvironment function in MDS development. It could also identify new targets involved in cells being a key part of MDS microenvironment. 
Aims 


\section{General aim:}

The general aim of this thesis was to gain insight into the molecular basis of MDS patients identifying genetic interactions in haematopoietic progenitor cells and mesenchymal stromal cells by applying Next Generation Sequencing techniques.

\section{Specific aims:}

1. To assess the feasibility of NGS with a large panel of genes in the routine diagnostic setting.

2. To analyse the presence of mutations in SF3B1 and other splicing genes (SRSF2, U2AF1 and ZRSR2) in MDS with ring sideroblasts by combining the conventional sequencing and Next Generation Sequencing (NGS), by using a panel of genes related to myeloid diseases.

3. To correlate the clinical characteristics and outcome with the presence of mutations in the splicing machinery in MDS-RS.

4. To analyze the concurrence of mutations in SF3B1 and other myeloid-related genes in very low, low and intermediate-risk MDS patients.

5. To analyze the implications of the presence of SF3B1 concomitant mutations in the clinical and biological phenotype as well as in the prognosis in a cohort of very low, low and intermediate-risk MDS patients.

6. To characterize the mutational profile of MSC in MDS patients and to compare them with the genetic alterations in their hematopoietic counterparts, as well as to evaluate the mutation's role in the pathophysiology of the disease. 
Results 
This section includes the experimental work performed on this thesis, including Material and Methods, Results and Discussion. This section has been divided into three chapters:

Chapter 1: Kamila Janusz', Mónica del Rey', María Abáigar, Rosa Collado, David Ivars, María Hernández, Alberto Valiente, Cristina Robledo, Rocío Benito, María Díez-Campelo, Fernando Ramos, Alexander Kohlmann, Consuelo del Cañizo and Jesús María Hernández-Rivas

A two-step approach for sequencing spliceosome-related genes as a complementary diagnostic assay in MDS patients with ringed sideroblasts

Chapter 2: Kamila Janusz, Marta Martín Izquierdo, Félix López Cadenas, Fernando Ramos, Jesús María Hernández Sánchez, Eva Lumbreras, Cristina Robledo, Javier Sánchez del Real, Rosa Collado, Teresa Bernal, Carme Pedro, Andrés Insunza, Raquel de Paz, Blanca Xicoy, Eduardo Salido, Joaquín Sánchez García, Sandra Santos Mínguez, Cristina Miguel García, Ana María Simón Muñoz, Jesús María Hernández Rivas, María Abáigar, María Díez Campelo

Clincal, biological and prognostic implication of SF3B1 co-occurrence mutations in very low/low and intermediate-risk MDS patients

Chapter 3: Kamila Janusz, Sandra Muntion, Jesús María Hernández-Sánchez, Marta Martín Izquierdo, María Hernández-Sánchez, María Abáigar, Cristina Robledo, Félix López-Cadenas, Mónica del Rey, Juan Carlos Caballero, Rocío Benito, Alba Redondo Guijo, Tamara Jimenez, David Pescador, Juan Blanco, Fermín Sánchez-Guijo, Consuelo del Cañizo, María Díez-Campelo and Jesús María Hernández-Rivas

Mutational status of mesenchymal stromal cells in Myelodysplastic Syndromes patients

All of them have been developed to accomplish the general aim of this work and give the title to this doctoral dissertation: Characterization by Next Generation Sequencing of mutations of spliceosome genes and bone marrow mesenchymal cells in patients with myelodysplastic syndromes.

A General Discussion, with additional data and which comprises all research, is addressed in a separate section of this PhD work.

In addition, the supplementary material corresponding to each of the above chapters is collected at the end of the digital version of the PhD. 


\section{1}

\section{A two-step approach for sequencing spliceosome-related genes as a complementary diagnostic assay in MDS patients with ringed sideroblasts}

Kamila Janusz ${ }^{1,2^{*}}$, Mónica del Rey ${ }^{1,2^{*}}$, María Abáigar ${ }^{1,2}$, Rosa Collado ${ }^{3}$, David Ivars ${ }^{3}$, María Hernández ${ }^{1,2}$, Alberto Valiente ${ }^{4}$, Cristina Robledo ${ }^{1,2}$, Rocío Benito ${ }^{1,2}$, María DíezCampelo ${ }^{2,5}$, Fernando Ramos ${ }^{6}$, Alexander Kohlmann ${ }^{7}$, Consuelo del Cañizo ${ }^{2,5}$ and Jesús María Hernández-Rivas ${ }^{1,2,5}$

* These authors contributed equally to this work.

${ }^{1}$ IBMCC, Centro de Investigación del Cáncer, Universidad de Salamanca-CSIC, Spain.

${ }^{2}$ IBSAL, Instituto de Investigación Biomédica de Salamanca, Spain.

${ }^{3}$ Hospital General Universitario de Valencia, Spain.

${ }^{4}$ Complejo Hospitalario de Navarra, Spain. ${ }^{5}$ Hospital Universitario de Salamanca, Spain. ${ }^{6}$ Hospital Virgen Blanca, León, Spain.

${ }^{5}$ Hematología, Hospital Universitario de Salamanca,

${ }^{6}$ Hematología, Hospital Universitario de León,

${ }^{7}$ AstraZeneca, Personalized Healthcare and Biomarkers, Innovative Medicines and Early Development, Cambridge, UK

Leuk Res. 2017 May;56:82-87. doi: 10.1016/j.leukres.2017.01.031

PubMed PMID: 28222336 
Research paper

\title{
A two-step approach for sequencing spliceosome-related genes as a complementary diagnostic assay in MDS patients with ringed sideroblasts
}

\author{
Kamila Janusz ${ }^{2, b, 1}$, Mónica del Rey ${ }^{2, b, 1}$, María Abáigar ${ }^{2, b}$, Rosa Collado ${ }^{c}$, David Ivars ${ }^{c}$, \\ María Hernández-Sánchez ${ }^{\mathrm{a}, \mathrm{b}}$, Alberto Valiente ${ }^{\mathrm{d}}$, Cristina Robledo ${ }^{2, b}$, Rocío Benito ${ }^{\mathrm{z}, \mathrm{b}}$, \\ María Díez-Campelo ${ }^{\mathrm{b}, e}$, Fernando Ramos ${ }^{\mathrm{f}}$, Alexander Kohlmannn ${ }^{\mathrm{g}}$, Consuelo del Cañizo ${ }^{\mathrm{b}, e}$ \\ , Jesús María Hernández-Rivas ${ }^{2, b, e, 4}$

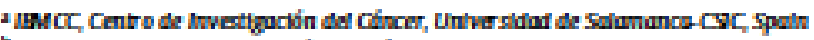

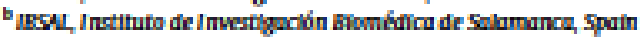 \\ chorpital Ceneral Untverslitario de Vaiencia, Spain \\ "Compleglo Hospitalario de Navarra, Servidio de Cenérica, Spain \\ - Hospital Untverstlario de Salamanca, Spain \\ 'Hosplted Virgen Blanca, Lein, Spain

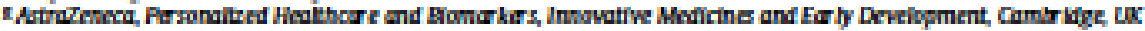

\section{A R TICLE I N F O}

\section{Article hitiory:}

Decelved 15 November 2016

Recehed in revised form 22 January 2017

Accepted 25 january 2017

Avaliable online 4 Fetruary 2017

\section{Keywards:}

Myelodysplastic syndrome

Ringed sideroblasts

Next generation sequending

Spliceosome

Sisi

\begin{abstract}
A B S T R A T
Our study aimed to analyze the presence of mutations in $\$$ FBI and other spliceosome-related genes in myelodysplastic syndromes with ringed sideroblasts (MDS-RS) by combining conventional Sanger and next-generation sequencing (NGS) methods, and to determine the feasibility of this approach in a clinical setting.

122 bone marrow samples from MDS-RS patients were studied. Initially, exons 14 and 15 of the $\$ 3 B 1$ gene were analyeed by Sanger sequencing. Secondly, they were studied by NGS covering besides SF3BI, SRO2, URAFI and ZRSRZ genes.

An 869 of all patients showed mutations in the SF3BI gene. Six of them, which were not identifiable by conventional sequencing in the first diagnostic step, were revealed by NGS. In addition, $19.5 \%$ of cases showed mutations in other splicing genes: $S R Q 22$, UZAFI, and $Z R Q R 2$. Furthermore, 8.72 of patients had two mutations in $\$ F 3 B 1, S 3 B I$ and SKSF2, and $\$ 7 B B 1$ and $U D A F 1$, while 5.72 showed no mutations in the four splicecosome-related genes analyzed.

The combined use of conventional Sanger and NCS allows the identification of mutations in spliceosome-related genes in almost all MDS patients with RS. This two-step approach is affordable and could be useful as a complementary technique in cases with an unclear diagnosis.
\end{abstract}

Q 2017 Elsevier Ltd. All rights reserved.

\section{Introduction}

Myelodysplastic syndromes (MDS) are a group of heterogeneous clonal stem cell disorders. They are characterized by ineffective hematopoiesis, dysplasia of at least one hematopoietic lineage,

\footnotetext{
* Corresponding author at Jesüs Maria Hemández-Bhraz, Servicio de Hematalogia y Departamento de Medidina, Hospital Universiltario de Salamunca, Paser San Vicente 58, 37007 Salamanca, Spain.

E-mall adithes: jmithrousal.es (L.M. Hemández-filvzs)

1 These authors contributed equally to this work.

http:/Whadol.arg/10.1016/.keukres:2017.01.031

0145-2126/0 2017 Elsevier thd All rights reserved.
}

hypercellular bone marrow (BM), and peripheral blood ( $\mathrm{PB}$ ) cytopenias $[1,2]$. MDS are also characterized by a high risk of developing acute myeloblastic leukemia (AML) [3].

Massive parallel deep-sequencing techniques, applied recently in the study of a large number of patients with various hematological malignances, have defined different mutations that could be involved in the MDS disease. These studies have shown that approximately $80 \%$ of patients with MDS carry mutations of genes such as epigenetic regulators (TET2, ASXL1, DNMT3A, IDHI, IDH2, EZH2), transcription factors (ETV6, RLNXI, TP53), signal transduc- 
tion proteins (CBL, JAK2, KRAS, NRAS), and genes related to the RNA splicing machinery (SFBBI, SRSR2, UZAFI, ZRSRZ) [4-6].

According to the World Health Organization (WHO) classification, refractory anemia with ringed sideroblasts (RARS) and refractory cytopenia with unilineage dysplasia and ringed sideroblasts (RCMD-RS) are two subtypes of low-risk MDS [7,8). Although the abnormal mitochondrial iron metabolism that characterizes these patients is not completely understood, many studies have revealed recurrent mutations of the SF-3BI (splicing factor 3, subunit 1) gene that occur in more than 808 of cases. The association of mutations in SF3BI and the presence of ringed sideroblasts suggest a possible role in the deregulation of iron metabolism of MDS with ringed sideroblasts (MDS-RS) [9-15]. However, there is a group of MDS-RS patients without SF3BI mutations that may feature variations in other splicing genes. A detailed analysis of other spliceosome-related genes in MDS-RS without mutations in S S $3 B \mathrm{BI}$ could help explain the phenotype in these cases.

The aim of this study was to analyze the presence of mutations in SFBBI and other splicing genes in MDS-RS by combining conventional capillary (Sanger) and next-generation sequencing (NGS) techniques and to determine the feasibility of these methods in a clinical diagnostic setting. We observed that almost all patients with MDS-RS carried at least one mutation of the four genes analyzed. This two-step approach is affordable and could be a useful complementary diagnostic technique in cases with an unclear diagnosis.

\section{Materials and methods}

\subsection{Patients, samples and cell separation}

A cohort of 122 low-risk MDS patients (66 patients with RARS, and 56 with RCMD-RS) was studied. All patients were classified according to the WHO 2008 criteria (with the exception of RCMDRS, which we maintain as a separate category on the basis of WHO 2001 criteria) (Supplementary Table S1) $[7,8,16]$. Mononuclear cells were isolated from bone marrow (BM) of MDS patients on a density gradient (Ficoll). The study was approved by the Local Ethical Committee ('Comité Ético de Investigación Clínica, Hospital Universitario de Salamanca") and written informed consent was obtained from each patient.

\section{DNA isolation}

Genomic DNA from BM mononuclear cells was extracted using QIAamp DNA Mini Kit (Qiagen, Valencia, CA, USA) following the manufacturer's protocol. DNA quantity was determined by dsDNA HS or BR Qubit "Fluorometric Quantitation Assay Kit (Life Technologies, Carlsbad, CA)

\subsection{Sanger captllary sequencing}

Sanger sequencing was carried out to identify the presence of gene variations. The previously published primers against the exons that more frequently exhibited mutations of SF $3 B 1$ (exons 14 and 15) were used [17]. Genomic DNA was amplified with the FastStart High Fidelity PCR System (Roche Diagnostics, Mannheim Germany) following the manufacturer's instructions, but including some variations of the annealing temperature (Supplementary Table 52).

DNA sequences were evaluated using Chromas Lite v2.1.1 (Technelysium Pty Ltd) and DS Gene v1.5 (Accerlys, Inc.) software. Obtained sequences were aligned to the reference genome (GRCh37/hg19).

\subsection{Amplicon-based next-generation deep-sequencing}

NCS was carried out using the GS Junior 454 Roche (454 Life Sciences, Branford, CT, USA) sequencing platform in order to identify patients with concomitant mutations or to find new mutations that were not detectable by conventional Sanger sequencing. We analyzed 23 patients that were negative for the first diagnostic screening by Sanger sequencing. Moreover 59 patients that were positive for SF $3 B I$ mutations in which enough DNA was available for the analysis were studied to find out the presence of additional mutations. A total of 28 exons from: SF3BI (Transcript-ID ENSTO0000335508, exons 10-16), SRSF2 (Transcript-ID ENSTO0000392485, exons 1 and 2), UZAFI (Transcript-ID ENSTO0000291552, exons 1-8), and ZRSR2 (Transcript-ID ENSTO0000307771, exons 1-11) genes were amplified using oligonucleotide primer plates designed as part of the IRON-II collaborative network of hematological laboratories applying 454 amplicon-NCS [18]. Information about primer sequences is listed in Supplemental table S3. Amplicon libraries were prepared following the manufacturer's recommendations and previously described methods $[18,19]$. Sequencing data were analyzed using GS Amplicon Variant Analyzer (AVA, v2.9; 454 Life Sciences) and Sequence Pilot (v3.5.2; JSI Medical Systems, Kippenheim, Germany) software. Minimum coverage was 200 total bidirectional reads ( 100 reads per direction) and the sensitivity of variant detection was set to a lower limit of $>2 \%$

$R$ version 3.1.1 software was used to illustrate the distributions of the variation.

NCS VAF higher than $15 \%$ were validated by Sanger sequencing.

\subsection{Statistical analysts}

Continuous variables were summarized as their median and range; categorical variables were described as the frequency and percentage of subjects in each category. Continuous variables were analyzed by applying the student's T-test when data were normally distributed and by using the Mann-Whitney $U$ test otherwise. Kaplan-Meier analysis (log-rank test) was used to assess the relationship between mutations and overall survival (OS). The os was defined as from the diagnosis of the disease to death; patients who were alive at last contact were treated as censored for $0 S$ analysis. Values of $p<0.05$ were considered significant.

\section{Results}

3.1. SF3B1 mutational analysts reveals the presence of mutations in exons 14 and 15 of most patients with MDS with ringed sideroblasts

In an initial screening, the exons most commonly mutated in SFBBI (exons 14 and 15) were analyzed in 122 MDS-RS by conventional Sanger sequencing. SF $3 B 1$ mutations were observed in 99 patients $(81.1 \%)$. In addition, variations in 6 more patients were observed when analyzed by NGS deep-sequencing technology (Represented with red lines in Fig. 1; detailed data included in Supplemental Table S4). A total of 105 MDS-RS cases (86.1X) had mutations in the SFBBI gene by Sanger and NGS sequencing. No differences in the incidence of mutations were observed between RARS (87.9X) and RCMD-RS (84\%) patients.

$42.2 \%$ of SF $3 B 1$ mutations were located in exon 14, while $55 \%$ in exon 15. It should be noted that four patients (3.8\%) had mutations in two different \$ 381 locations. The most frequently mutated codon 700 (p.Lys700Glu) was present in $57.1 \%$ of patients with MDS-RS. Mutations in codons 623 (p.Tyr623Phe), 658 (p.Trp6585er), 740 (p.Gly740Glu), 742 (p.Gly740Asp) and 748 


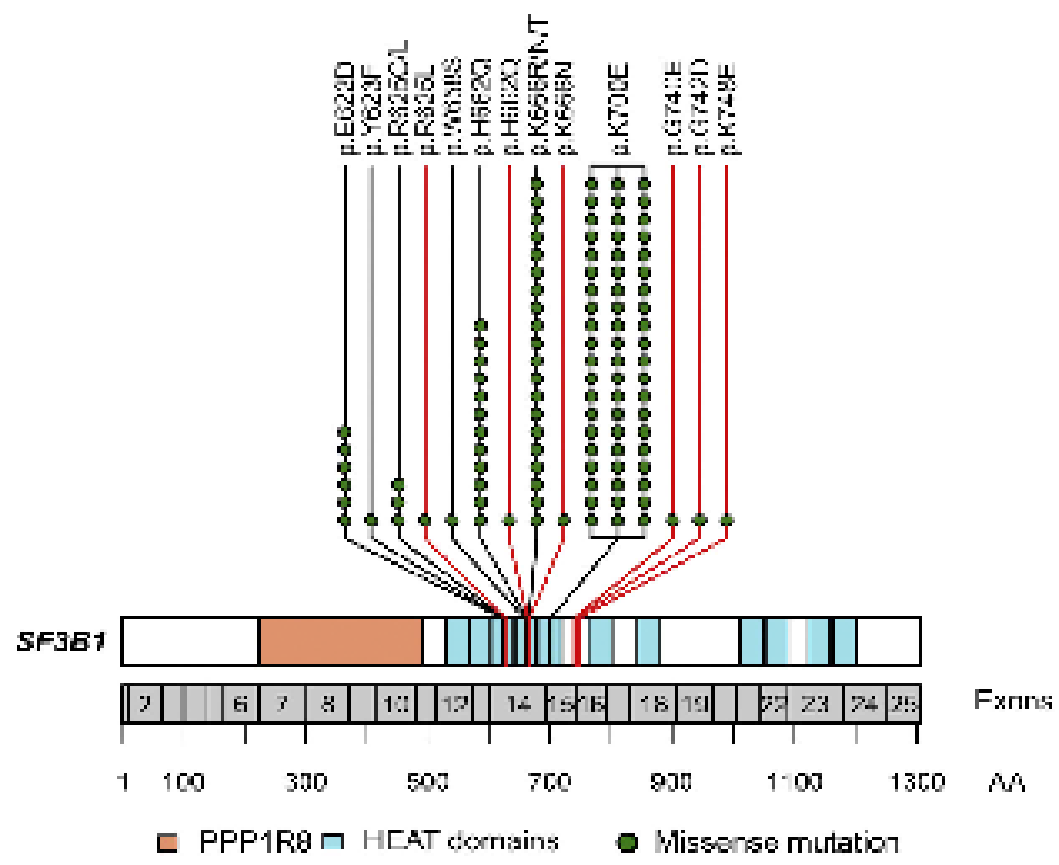

Fig. 1. Distribution of miksense mutations in $\$ 381$ in MDS-RS.

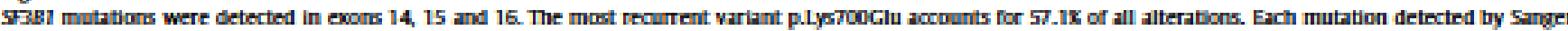
sequencing is shown with a black line. Each mutation detected by NCS is shown with a red line. Each green circle represents a misserse mutation found in a single pabent.

(p.lys748Glu) were observed in fewer than 5X of patients included in the study. Variant allele frequencies (VAFs) of these mutations were between 10 and 50\%. All detected mutations in S53BI were represented in Fig. 1.

3.2. NCS sequencing shows the presence of mutations in other genes involved in the splicing machinery in MDS-RS

Moreover, three genes involved in the splicing machinery, SRSF2, UZAFI and ZRSR2, were analyzed by NGS, SRSF2 mutations were observed in 12 cases (14.68) while mutations in U2AFI gene were detected in 3 patients (3.7X). SRSF2 gene mutations involved exon 1, whereas U2AFI gene variations were located in exons 2 and 6. Variations in ZRSR2 were less frequent, with only one RARS patient featuring a mutation. The mutations in these three genes involved in the splicing machinery were distributed equally in RARS and RCMD-RS patients and were mutually exclusive (Table 1).

\subsection{MDS-RS display novel mutations in splicing-related genes}

Our study demonstrated the presence of 4 new mutations in splicing-related genes. Three mutations were located in the SF3BI gene, at codons 623 (p.Tyr623Phe), 658 (p.Trp658Ser) and 748 (p.Lys748Glu). The mutations on codon 623 and 748 were present in RARS patients in $40 \%$ and $35 \%$ of variant allele frequency, respectively. The mutation on codon 658 was detected in an RCMD-RS patient in 25\% of variant allele frequency. All variants on SF3B1 gene were missense mutations (Fig. 2A). Moreover, the variant on ZRSR2 gene was a deletion in $54 \%$ of variant allele frequency that resulted in a frameshift mutation (Fig. 2B).

\section{4. $8.7 x$ of MDS-RS have concomitant mutations in} splicting-related genes

Our study showed that ten patients of those analyzed ( 8.78 ; 10/115) had double mutations as confirmed by Sanger and NGS sequencing. Four cases had two mutations in the SF3BI gene. The variants of two of them were located in the same exon (Exon 14). The analysis of the NGS sequencing reads in these two patients enabled to delineate that one patient had two distinct $\$$ F 3 BI -mutated dones (p.His662Gln; p.Lys666Thr; these two variants were detected in separate reads derived from the same single amplicon), while the other patient harbored two different mutations that belonged to the same clone (p.Glu622Asp and p.Tyr623Phe; both located in the same sequencing reads). The variations of the other two patients were present in different exons (Exon 14 and Exon 15) p.Lys666Arg and p.Lys700Glu; p.Lys666Asn and p.Lys700Glu. In these cases it was not possible to determine by NGS whether they were present in the same clone.

We also observed two mutations in six cases including SF3BI and another spliceosome-related genes: five with SRSF2 and one with U2AFI (Included in Table 1). These patients had similar clinical and biological characteristics compared with the MDS-RS patients carrying a single SF3BI mutation (Supplementary Table 55).

\subsection{Combined diagnostic use of NCS and conventional sequencing shows mutations in splicing-related genes in $94.3 x$ of MDS-RS patients}

94.3\% of the whole cohort of patients had mutations in one or more of the splicing-related genes (SFBBI, SRSF2, UZAFI and ZRSR2) analyzed. No differences in the incidence of spliceosomerelated genes mutations were observed between RARS (95.5\%) and RCMD-RS (92.98) patients. Only seven patients (5.7X) showed no mutations of the genes studied. These patients had similar clin- 
Table 1

SREZ, LRAY7 and ZRSR2 gene mutations in MDS-BCS.

\begin{tabular}{|c|c|c|c|c|}
\hline Case number & MOS subtype & Aflected gene & Amino adid change & VAF by NCS \\
\hline 1 & RARS & $\sin 82$ & p.ProesArg & $33 x$ \\
\hline 2 & RARS & $\sec 2^{u}$ & p.Pros Arg & $42 x$ \\
\hline 3 & RARS & $\sec 2^{u}$ & p.PrwosMrg & $14 \pi$ \\
\hline 4 & RARS & $\sin 2$ & p.Pronshis & $33 x$ \\
\hline 5 & RARS & $\sec 2^{u}$ & pProfoshis & $35 x$ \\
\hline 6 & RARS & $\sin 22$ & p.Prosteu & $30 x$ \\
\hline 7 & RARS & $\operatorname{sen} 2^{u}$ & pProsten & $12 x$ \\
\hline 8 & ROMD-RS & $\sin 82$ & pProes.103delinshrg & $30 x$ \\
\hline 9 & ROMD-RS & $\sin 2$ & proeshis & $45 x$ \\
\hline 11 & ROMD-RS & $\sec 2^{u}$ & p.ProshHis & $15 x$ \\
\hline 12 & ROMD-RS & $\operatorname{sen} 2$ & p.Prosten & $27 x$ \\
\hline 13 & ROMD-RS & URAF1 ${ }^{2}$ & p.CIn157/Arg & $40 x$ \\
\hline 14 & RCMD-RS & UDAF1 & pCln15TPro & $31 x$ \\
\hline 15 & RARS & UDAF1 & p.Ser34Phe & $49 x$ \\
\hline 16 & RARS & ZREN2 & pPhe2sy Leufs 18 & $53 x$ \\
\hline
\end{tabular}

MDS: myelodysplastic syndrume; RARS: refractury anemla with ring slderoblasts; RCMD-RS: refractory cytopenia with multineage dysplasia and ring siderublasts

1 Patient with an additional mutation in 5382.

\section{A}

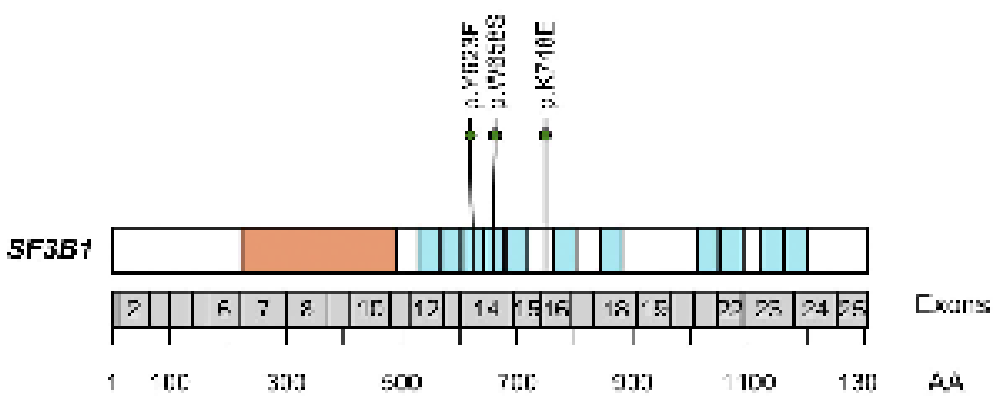

ㅁ PPP1R8 - HEST comains o rissense mutation

B

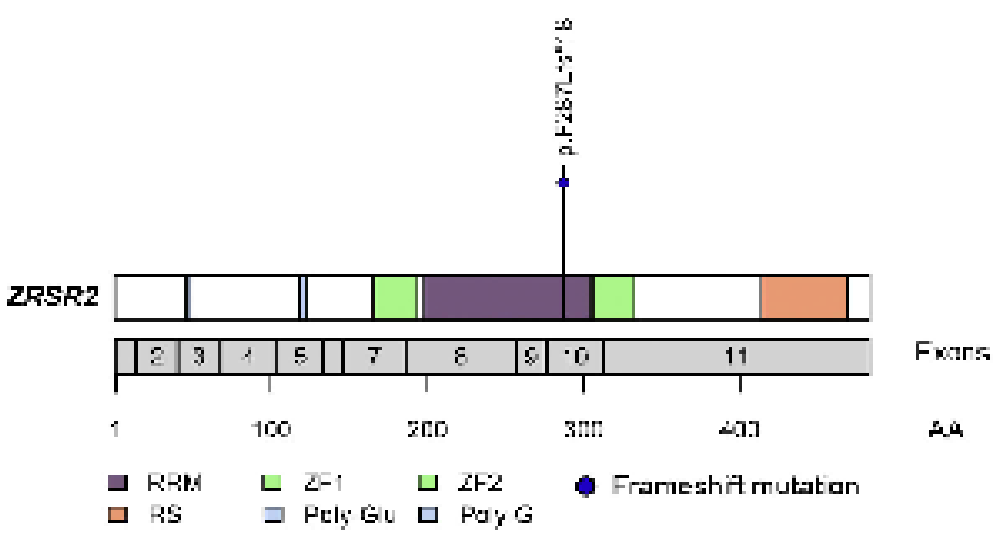

Fig. 2. Location of novel mutations identified in spliceosome-related genes in patients with MDS-BCS

(A) Novel mutabons detected in the SF3Bg gene. (B) Novel mutations detected in the $205 \% 2$ gene. Each miscense mutation is shown with a green circle, while each frame-shift mutation is shown with a bloe circle.

ical and biological characteristics to those of the other MDS-RS (Supplementary Table S6).

\subsection{Cene mutations are related to os}

Patients with a single alteration of SF3B1 had longer overall survival (OS) (median-20months) than cases with other splicing gene mutations (median-10 months, p- 0.04) (Supplementary Fig S1A). Furthermore we did not see significant differences in 05 comparing patients with double mutations and those carrying only one mutation in $\mathrm{SF} 3 \mathrm{~B} 1$ gene (Supplementary Fig. S1B). We did not see any differences in prognostic value either, analyzing wild type group of patients compared to the mutated ones (Supplementary Fig. S1C).

\section{Discussion}

In this study we analyzed the presence of mutations of the $\$ \mathbf{3 B} 1$ and other splicing-related genes in MDS with ringed sideroblasts by combining conventional diagnostic Sanger and NGS sequenc- 
ing. This two-step approach revealed that almost all the patients carry mutations in at least one of the genes analyzed. In addition, almost 108 of MDS with ringed sideroblasts showed more than one mutation in the splicing-related genes.

$S F 3 B I$ is the most commonly mutated splicing-related gene in MDS. Recurrent mutations occur in more than $20 \%$ of these patients $[9,17]$. In addition, the mutations have been found at a higher frequency in patients with ringed sideroblasts. These findings suggest the involvement of the mutations into the MDS-RS phenotype $[9,10,15]$. The current study also showed a high prevalence of SF3B1 mutations. An initial screening by conventional Sanger sequencing followed by an NGS strategy showed SF $3 B 1$ mutations in 105 cases ( $86.1 \%$ ), which was higher than that reported by other groups $[10,12,20]$. Furthermore, six of these variations could only be detected by NCS. In comparison with the typical detection variant allele frequency level of $15 \%$, as revealed by Sanger sequencing. NCS can detect far lower levels of variation, ensuring a more comprehensive coverage of the gene $[21,22]$. When we analyzed mutations between different subtypes of MDS, there were no differences between the SFBBI mutation frequencies in RARS and RCDM-RS patients. Recent studies have revealed that these two MDS-RS subgroups have a similar phenotype when carrying an $\mathrm{SF} 3 \mathrm{~B} 1$ mutation, and that the threshold of $15 \%$ of $\mathrm{FS}$ in no longer prognostically relevant in these two MDS subtypes [23,24]. Thus, the revised WHO classification (WHO 2016) of MDS have included the presence of an $\mathrm{SF} 3 \mathrm{~B} 1$ mutation to consider a diagnosis of MDSRS (with single or multilineage dysplasia), when as few as 5\% RS are identified $[23,24]$.

Most of the variations already reported are usually located at hot-spot locations of exons 14 and 15 of Sr3B1 gene [11-13]. Our findings are consistent with those of previous studies $[11,12,25]$. The mutation p.Lys700Clu was the most frequently detected in MDS-RS. The incidence of this mutation was $57.1 \%$, similar to the incidence reported by other groups $[11,12,25]$. However, mutations in exon 14 were detected in approximately $40 \%$ of patients. Therefore the mutational analysis focused on the hot-spot exons of this gene revealed information about clonality in almost all MDS-RS patients.

Recurrent somatic mutations in other splicing machinery components, including UZAFI, SRSF2 and ZRSR2 genes, have recently been described in MDS $[25,26]$. Our mutational analysis by NCS revealed 16 cases with ringed sideroblasts carrying alterations in these genes. SRSF2 mutations were present in 12 patients (14.6\%). All mutations were located in the most frequently affected amino acid residue, Pro95 $[25,27]$. Three patients showed mutations in the U2AFI gene, all known to affect the Ser34 and Gln157 positions of exon 2 and 6, respectively, while one patient showed a mutation in ZRSR2 $[28,29]$.

Despite the large number of already known alterations in splicing genes, our NCS study revealed four mutations that have not previously been described in COSMIC. Three of them were missense mutations located in \$3B1 (p.Tyr623Phe; p.Trp6585er; pLys748Asp). ZRSR2 gene carried a novel frameshift mutation (p.Phe287Leufs"18).

Ten patients presented double mutations, involving S53B1 and SRSF2 in five cases, SFJBI and UZAFI in one, and two distinct mutations in SFJBI in the other four cases. The presence of concomitant mutations in splicing genes is an infrequent event in MDS-RS, and usually involves SFJBI and SROF2 $[11,26,27]$, In addition, in the present study, we were able to reveal double mutations occurring in the SF $\mathrm{BBI}$ gene. The study of concomitant mutations in spliceosome-related genes could shed new light on the understanding of the mechanisms underlying the pathogenesis of MDS with ringed sideroblasts and should be investigated in future studies.

The present study found no mutations in the splicing genes in seven MDS-RS (5.7X) patients. This incidence was lower than previously reported and could be related to the use of the combined conventional and NGS approach $[11,25]$. These patients had similar clinical and biological characteristics to the other MDS-RS patients. These findings led us to hypothesize that the patients may have mutations in other splicing-related genes, such as PRPF8, SFI, U2AF65, PRPF4OB or SFIAI, as reported by other groups, or in genes associated with iron and mitochondrial metabolism $[11,30]$ Therefore, there may be an association between the mutations in spliceosome-related genes and the presence of ringed sideroblasts in patients with MDS, which has normally been assigned to the Sr3BI alterations only $[17,31,32]$.

In summary, our study shows that diagnostic NCS sequencing can identify new mutations that are not detectable by conventional Sanger sequencing of note, all mutations detected by Sanger sequencing were indeed identified by NGS. The two-step approach for sequencing splicing-related genes is affordable and reveals mutations in almost all MDS-RS patients. In addition, the presence of mutations in SRSF 2, UZZAFI and ZRSR2 beyond SF3BI suggests that all of them could influence the MDS-RS phenotype.

\section{Acknowledgements}

The authors would like to thank to Irene Rodriguez, Sara Gonzślez, Teresa Prieto, Maria Ángeles Ramos, Almudena Martín, Ana Díaz, Ana Simón, María del Pozo, Isabel M Isidro, Vanesa Gutiérrez and Sandra Pujante from the Centro de Investigación del Cáncer, Salamanca, Spain, for their technical assistance.

The research leading to these results received funding from the European Union's Seventh Framework Programme (FP7/2007 2013) under Grant Agreement n 306242-NGS-PTL. Fundación Castellano Leonesa de Hematologia y Hemoterapia (FUCALHH 2013), Consejeria de Educación, Junta de Castilla y León (HUS272U13), Proyectos de Investigación del SACYL, Spain: GRS $994 / \mathrm{A} / 14, \mathrm{BlO} / \mathrm{SA} 52 / 14, \mathrm{BIO} / \mathrm{SA} 10 / 14, \mathrm{BIO} / \mathrm{SA} 31 / 13$. The work was partially supported by grants from the Spanish Fondo de Investigaciones Sanitarias FIS 09/01543, PI12/00281, COST Action EuGESMA (BMO801) and by grants (RD12/0036/0069, RD12/0036/0029 and RD12/0036/0044) from the Red Temática de Investigación Cooperativa en Cincer (RTICC), Instituto de Salud Carlos III (ISCIII), Spanish Ministry of Economy and Competitiveness and the European Regional Development Fund (ERDF) "Una manera de hacer Europa" (Innocampus; CEI-2010-1-0010), and FIS Grant Program (FIS PI 14/01971) Mutation analyses were performed using oligonucleotide primer plates designed as part of the IRON-II collaborative network of hematological laboratories applying 454 ampliconNGS.

MDR was fully supported by a "Grant from Fundación Espanola de Hematologia y Hemoterapia". MA was supported by the NGS-PTL. Project and by a "Grant from Fundación Espanola de Hematología y Hemoterapia". MHS was fully supported by an "Ayuda predoctoral de la Junta de Castilla y León" from the "European Regional Development Fund" (JCYL-EDU/346/2013 Ph.D scholarship).

\section{Appendix A. Supplementary data}

Supplementary data associated with this article can be found, in the online version, at http://dx.doi.org/10.1016/j.leukres.2017. 01.031.

\section{References}

[1] 5D. Nimer, Myelodysplastic syndrumes, Blood 111 (10) (2008) 4841-4851. [2] C. Gardi2-Manern, Myelodysplastic syndromes: 2015 update on dlagnosis, risk-stratifincation and management, Am. J. Hematol 90 (9) (2015) 831-841.

[3] P. Creenberg, C. Coox, M.M. Lelleau, P. Fenaux, P. Mored, C. Sanz, M. Sarz, T.

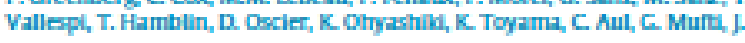


Bennett, Intemational scoring system for evaluating promosis in myelodysplastic syndrume, Bbod 80 (6) (1907) $2079-2088$.

[4] R. Itzykson, O. Kosmider, P. Fenawa, Somatic mutations and epigenetic abnommalities in myelodysplastic syndromes, Best Pract. lies. Ciin. Haematol. 26 (4) (2013) $355-364$.

[5] E. Papaemmanull, M. Gerstung, L Malcovath, S. Taura, C. Cundem, P. Van Loo, C., Yoon, P. Ellis, D.C. Wedge, A. Fellagatti, A Shlien, M.) Groves, SA. Forbes, K. Raine, f Hinton, L4 Modle, S. Mdiaren, C Hardy, C Latimer, M.C. Della Porta 5. OMeara L. Ambaglia, A. Call, A. P. Bubler, C Walldin. IW. Teanue, L Quek, A. Stemberg. C. Garmbacurti-Passerini, N.C Cross, A.R. Green, f. Boultwood, P. A. Stemberg, C. Gambacurti-Passerini, N.C. Cross, AR. Green, f Boultwo
Vyas, E. Hellstrom-Undbers D. Bowen, M. Caz zola, M.R. Stratton, P. Vyas, E. Helistrom-Lindberg D. Bowen, M. Cazzola, M. R. Stratton, P, Cancer Cenome, Cainical and biological implications of driver mutations in myelodysplastic syndrume, Blood 122 (22) (2013) 3516-3627 (cule 36D9).

[6] R. Bejar, K. Steverson, Q. Nbdel-Wahak, N. Galin, B. Nilsson, G. Garcla-Manerd, H. Kantarjlan, A. Ilaza, R.L Levine, D. Neuberg, B.L. Eeert, Clinical eflect of point mutations in myelodysplastic syndromes, N. End. 1. Med 364 (26) (2011) 2496-2506.

[7] E.S. Jaffe, N.L. Harris, H. Stein, J.W. Vardiman, World Health Organte ation Classiffication of Tumours, Pathology and Cenetics of Tumours of Haematopoietic and Lymphoid Tissues, LARC Pres, Lyon, 2001.

[8] S.H. Swerdlow, E. Campo, N.L. Harris, E.S. Jaffe, Sh. Fleri, H. Stein. \& Thiele, IW. Vardiman, WHO Classiffcation or Tumours of Haematopoletic and Lymphoid Tissues, Vol, 2, 4th edition, WRE, 2008

[פ T. Haferlach, Y. Nagata, v. Grossmann, Y. Okunn, U. Bacher, C. Nagre, S Schniltwer, M. Sanada, A. Kon, T. Alpermann, K. Yoshida, A. Roller, N. Nadarajalh, Y. Shiraishi, Y. Shimzawa, K. Chilbe, H. Tanaka, H.P. Koeffler, HW. Klein, M. Dugax, H. Aburatani, A Kohimann, S Mlyann, C Hafertach, W. Kerm, 5. Ogawa, Landscape of genetic lesions in 944 patients with myelodysplastic syndromes, Leukemia 28 (2) (2014) 241-247.

[10] E. Papaemmanuil, M. Cazolia, Joultwood, L Malcovati, P. Vyzs, D. Bowen, A. Godfrey, L. Rapado, A. Cvejic, R. Rance, C. Mociee, P. Ellis, L. . Mudle, P.J. Stephens, S. Mcl aren CE Massie, P.S Tarpey, L Varela, S. Nik-Zainal, H.P. Davies, A Shlien, D. Jones, K. Raine, Hinton, A.P. Butler, fW. Teague, E. Baxter, / Score, A. Gall, M.C. Della Porta, E. Travagdino, M. Gruves, S Tauro, N.C. Munshi, KC. Andersan, A. El-Naggar, A. Fischer, V. Mustonen, A. Warter. N.C. Cross, A.R. Green, P.A. Putreal, M.R. Stratton, P\$ Campbell, C Chronile Myeloid Disonders Working Group of the International Cancer Cenome, Somatic SF3B1 mutation in myelodysplasia with ring sideroblasta, N. End. . Med. 365 (15)(2011) 1384-1305.

[11] K. Yoshida, M. Sanada, Y. Shiralshl, D. Nowak, Y. Nagata, R. Yamamotn, Y. Sato A. Satn-Otsubn, A. Kon, M. Nagrasal, C. Challddls, Y. Surukd, M. Shiocaka, R. Kawahuta, T. Yamaguchil. M. Oten, N. Deara, M. Sakata-Yanagimotn, K. Ishilyama, H. Mori, E. Nolte, W.K. Hotmann, 5. Myawahi, S. Sugana, C Haferlach, H.P. Koeflier, LY. Shih, T. Haferlach, S Chila, H. Nakauchi, S. Milyano, S. Ogaws, Frequent pathway mutations of splicing machinery in myelodysplasia, Nature $488(7367)(2011) 64-69$

[12] R. Cul, R.P. Gale, Z. Xu, T. Qin, L. Fane, H.Zhang, L Pan, Y.Zhang, Z. Xlan, Clinical importance of SF3B1 mutations in Chinese with myelodysplastic syndromes with ring sideroblasts, Leuk. Res. 35(11) (2012) 1428-1433.

[13] H. Makishima, V. Visconte, H. Sakaguchi, A.M. Janiowska, S. Abu Kar, A. Jerez, B. Przychodzen, M. Bupathi, K. Cuinta, M.C. Mable, M. S. Sekeres, R.A. Padgett, R.V. Tiu, JP. Maciejewsid, Mutations in the spliceosome machinery, a novel and ubiquitous pathway in leukemogenesis, Blood 119 (14)(2012) $3203-3210$.

[14] M. del Rey, R. Benitta, C Fontanilla, F., Campos-Laborie, K. Janusz, T. Velasco-Hermandez, M. Nhaigar, M. Hernandez, R. Cuella, D. Bocregn, D. Martin-Zanca, L. De Las Rhrzs, K. MIIls, LM. Hemandez-Rivas, Deregulation of genes related to iron and mitochondrial metabolism in refractory anemia with ring sideroblasta, Plas One 10 (5) (2015) e0126555.

[15] L Mallowath, M. Cuzzola, Refractory anemla with ring sideroblasts, Best Pract. Res. Clin. Haematnl. 26 (4) (2013) 372 -385.

[16] JW. Vardiman, f Thiele, D.A. Arter, R.D. Brunning, M. . Borowitz, A. Ponwit N.L. Harris, M.M. Le Beau, E. Hellitrom-Undberg, A. Tefteri. C.D. Bloomfleld, The 2008 revision of the Worid Health Organteation (WHO) classification of myeloid neoplasms and acute leukemia: rationale and important changes, Blood 114(5) (2009) 937-951.

[17] L Malograti, E. Papaemrmanull, DT, Bowen, 1 Boultwood, MC. Della Porta, C Pascutto, E Travadinn, M.J. Crove, A. Codfrey, L Ambaglio, A. Galli, M.C Da Via, S. Conte, S. Tauro, N. Keenan, A. Hyslop. J Hinton, L4 Mudle, J5. Wainscuat, PA. Futreal, M.R. Stratton, P., Camptell, E Hellstrom-Undberg, M Carzola C.Chronic Myeloid Disonders Wurking Croup of the Intermational Cancer Cenome, M. of the Associzzione Itallana per la Ricerca sul Cancro Gruppo Italiano Malattie, Clinical significance of SF3B1 mutations in myelodysplastic syndrumes and myelodysplastic/myeloproliferattive neoplasms, Blood $118(24)(2011) 6239-6245$.

[18] A. Kohimann. HW, Klein, S. Weissmann, 5 Bresolin, T. Chaplin, H. Cuppens, E Haschive-Becher, B. Garicochea, V. Crossmann, B. Hanczaruk, K. Hebestrelt, C Gateriel, I. lacobucal, JH. Jansen, C. te Kronnie, L van de Locht, C. Martinelli, K.
MoGowan, M.R. Schweiger, B. Timmermann, P. Yandenterghe, BD, Young, M. Dugas, T. Haferlach, The Interlaboratory nobustness of Next-generation sequencing (IRON) study: a deep sequencing investigation of TET2, CBL and KRWS mutations by an intermational consortium involving 10 laboratories, Leukemia 25 (12) (2011) 1840-1848.

[19] JA. Hermander, M. Hermandez-Sancher, AE, lindriguez-Vicente, V. Grossmann, R. Colladn, C. Heras, A. Pulgros, A.A. Martin, N. Pulig, R. Benitn, C. Robliedo, J. Delgado, T. Corzalez, J . Quetzan, \& Galende, L de la Fuente, C. Martin-Nunez, IM Nonso, P. Abrisqueta, E. Lung, L Marugin, L. Cormalez-Cascon, F. Bosch, A Kohimann, M. Corrzalez, B. Espinet, JM. Hemandez-Rivas, H. Crupo Cooperativo Espanol de Citogenetica, C. Grupo Espanol de Leucemla Unfatica, A low frequency of losses in 11 q chromosome is assodiated with better outome and lower rate of genomic mutations in patients with chroni: lymphocytic leukemla, Plos One 10 (11) (2015) 0143073.

[20] C.C Un, H.. Hou, W.C. Chou, Y.Y. Kun, s.. Wu, CY. Lu, CY. Chen, M.H. Tseng C.F. Huang E.Y. Lee M.C Uu, CW. Uu, JI. Tang, M. Yaa, S.Y. Huang, S.C. Hsu, BS. Ko, W. Tray, Y.C. Chen, H.F. Tien, SFBB1 mutations in patients with myelodysplastic syndromes: the mutation is stable during dlsease evolution, Am , Hermatnl. 89 (8) (2014) E100-E115.

[21] A.C. Tslatis, A. Norris-Kirty, R.C. Fich, M.j. Hafer, C.D. Cocke, J.R. Eshleman, K.M. Murphy, Comparison of Sange sequending, pyrosequencing, and melting curve analysis for the detection of KRNS mutations: dlagnostic and dinical implications, f. Mol. Diagn. 12 (4) (2010) 425-432.

[22] C. Melanum, M.A. Doyle, R.W. Tothill, Next-generation sequending for cancer diagnostics: a practical perspective, Clin. Biochem. Rev. 32 (4) (2011) $177-195$

[23] L Malcovath, M. KarimL, E Papaemmanull, L. Ambaglo, M. Jadersten, M. Jansson, C. Eena, A. Galli, G. Wallin, M.C. Della Porta, K. Raaschou-Jerisen, E Travaglino, K. Kallentbach, D. Pietra, V. Ljungstrom, S. Conte, E Boveri, R. Invernizzi, R. Rnsenquist, P.. Campbell, M. Cuzoli, E. Hellstrom Lindberg, S53B1 mutabion identifies a distinct subset of myelodysplastic syndrome witt ring siderublasts, Blood 126 (2) (2015) 233-241.

[24] D.A. Artber, A. Orazi, R. Hasserjlan, J Thiele, M.]. Borowitz, M.M. Le Bealn, CD. Bloomfleld, M. Cuz zola, LW. Vardiman, The 2016 revision to the World Health Organization classification of myeloid neoplasms and acute leukemia, Blood 127 (20) (2016) 2391-2405

[25] F. Damm, Q. Koosmider, V. Celsi-Boyer, A. Renneville, N. Carbucria, C Hidalgo-Curtik, V. Delly Valle, L Couronne, L Scourric, V. Chesnals, A. Cuerci-Bresler, B. Slama, O. Beyne-Rluzy, A. Schmidt-Tanguy, A. Stamatnullas-Bastart, E. Dreyfus, T. Prebet, S. de Botton, N. Vey, M.A. Morgan, N.C. Cross, C. Preudhomme, D. Birntuaum, o, Bernard, M. Fontenay, M. Croupe Francuphone des, Mutations affecting miNA splicing define distind dinical phenotypes and correlate with patient outome in myelodysplastic syndrumes, Blood 119(14) (2012) 3211-3218.

[26] F. Thol, S. Kade, C. Schlammann, P. Loffeld, M. Morgan, J. Krauter, M.W. Whodarsh, B. Kolking, M. Wichmann, K. Corllich, C. Cohring, C. Bug, O. Ottmann, C.M. Niemeyer, W.K. Hofmann, B. Schlegelberger, A. Ganser, M. Heuser, Frequency and prognostic impact of mutations in SRSF2, U2NF1, and ZBSIRZ in patients with myelodysplastic syndromes, Blood 119(15) (2012) $3578-3584$.

[D] E.M. J, N.J. Yoa, Y.J. KIm, MS KIm, S.H. Le, Mutational analysis of splicing machinery genes SF3B1, U2AF1 and SRSF 2 in mryelodysplasla and ocher common tumors, Int. 1 Cancer 133 (1) (2013) 260-265.

[28] T.A. Graubert, D. Shen, L. Ding, T. Okeyo-Owuor, CL. Lunn, / Shan, K. Krysiak, C.C. Harria, D.C. Koboldt, D.E. Larson, M.D. Mctellan, D.J. Dooling, R.M. Nbbott, R.S. Pulton, H. Schmidt, f Kallicld-Veizer, M. O'Laughilin, M. Grillot, \& Raty, S. Heath, ㄱ. Frater, T. Nasim, D.C. Link, M.H. Tomasson, P. Westervelt, J. Difersia, E.R. Mardis, T.J. Ley, R.K. Wilson, M.J. Walter, Recurrent mutations in the U2NH splicing factor in myelodysplastic syndromes, Nat. Cenet. 44 (1) (2012) $53-5 ?$

[29] B. Przychodzen, A. Jerez, K. Cuinta, MA. Sekeres, R. Padgett, JP. Maciejewsid, H. Maldishima, Patterns of missplicing due to somatic U2NF mutations in myeloid neoplasms, Blood 122 (6) (2013) 990-1006.

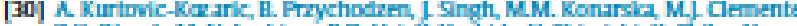
ZK. Otrock, M. Nakcashima, E.D. Hsi, K. Yoshida, Y.Shiraishi, K. Chilba, H. Tanaka, S. Miyana, S. Ogawa, f Boultwood, H. Makdishima, JP. Madejewsid, R.A. Padgett, FirFs defects cause missplicing in myeloid mallignancies, Leukemia 20 (1) (2015) 126-135.

[31] V. Visconte, H.) Rogers, f Singh, f. Barnard, M. Bupathl, E. Traina, f. McMahon, H. Malishima, H. Szpuria, A. Jankuwska, A. Jerer, MA Sekeres, Y. Sunthararajah, A.S. Advani. E Copelan, H. Koseki, K. Isona, RA. Padgett, S. Dsman, K. Koide, C OKKetfe, ,P. Madiejewski, R.V. Tiu, SF3B1 haploinsumciency leads to formation of ring sideroblasts in myelodysplastic syndromes, Blood 120(16) (2012) 3173-3186

[32] v. Visconte, H. Makdshima, A Jankerwska, H. Sspurka, F. Traina, A. Jerez, C OKKeele, H.J. Rogers, M. Sekeres, JP. Maciejewski, R.V. Tn, Ş3Bi, a splicing factor is frequently mutated in refractury anemia with ring siderublasts, Leukemia 26 (3) (2012) 542-545. 


\section{2}

\section{Clincal, biological and prognostic implication of SF3B1 co- occurrence mutations in very low/low and intermediate-risk MDS patients}

Kamila Janusz ${ }^{1}$, Marta Martín Izquierdo ${ }^{1}$, Félix López Cadenas ${ }^{2}$, Fernando Ramos ${ }^{3}$, Jesús María Hernández Sánchez ${ }^{1}$, Eva Lumbreras ${ }^{1}$, Cristina Robledo $^{1}$, Javier Sánchez del Real ${ }^{3}$, Rosa Collado ${ }^{4}$, Teresa Bernal ${ }^{5}$, Carme Pedro ${ }^{6}$, Andrés Insunza $^{7}$, Raquel de Paz ${ }^{8}$, Blanca Xicoy ${ }^{9}$, Eduardo Salido ${ }^{10}$, Joaquín Sánchez García ${ }^{11}$, Sandra Santos Mínguez ${ }^{1}$, Cristina Miguel García ${ }^{1}$, Ana María Simón Muñoz ${ }^{1}$, Jesús María Hernández Rivas ${ }^{1,2}$, María Abáigar ${ }^{1}$, María Díez Campelo

${ }^{1}$ Unidad de Diagnóstico Molecular y Celular del Cáncer, Centro de Investigación del Cáncer-Universidad de Salamanca (IBMCC, USAL-CSIC); Genética Molecular en Oncohematología, Instituto de Investigación Biomédica de Salamanca (IBSAL),

${ }^{2}$ Hematología, Hospital Universitario de Salamanca,

${ }^{3}$ Hematología, Hospital Universitario de León,

${ }^{4}$ Hematología, Hospital Clínico de Valencia, Valencia,

${ }^{5}$ Hematología, Hospital Universitario Central de Asturias, Oviedo,

${ }^{6}$ Hematología, Instituto Hospital del Mar de Investigaciones Médicas (IMIM), Barcelona,,

${ }^{7}$ Hematología, Hospital Universitario Marqués de Valdecilla, Santander,

${ }^{8}$ Hematología, Hospital Universitario de la Paz, Madrid,

${ }^{9}$ Hematología, Hospital Universitari Germans Trias I Pujol, Instituto Catalán de Oncología (ICO), Badalona,

${ }^{10}$ Hospital Universitario de Canarias, Universidad La Laguna

${ }^{11}$ Hematología, Hospital Universitario Reina Sofía, Córdoba 


\title{
CLINICAL, BIOLOGICAL AND PROGNOSTIC IMPLICATION OF SF3B1 CO-OCCURRENCE MUTATIONS IN VERY LOW/LOW AND INTERMEDIATE-RISK MDS PATIENTS
}

\author{
Kamila Janusz ${ }^{1 *}$, Marta Martín Izquierdo ${ }^{1 *}$, Félix López Cadenas ${ }^{2}$, Fernando Ramos ${ }^{3}$, Jesús \\ María Hernández Sánchez ${ }^{1}$, Eva Lumbreras ${ }^{1}$, Cristina Robledo ${ }^{1}$, Javier Sánchez del Real ${ }^{3}$, Rosa \\ Collado $^{4}$, Teresa Bernal ${ }^{5}$, Carme Pedro ${ }^{6}$, Andrés Insunza ${ }^{7}$, Raquel de Paz ${ }^{8}$, Blanca Xicoy ${ }^{9}$, \\ Eduardo Salido ${ }^{10}$, Joaquín Sánchez García ${ }^{11}$, Sandra Santos Mínguez ${ }^{1}$, Cristina Miguel García ${ }^{1}$, \\ Ana María Simón Muñoz ${ }^{1}$, Jesús María Hernández Rivas ${ }^{1,2}$, María Abáigar ${ }^{1}$, María Díez \\ Campelo ${ }^{2}$ \\ *these authors contributed equally \\ ${ }^{1}$ Unidad de Diagnóstico Molecular y Celular del Cáncer, Centro de Investigación del Cáncer- \\ Universidad de Salamanca (IBMCC, USAL-CSIC); Genética Molecular en Oncohematología, \\ Instituto de Investigación Biomédica de Salamanca (IBSAL), \\ ${ }^{2}$ Hematología, Hospital Universitario de Salamanca, \\ ${ }^{3}$ Hematología, Hospital Universitario de León, \\ ${ }^{4}$ Hematología, Hospital Clínico de Valencia, Valencia, \\ ${ }^{5}$ Hematología, Hospital Universitario Central de Asturias, Oviedo, \\ ${ }^{6}$ Hematología, Instituto Hospital del Mar de Investigaciones Médicas (IMIM), Barcelona,, \\ ${ }^{7}$ Hematología, Hospital Universitario Marqués de Valdecilla, Santander, \\ ${ }^{8}$ Hematología, Hospital Universitario de la Paz, Madrid, \\ 9 Hematología, Hospital Universitari Germans Trias I Pujol, Instituto Catalán de Oncología \\ (ICO), Badalona, \\ ${ }^{10}$ Hospital Universitario de Canarias, Universidad La Laguna \\ ${ }^{11}$ Hematología, Hospital Universitario Reina Sofía, Córdoba
}

\begin{abstract}
SF3B1 is one of the most frequently mutated genes in MDS patients, related to a specific subtype and parameters of good prognosis in MDS without excess blasts. However, more than $40 \%$ of MDS patients carry at least 2 mutations and little is known about the impact of concurrent mutations in the outcome of MDS patients. We aimed to analyse the co-occurrence of SF3B1 with other mutations and reveal their clinical, biological and prognostic implications in very low/low and intermediate-risk of MDS patients. Mutational analysis of 102 SF3B1 ${ }^{\text {mut }}$ patients showed that $19.6 \%$ of cases carry isolate SF3B1 mutation, while $80.4 \%$ of patients presented additional mutations in other genes, with a median of 2 additional mutations per patient (range $0-5$ ). The genes most frequently mutated concomitant to SF3B1 were: TET2 (39.2\%), DNMT3A (25.5\%), SRSF2 (10.8\%), CDH23 (5.9\%) and ASXL1, CUX1, KMT2D (4, 9\% each). We observed that presence of $\geq 2$ concomitant mutations to SF3B1 had an adverse impact on survival as compared to those with $S F 3 B 1+<2$ additional mutation (median of $54 v s .87$ months, respectively, $p=0.007$ ). Furthermore co-occurrence of SF3B1 with SRSF2 mutations was associated with shorter overall survival as compared to isolated SF3B1 mutation with SRSF2 wt (median of 27 vs. 75 months, respectively, $\mathrm{p}=0.001$ ). The similar adverse effect was observed with concomitant IDH2 mutations, (median OS of 11 vs. 75 months, respectively, $\mathrm{p}=0.001$ ), and $B C O R$ (median OS of 11 vs. 71 months, respectively, $\mathrm{p}=0.036$,). Interestingly, SF3B1 with NUP98, and SF3B1 with STAG2 had also a negative effect on patients prognosis (medians of 27 and 11 vs. 71 months, respectively, $p=0.008$ and $p=0.002$ ). In summary, Therefore our results suggest that
\end{abstract}


more complete NGS study in MDS SF3B1 ${ }^{\text {mut }}$ patients would be recommend to better estimation of the evolution of the disease discarding the influence of additional mutations that could interfere in the good prognosis associated with SF3B1 mutations and would allow proposing more adequate therapeutic options for each patient.

\section{Introduction}

Myelodysplastic syndromes (MDS) represent heterogeneous group of clonal hematopoietic stem cells disorders leading to abnormal blood production with a variable risk of progression to acute myeloid leukemia (AML) [1-3].

In recent years large scale analysis using the next-generation sequencing (NGS) allowed the identification of recurrent genetic alterations improving the knowledge in MDS pathogenesis [4-8]. More than $80 \%$ of MDS patients harbour at least one mutation, affecting genes from different functional groups: splicing machinery (SF3B1, SRSF2), DNA methylation (DNMT3A, TET2), transcription factors (TP53, RUNX1), chromatin modification (ASXL1, EZH2), RAS pathway (KRAS, NRAS), cohesin complex (STAG2, RAD21), kinases (JAK2, FLT3) and/or DNA repair (ATM, BRCC3) [4, 9-11].

Several clinical and biological implications of specific mutations have been demonstrated. Some of these gene mutations has been associated with morphological and clinical features such as complex karyotypes (TP53), excess bone marrow blast proportion (RUNX1, NRAS) or ring sideroblasts (SF3B1) and moreover, with prognosis regarding leukemia-free survival and overall survival $[12,13]$. Mutations in TP53, U2AF1, RUNX1, SRSF2, IDH2, CUX1, ASXL1, and BCOR genes are associated with significantly worse leukemia-free survival [5]. Morevoer mutations in TP53, EZH2, ETV6, RUNX1 as well $A S X I 1$ are predictors of poor overall survival, while mutations in SF3B1 are associated to a better outcome in MDS patients $[6,14]$. Most of these studies have analyzed single mutations. However little is known about the impact of concurrent mutations in the outcome of MDS patients [15].

The presence of more than one mutation is frequent in MDS. Thus, studies conducted in large series of MDS showed more than two mutations in $40 \%$ of MDS, while $10 \%$ had more than four mutations. It has been clearly demonstrated the variety of gene mutation numbers per case, in this sense, Papaemmanuil and colleagues shown that $40 \%$ of cases had 2 or 3 mutated genes and up to $10 \%$ of patients presented 4 to 8 oncogenic point mutations. All these features correlates with a more complex disease and adversely impact on overall survival (OS) [4]. Although no significance affinity of SF3B1 with common mutational genes other than DNMT3A and JAK2 has been found, different co-existing gene mutations with SF3B1 have been described [4, 5]. SF3B1 encodes a core component of RNA splicing machinery. NGS studies have revealed that approximately $30 \%$ of MDS cases presented mutation of SF3B1 gene, with particularly high prevalence in MDS with ring sideroblasts subtype (MDSRS), which is reflected in the new 2016 WHO classification (>90\%) $[3,13,14]$. Furthermore, SF3B1 mutations in low risk MDS patients were associated with good prognostic parameters [13].

Nevertheless and regarding that the mayority of MDS patients carry on multiple genetic alterations, the well-known better overall and leukemia free survival referred to SF3B1 mutations in low risk MDS patients may be worse. Recent studies in low risk MDS-RS 
patients have highlight the adverse influence of DNMT3A or ASXL1-SF3B1 coexisting mutations into clinical outcome $[15,16]$.

However, information about the influence of other co-existing gene mutations with $S F 3 B 1^{\text {mut }}$ in MDS patients is scanty. Detailed molecular characteristic of these group would allow to a better stratification among patients within the low- risk MDS cathegories as well as a better choice of treatment for these patients. The aim of this study was to analyze, by means of NGS, the presence of mutations associated to SF3B1 mut and to evaluate the prognostic value in a large series of very low/low/intermediate-risk MDS patients.

\section{Matherials and methods}

\section{Patients}

The mutational profile of 324 myelodysplastic syndromes (MDS) patients, diagnosed in our center since 1999 to 2017 was analysed. Diagnosis was based according to World Health Organization (WHO) criteria. Patients with Refractory Anemia with Excess of Blasts (RAEB) and MDS associated with isolated del(5q) were excluded from the study.

SF3B1 mutations were detected in 135 patients (42\%). Detailed analysis of clinical parameters and cytogenetic findings was performed to risk stratification according to the International Prognostic Scoring System (IPSS) and the revised IPSS (IPSS-R). Finally, a total of 102 MDS cases with SF3B1 mutations and IPSS-R very low (34.4\%), low $(60.4 \%)$ or intermediate (5.2\%) risk category were included. Regarding WHO 2008 classification, 36 patients $(35.3 \%)$ had refractory anemia with ring sideroblasts (RARS), 60 (58.8\%) had refractory cytopenia with multilineage dysplasia (RCMD) and the remaining 6 (5.9\%) had refractory cytopenia with unilineage dysplasia (RCUD). The median age was 76 years (range: 41-90). More detailed clinical features of the cohort are listed in Table 1. The study was approved by the Local Ethical Committee "Comité Ético de Investigación Clínica, Hospital Universitario de Salamanca" and, for each patient, written informed consent was obtained according to the guidelines of the Declaration of Helsinki.

Table 1. The clinical features of 102 MDS patients

\begin{tabular}{|c|c|c|c|c|c|}
\hline Variable & $\mathrm{N}=102$ & $\%$ & $\begin{array}{l}\text { Median } \\
\text { (range) }\end{array}$ & p10 & p90 \\
\hline \multicolumn{6}{|l|}{ Gender } \\
\hline $\begin{array}{l}\text { Male } \\
\text { Female }\end{array}$ & $\begin{array}{l}56 \\
45\end{array}$ & $\begin{array}{l}55,4 \\
44,6\end{array}$ & \multirow{7}{*}{$76(41-90)$} & \multirow{6}{*}{63} & \multirow{6}{*}{84} \\
\hline Age & & & & & \\
\hline WHO 2008 & & & & & \\
\hline RARS & 36 & 35,3 & & & \\
\hline RCUD & 6 & 5,9 & & & \\
\hline RCMD & 60 & 58,8 & & & \\
\hline \multicolumn{5}{|l|}{ WHO 2016} & \\
\hline MDS-SLD & 1 & 1 & \multirow{8}{*}{$0,8(0-4,2)$} & \multirow{8}{*}{0} & \multirow{8}{*}{3} \\
\hline MDS-MLD & 5 & 5,2 & & & \\
\hline MDS-RS-SLD & 39 & 40,6 & & & \\
\hline MDS-RS-MLD & 51 & 53,1 & & & \\
\hline Blasts & & & & & \\
\hline$\leq 2$ & 84 & 82,4 & & & \\
\hline$>2<5$ & 12 & 11,8 & & & \\
\hline NA $(<5)$ & 6 & 5,9 & & & \\
\hline Ring sideroblasts & & & $41,5(0-95)$ & 7,5 & 73,7 \\
\hline$<5$ & 6 & 5,9 & & & \\
\hline$\geq 5<15$ & 5 & 4,9 & & & \\
\hline$\geq 15$ & 85 & 83,3 & & & \\
\hline \multicolumn{6}{|l|}{$\mid \begin{array}{l}\text { NA }<15) \\
\text { Citigenetic risk }\end{array}$} \\
\hline Verv good & 7 & 6,9 & & & \\
\hline Good & 88 & 87,2 & & & \\
\hline Intermediate & 6 & 5,9 & & & \\
\hline \multicolumn{6}{|l|}{ IPSS } \\
\hline Low & 68 & 67,3 & & & \\
\hline Int-1 & 18 & 17,8 & & & \\
\hline NA (Low/Int-1) & 15 & 14,9 & & & \\
\hline \multicolumn{6}{|l|}{ IPSS-R } \\
\hline Verv Low & 33 & 33 & & & \\
\hline Low & 58 & 58 & & & \\
\hline Intermediate & 5 & 5 & & & \\
\hline NA (Verv low/low) & 2 & 2 & & & \\
\hline & 2 & 2 & & & \\
\hline \multicolumn{6}{|l|}{ AML transformation } \\
\hline No & 66 & 81,5 & & & \\
\hline Yes & 15 & 18,5 & & & \\
\hline \multicolumn{6}{|l|}{ Status } \\
\hline Live & 41 & 40,2 & & & \\
\hline Death & 61 & 59,8 & & & \\
\hline $\mathrm{Hb}(\mathrm{g} / \mathrm{dL})$ & & & $9,6(5,4-13)$ & 7,9 & 11,6 \\
\hline ANC $\left(\times 10^{9} / L\right)$ & & & $2,7(0,6-8,7)$ & 1,5 & 6,1 \\
\hline Platelets $\left(\times 10^{9} / 1\right)$ & & & $251(34-878)$ & 150 & 430 \\
\hline
\end{tabular}

\section{Mutational analysis}

Mutational screening on genomic nonamplified DNA from bone marrow (BM) or peripheral blood (PB) cells was performed. Therefore a customized myeloid panel of 117 genes related to MDS was applied (Supplementary Table S1). Next generation sequencing (NGS) was achieved on NextSeq sequencing platform (Illumina, San Diego, CA, 
USA) following Illumina's standard protocol as previously reported. Sequencing data was analyzed by applying an in house informatic pipeline that uses different software tools to perform quality assessment, alignment and variant calling (Trimmomatic, FastQC, NGSQCToolkit, BWA, GATK, VarScan, SAMTools, ANNOVAR). Integrative Genomics Viewer (IGV, Broad Institute) was used for variants visual evaluation.

After analysis, only those variants with good quality ( $Q>30$ ), supported by $\geq 100$ total and $\geq 10$ mutated reads, with a $\mathrm{VAF} \geq 3 \%$, located in exonic or splicing regions and which generate an AA change was considered. In addition, already reported polymorphisms (SNPs) (dbSNP144, 1000-genomes Project, EXAC, ESP-6500, when MAF $\geq 1 \%$ ) and sequencing artifacts (internal laboratory database) were discarded.

For variant interpretation and oncogenic potential evaluation COSMIC and ClinVar databases, SIFT, PolyPhen-2 and Mutation Taster predictors, among others, were used (Supplementary Figure 1).

\section{Statistical analysis}

Numerical variables were summarized by median and range; categorical variables were described with count and relative frequency (percentage) of subjects in each category. Comparison of numerical variables between groups was carried out as required using a non-parametric approach (Mann-Whitney test) or the Student $t$ test for continuous variables. Overall survival was measured from the time of diagnosis to the time of last follow-up or death from any cause. Survival curves were generated using the KaplanMeier method and differences were assessed by log-rank test. For multivariate analysis, a Cox proportional hazards models were constructed, adjusting for potential confounding covariates. The level of significance for all statistical tests was defined at a probability value of less than $.050(P<.050)$. The analyses were generated using the SPSS statistical software package, version 22.0 (SPSS Inc, Chicago, IL).

\section{Results}

\section{Characterization of SF3B1 mutations in MDS patients}

One hundred and seven SF3B1 mutations were found in 102 MDS patients. Medium VAF was $33.33 \%$ (range $5.72 \%-50 \%$ ). All mutations were missense, heterozygous, and except three (K748E, Y623F and L536V), previously reported. The most frequent mutation was $\operatorname{K} 700 E(47,43.9 \%)$ followed by K666R (12, 11.2\%) and E622D (9, 8.4\%). All SF3B1 mutational variants detected are represented in Figure 1. Five of 102 MDS patients presented double SF3B1 mutations. The variants of four patients were located in the exon 14 (E622D and Y623F; H662Q and K666T; and two cases with E622V and T663I) while the double SF3B1 mutation in the remaining patient affected exons 14 and 15 (R625H and K700E).

\section{Co-occurrrence SF3B1 mutations with other gene mutations}

Co-occurrence of SF3B1 with other gene mutations was observed in 82 out of 102 patients (80.4\%). A total of 192 co-occurrence mutations, covering 51 genes, were found in the $102 S F 3 B 1^{\text {mut }}$ patients, with a median of 2 additional mutations per sample (range: $0-5$ ). Patients with one additional mutation to SF3B1 was the most frequent group $(n=26$, $25.5 \%)$, followed by two and three cooccurrence mutations $(n=23,22.5 \%$, and 
$\mathrm{n}=19,18.6 \%$, respectively). Cases with four and five concomitant SF3B1 mutations were unfrequent $(n=7,6.9 \%$ and $n=8,7.8 \%$, respectively). The most frequently mutated genes co-occurring with SF3B1 were: TET2 $(n=40,39.2 \%)$, DNMT3A $(n=26,25.5 \%)$,

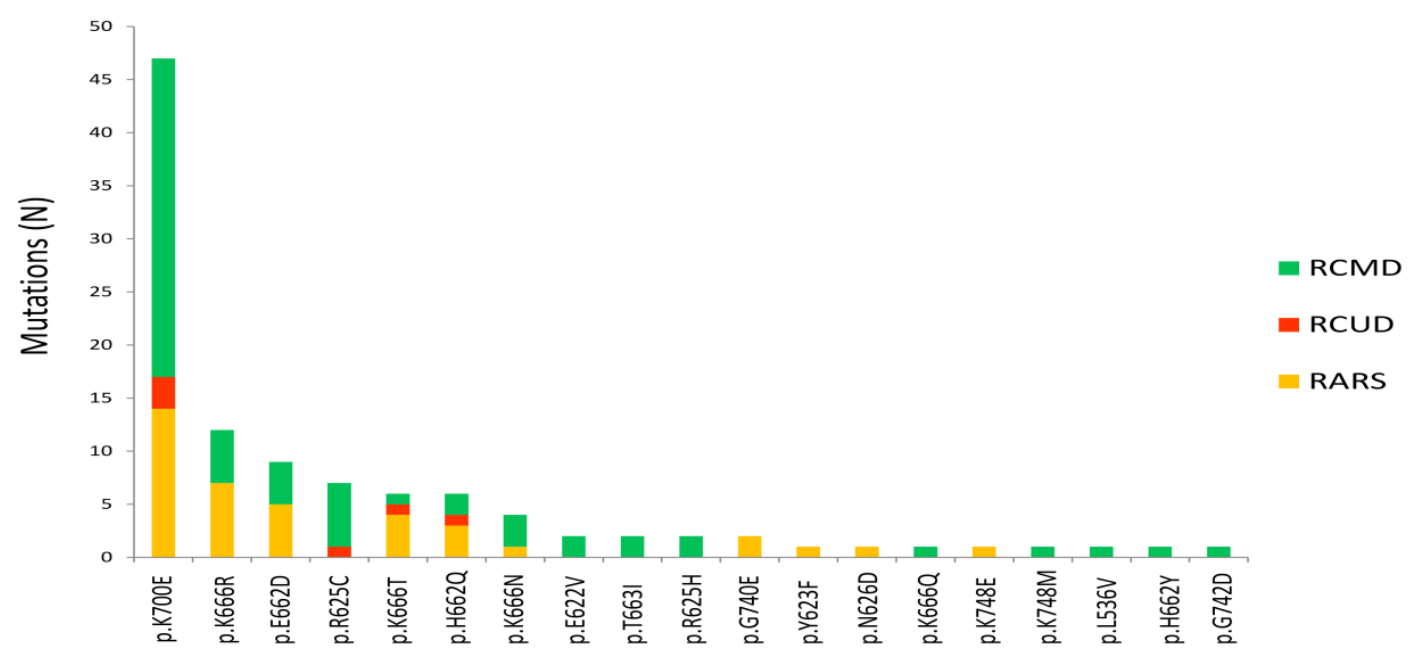

Figure 1. One hundred and seven SF3B1 mutations distributed in 102 patients according to WHO 2008 MDS subtype

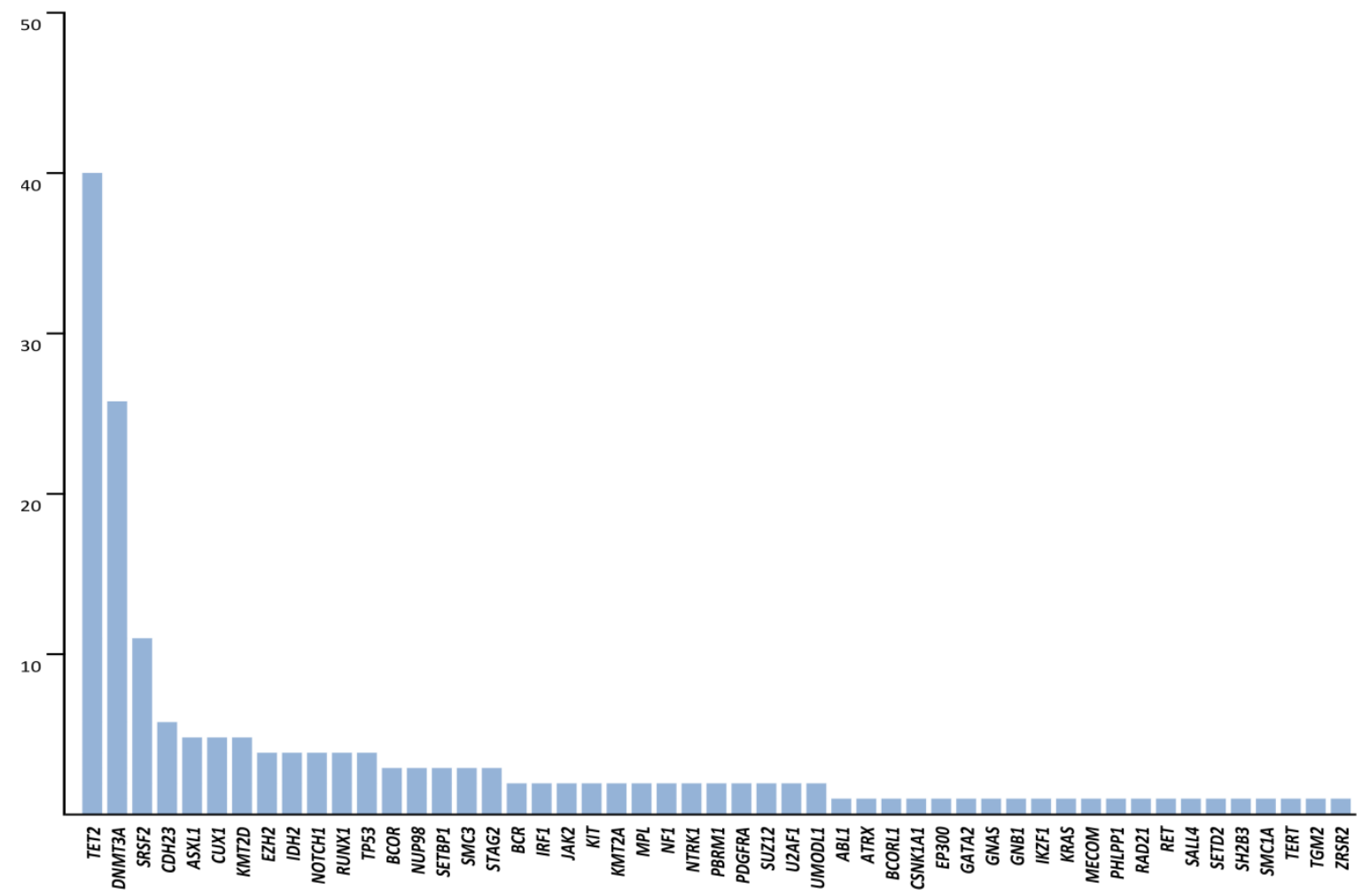

Figure 2. Frequency of mutations in fifty one genes co-occurring with SF3B1 in 102 very low/low/intermediate-risk MDS patients. 
The wide heterogeneity in the overall distribution of concomitant mutations was described in Figure 3. Interestingly, the addition of one single mutation to SF3B1 mutation usually involve TET2 or DNMT3A genes. However the addition of two concomitant mutations to SF3B1 mutations did not show a clear pattern of distribution or evolution.

\section{Impact of the number of co-occurring SF3B1 mutations}

In the next step of the study, the influence of the number of co-occurrence mutations were analysed considering the clinical characteristics and the overall survival (OS). No differences were observed in clinical characteristic of the patients affected by 1 to 5 of additional SF3B1 mutations, (Supplementary table S2). However, regarding overall survival (OS), after a median follow-up of 54 months and an overall survival of the series of 70 months, we found that the presence of $\geq 2$ concomitant mutations to SF3B1 had an adverse impact on survival as compared to those with SF3B1+ $<2$ additional mutation (median of 54 vs. 87 months, respectively, $p=0.007$ ) (Figure 4A).

\section{Several co-occurring SF3B1 gene mutations reduce $O S$ of MDS patients}

Frequently mutated genes overlapping SF3B1 were analyzed (Figure 1). There were no differences, comparing the clinical features, between groups of $S F 3 B 1^{\text {mut }}$ patients with wild type or mutated forms of the most frequently mutated genes (Data not provided). Interestingly, we observed that the presence of somatic mutations in other genes can modify the good prognosis of the patients with isolated SF3B1mut. Thus, in the univariate analysis, co-occurrence of SF3B1 with SRSF2 mutations was associated with shorter overall survival as compared to isolated SF3B1 mutation with SRSF2 wt (median of 27 vs. 75 months, respectively, $p=0.001$ ), (Figure 4B). The similar adverse effect was observed with concomitant IDH2 mutations, (median OS of 11 vs. 75 months, respectively, $\mathrm{p}=0.001$ ), (Figure $4 C$ ) and $B C O R$ (median OS of 11 vs. 71 months, respectively, $\mathrm{p}=0.036$,) (Figure 4D). Interestingly, SF3B1 with NUP98, and SF3B1 with STAG2 had also a negative effect on patients prognosis (medians of 27 and 11 vs. 71 months, respectively, $p=0.008$ and $p=0.002$ ) (Figure $4 E$ and $4 \mathrm{~F}$ ).

\section{SF3B1 and Clonal Hematopoiesis Indeterminate Potential (CHIP) mutations co-ocurrence}

The presence of mutations in some genes considered CHIPs in co-ocurence with SF3B1 was analyzed. More than half of MDS patients $(57.8 \%, \mathrm{~N}=59)$ displayed mutations in TET2, DNMT3A and/or ASXL1 (Figure 3). The comparison of the most relevant clinical and biological charactersitics, such as age, hemoglobin, platelets, neutrophils, bone marrow percentage of blast and ring sideroblast as well the overall survival, did not show any difference between the low-risk MDS patients with CHIPs mutations associated to SF3B1 mutations and SF3B1 mutations as the single abnormality. Therefore CHIP mutations had no effect on SF3B1 mutated cases (Table 2 \& Figure 5).

Table 2. Comparison of median values between patients with vs. without co-occurrence SF3B1 mutation with CHIPs genes mutations (wt-wild type, mut-mutated). 


\begin{tabular}{|c|ccccccccc|}
\cline { 2 - 11 } \multicolumn{1}{c|}{} & ASXL1wt & ASXL1mut & $\mathrm{p}$ & DNMT3Awt & DNMT3Amut & $\mathrm{p}$ & TET2wt & TET2mut & $\mathrm{p}$ \\
\hline Age & 76.5 & 76.3 & 1 & 76.7 & 72.7 & 0.495 & 76 & 76.8 & 0.156 \\
\hline $\begin{array}{c}\% \text { Blasts } \\
\text { (BM) }\end{array}$ & 0.9 & 0.7 & 0.625 & 0.7 & 1 & 0.598 & 0.8 & 0.95 & 0.769 \\
\hline$\%$ RS & 42.5 & 28.5 & 0.608 & 41 & 42.5 & 0.803 & 44 & 36 & 0.649 \\
\hline $\mathrm{Hb}$ (g/dL) & 9.7 & 9.5 & 1 & 9.6 & 9.7 & 0.820 & 9.7 & 9.6 & 0.682 \\
\hline $\begin{array}{c}\text { ANC } \\
\text { (x109/L) }\end{array}$ & 2.7 & 2.6 & 0.930 & 2.65 & 2.7 & 0.860 & 2.9 & 2.2 & 0.185 \\
\hline $\begin{array}{c}\text { Platelet } \\
\text { (x109/L) }\end{array}$ & 252 & 200 & 0.371 & 247 & 255 & 0.323 & 259 & 245 & 0.338 \\
\hline
\end{tabular}




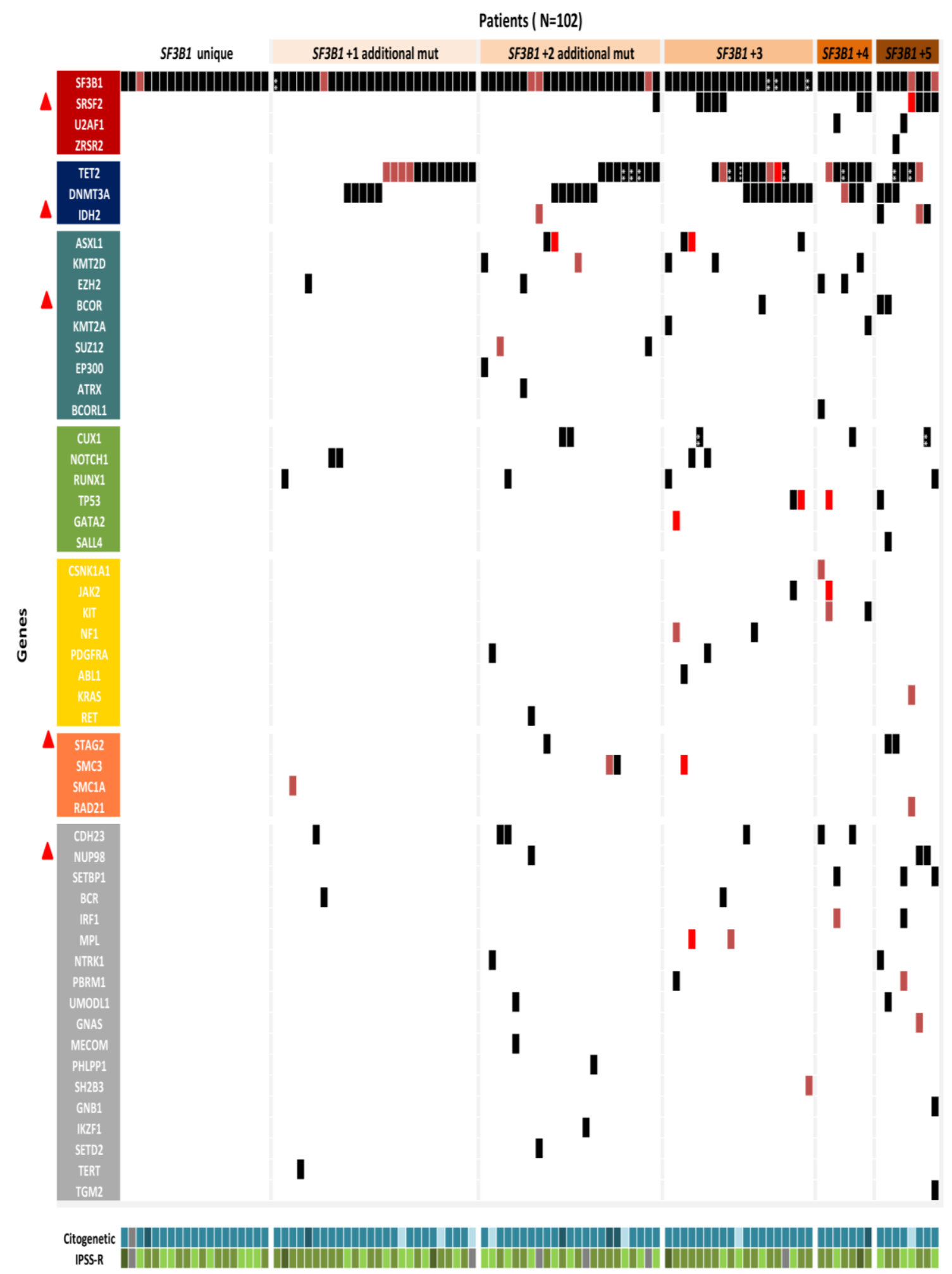

Figure 3. Mutational landscape of 102 MDS. Each column represents one patient. Patients are grouped according to number of additional SF3B1 mutations. Each line represents one gene. Genes are grouped according to the function. Red triangle marked genes that reduce overall survival of MDS patients. VAF: $\quad 3<5 \% \quad \geq 5<10 \% \quad \square \geq 10 \%$. Gene function: splicing, DNA methylation, chromatin modification, Transcription factors, activated signaling, Cohesin complex, Others.. Cytogenetics: Very good, Good, Intermediate, NA. IPSS-R: Very low, Low, Entermediate, NA. 
A

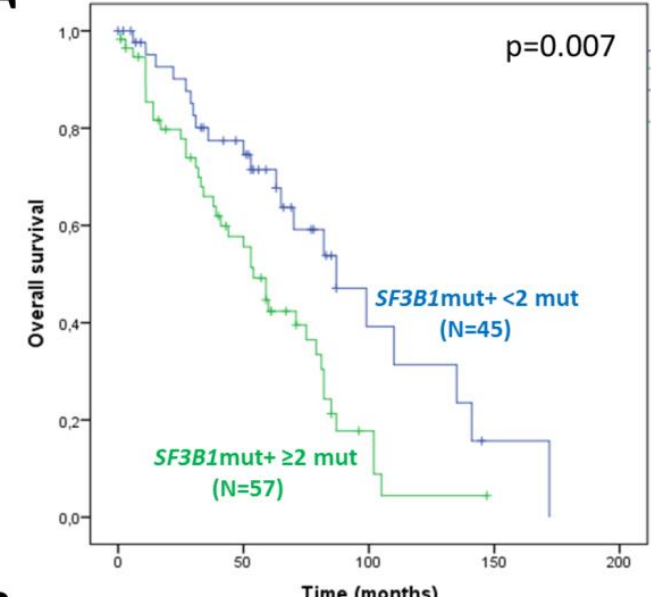

B

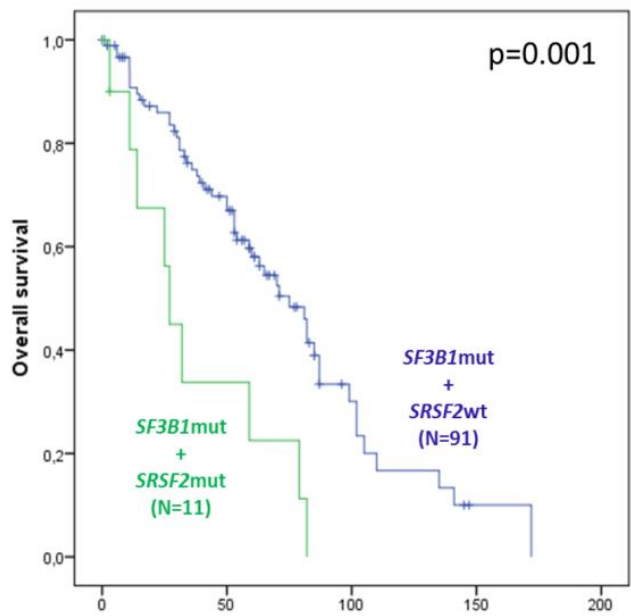

C

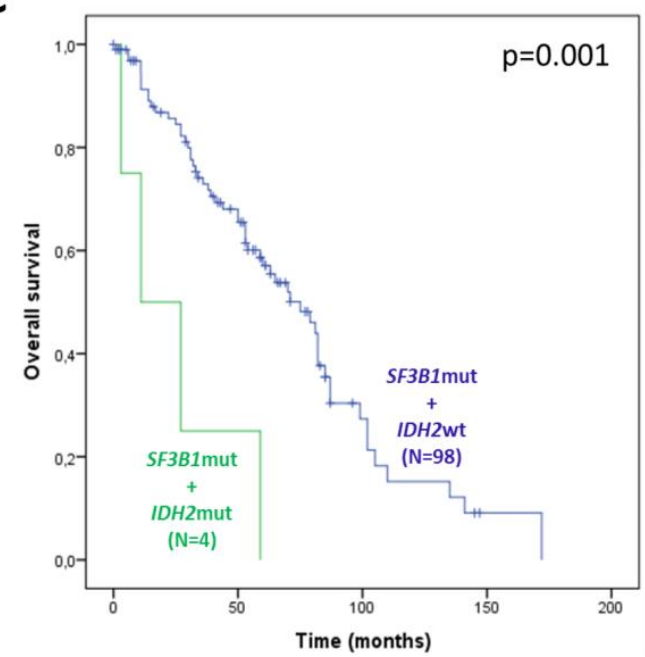

D

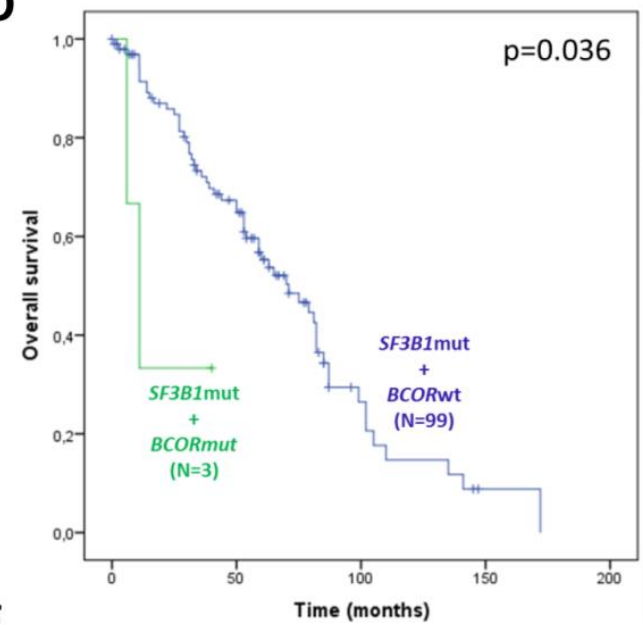

$\mathbf{E}$

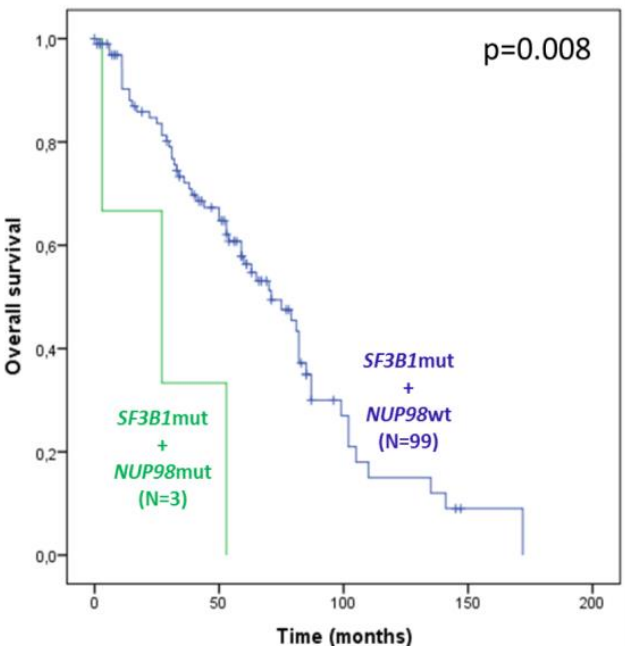

$\mathbf{F}$

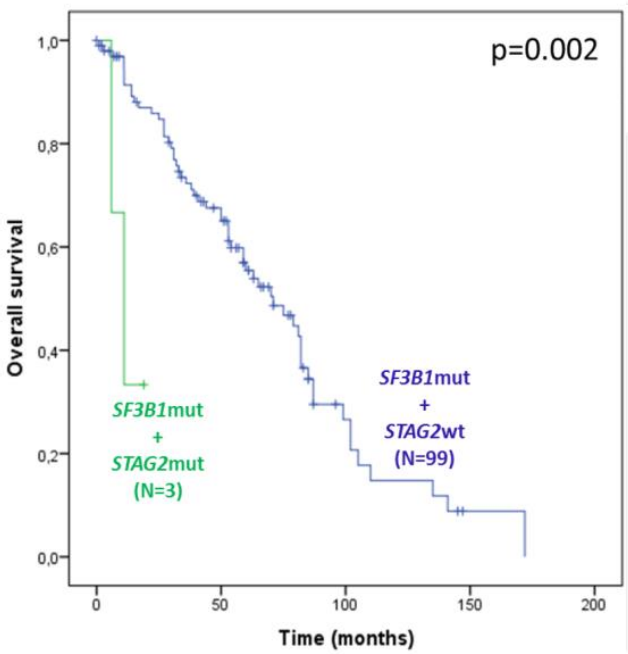

Figure 4. Overall survival of MDS $S F 3 B 1^{\text {mut }}$ patients regarding the number of concomitant mutations (A), SRSF2mut co-occurrence (B), IDH2mut co-occurrence (C), BCORmut co-occurrence (D), NUP98mut cooccurrence (E), STAG2mut co-occurrence (F). 
A

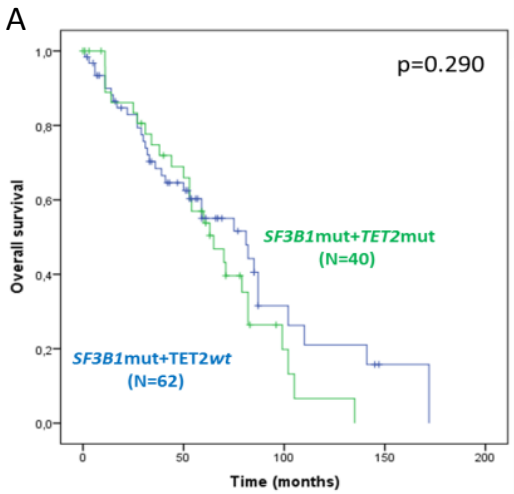

B

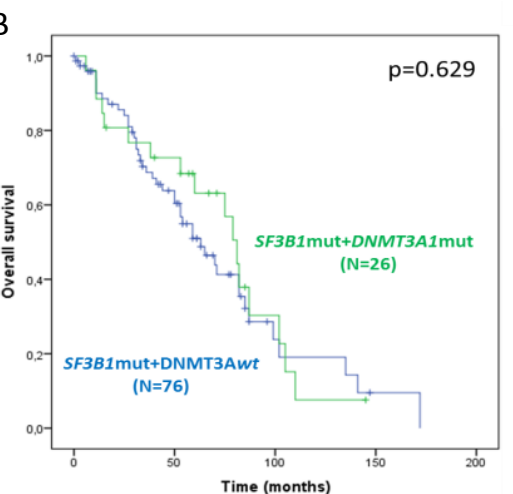

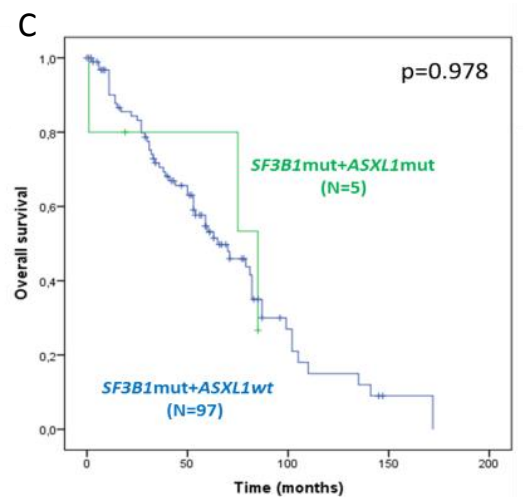

Figure 5. Overall survival of MDS SF3B $1^{\text {mut }}$ patients regarding to CHIPs gene co-occurrence: TET2mut (A), DNMT3Amut (B), ASXL1mut (C).

\section{Discussion}

SF3B1 is one of the most frequently mutated genes in MDS and the presence of mutations in this gene is associated with favourable outcome among MDS patients without excess of blasts $[4,13]$. However information about the appearance and the influence of other co-concurrent mutations in prognosis is scanty althought is a relevant question considering that at least $40 \%$ of patients with MDS have at least 2 mutations $[4,5,17]$. In the current study we analyzed the cooccurrence of mutations in SF3B1 and other frequent myeloid-related genes, the consequences of these concomitant mutations in the clinical and biological phenotype and the impact on prognosis in a cohort of 102 MDS low risk patients without excess of blasts. Our study confirms that the presence of more than one mutation associated to SF3B1 is associated with a dismal prognosis in MDS patients.

To unify analysis in the study, we included only low risk patients categorized as very low, low and intermediate-risk according to the IPSS-R. Clinical features did not differ from the typical features of low-risk MDS patients regarding age gender and WHO classification [18-20]. Patients with excess of blasts were excluded from the study because the frequency of SF3B1 mutations in this population is low and due to an adverse outcome predefined in these subset of patients [4, 5, 21]. In addition, and based in a recognized different entity, with a clear genotype-phenotype relationship and prognosis, MDS with isolated $5 q$ deletion patients were removed from the study [22, 23].

The MDS subtype most frequently found in our cohort was MDS-RS $(93,7 \%)$ according to WHO-2016 classification. The percentage of RS ranged between 0 and $95 \%$ with the mayority of the cases $(83,3 \%)$ with more than $15 \%$ of RS [24, 25]. The last 2016 WHO classification, expanded the MDS-RS group with cases carrying RS level between $5 \%$ and $15 \%$ and confirmed SF3B1 mutation, which involved $4,9 \%$ of cases in our cohort (Table 1 ) [3]. Six patients could not be classified as WHO 2016 due to lack of information on the number of RS. The increase of MDS-RS diagnosed patients, after WHO-2016 reclassification, has been also seen in other studies [26].

The occurrence of SF3B1 mutations among MDS-RS patients was similar with previous studies. All mutations found, were missense, heterozygous with the change of lysine by glutamic acid in codon 700 (K700E) as the most frequent $[14,27]$. Besides three (K748E, Y $623 \mathrm{~F}$ and $L 536 \mathrm{~V}$ ) all of the remaining 
variants have been already known in hematologic cancer, and with similar frequency reported (Table 2) [28-30]. Interestingly five of 102 patients had double SF3B1 mutations (E622D and Y623F; H662Q and K666T; two cases with E622V and T663I and $\mathrm{R} 625 \mathrm{H}$ and $\mathrm{K} 700 \mathrm{E})$. The presence of double mutations in SF3B1 gene is rare, although it has been previously reported [14, 17].

Co-occurrence analyses of the SF3B1 with other myeloid-related genes revealed that only 20 patients $(19,3 \%)$ carried SF3B1 as isolated mutation. Previous reports demonstrated that more than $40 \%$ of cases of MDS had at least 2 mutations, wich confirms the need to perform a detailed complete molecular analysis for a better knowledge of the molecular pattern and risk of our patients, specially among low-risk MDS [4, 5]. The isolated SF3B1 mutation appeared as a minority group in our cohort and in other studies with a trend to be higher (40\%) among the MDS-RS cases [4, 17]. Those discrepances may be due to different type of NGS methodology used (Amplicon technique applied by Martin et al. analysed regions of 39 genes, when in our study capture of exons of 117 genes methodology was used), as well the different VAF used ( $5 \%$ by Martin et al. vs. $3 \%$ in the current study). Nevertheless the mayority group of the patients in both series suffered additional mutations coexisting with SF3B1.

TET2 and DNMT3A genes were the most frequently mutated, co-occurring with SF3B1 in $39.2 \%$ and $25.5 \%$ respectively, similar to data of the previous series $[4,5,16]$. The mutation in SRSF2 was the next most frequently observed. Although SRSF2 mutations are quite frequent in MDS or MDSRS patients, the co-occurrence with SF3B1 is rarely found $[8,31]$. Because of our previous study, where splicing genes in MDS-RS patients were analysed, double splicing gene mutations and their possible influence on outcome of patients were demostrated. Therefore we decided to enrich and investigated with more details the group of SF3B1 and SRSF2 occurring jointly [14]. As a consequence, SRSF2+SF3B1 mutated group is another, of the most frequently occurring $(10.8 \%)$ what does not agree with previously reported, where double splicing gene mutations are considerate as mutually exclusively [4, 5]. The remaining gene mutations known in MDS, were quite similar to previously reported MDS as well MDS-RS subtypes, as shown in Figure $2[4,5,17]$.

Previous studies suggested that higher number of driver mutations, get worse the clinical outcome in these patients [5, 32]. In our study we confirm that SF3B1 with more than one additional mutations is an independent prognostic factor associated to a short survival .

Regarding the role of particular gene mutation co-occurrence to SF3B1, previous studies suggested that the presence of some genes mutations in low-risk $S F 3 B 1^{\text {mut }}$ MDS patients could modified clinical features and prognosis. Malcovati et al. have found that in SF3B $1^{\text {mut }}$ patients, RUNX1 mutations were significantly associated with worse OS and higher cumulative incidence of disease progression [13]. Similary, Martin et al. have demonstrated the same pattern in RARS patients with SF3B1 and DNMT3A mutations [15]. As far as we known, these findings were not confirmed in other cohorts and were not confirmed in our study. It could be due to insufficient number of $S F 3 B 1^{\text {mut }}$ with RUNX1 ${ }^{\text {mut }}$ patients, and a more heterogeneous cohort included in our study in comparison with other series [15]. Nevertheless, we found a negative impact on prognosis when co-occurrence of SF3B1 with SRSF2 and/or BCOR and/or IDH2 and/or 
NUP98 and/or STAG2 mutations. Nevertheless, with the exception of SRSF2, due to small number of affected cases, further analysis and confirmation of these findings in a larger cohort of patients are needed.Moreover, the presence of SRSF2 mutations were associated with higher number of mutations in the patiens, suggesting their negative impact on OS in these cases.

In 2014 NGS studies in healthy individuals revealed that around of $10-20 \%$ of elder people ( $\geq 65$ years) carried somatic mutations in hematopoietic disorders-related genes making haematopoiesis- clonal. The majority of the variants occurred in three genes: DNMT3A, TET2 and ASXL1. The clonal haematopoiesis indeterminate potential (CHIP) in healthy people contributed to create an increased risk to subsequent hematologic cancer and cardiovascular diseases appearance $[33,34]$. In the current study, DNMT3A, TET2 and ASXL1 were seen as ones of most frequently mutated. No effect was seen in SF3B1 co-occurrence. However according to previously data, their existence could be crucial to initiate the clonal haematopoiesis that evolved into the MDS disease [33-35]. This data demonstrate the importance and utility of NGS technique application not only in patients monitoring but also in healthy people, giving a chance for early detection of molecular changing (clonal hematopoiesis) increasing the opportunities to immediate reaction and lack the possible further evolution of the disease.

In summary, our study demonstrated that mutations in SRSF2, IDH2, BCOR, NUP98 and/or STAG2 concomitant to SF3B1 as well as the co-ocurrence of $\geq 2$ additional mutations in very low/low/intermediate-risk MDS patients is associated with an unfavourable impact shortening the survival of patients. Therefore the complete mutational study in MDS patients and ring sideroblasts could allow to a better prognostication and could clarify the positive influence of the presence of SF3B1 isolated mutations in this subset of patients.

\section{References}

[1] N. Gangat, M.M. Patnaik, A. Tefferi, Myelodysplastic syndromes: Contemporary review and how we treat, American journal of hematology 91(1) (2016) 76-89.

[2] S.A. Bannon, C.D. DiNardo, Hereditary Predispositions to Myelodysplastic Syndrome, International journal of molecular sciences 17(6) (2016).

[3] D.A. Arber, A. Orazi, R. Hasserjian, J. Thiele, M.J. Borowitz, M.M. Le Beau, C.D. Bloomfield, M. Cazzola, J.W. Vardiman, The 2016 revision to the World Health Organization classification of myeloid neoplasms and acute leukemia, Blood 127(20) (2016) 2391-405.

[4] T. Haferlach, Y. Nagata, V. Grossmann, Y. Okuno, U. Bacher, G. Nagae, S. Schnittger, M. Sanada, A. Kon, T. Alpermann, K. Yoshida, A. Roller, N. Nadarajah, Y. Shiraishi, Y. Shiozawa, K. Chiba, H. Tanaka, H.P. Koeffler, H.U. Klein, M. Dugas, H. Aburatani, A. Kohlmann, S. Miyano, C. Haferlach, W. Kern, S. Ogawa, Landscape of genetic lesions in 944 patients with myelodysplastic syndromes, Leukemia 28(2) (2014) 241-7.

[5] E. Papaemmanuil, M. Gerstung, L. Malcovati, S. Tauro, G. Gundem, P. Van Loo, C.J. Yoon, P. Ellis, D.C. Wedge, A. Pellagatti, A. Shlien, M.J. Groves, S.A. Forbes, K. Raine, J. Hinton, L.J. Mudie, S. McLaren, C. Hardy, C. Latimer, M.G. Della Porta, S. O'Meara, I. Ambaglio, A. Galli, A.P. Butler, G. Walldin, J.W. Teague, L. Quek, A. Sternberg, C. Gambacorti-Passerini, N.C. Cross, A.R. Green, J. Boultwood, P. Vyas, E. Hellstrom-Lindberg, D. Bowen, M. Cazzola, M.R. Stratton, P.J. Campbell, C. Chronic Myeloid Disorders Working Group of the International Cancer Genome, Clinical and biological implications of driver mutations in myelodysplastic syndromes, Blood 122(22) (2013) 3616-27; quiz 3699. 
[6] R. Bejar, K. Stevenson, O. Abdel-Wahab, N. Galili, B. Nilsson, G. Garcia-Manero, H. Kantarjian, A. Raza, R.L. Levine, D. Neuberg, B.L. Ebert, Clinical effect of point mutations in myelodysplastic syndromes, The New England journal of medicine 364(26) (2011) 2496-506.

[7] R. Bejar, P.L. Greenberg, The Impact of Somatic and Germline Mutations in Myelodysplastic Syndromes and Related Disorders, Journal of the National Comprehensive Cancer Network : JNCCN 15(1) (2017) 131-135.

[8] K. Yoshida, M. Sanada, Y. Shiraishi, D. Nowak, Y. Nagata, R. Yamamoto, Y. Sato, A. Sato-Otsubo, A. Kon, M. Nagasaki, G. Chalkidis, Y. Suzuki, M. Shiosaka, R. Kawahata, T. Yamaguchi, M. Otsu, N. Obara, M. Sakata-Yanagimoto, K. Ishiyama, H. Mori, F. Nolte, W.K. Hofmann, S. Miyawaki, S. Sugano, C. Haferlach, H.P. Koeffler, L.Y. Shih, T. Haferlach, S. Chiba, H. Nakauchi, S. Miyano, S. Ogawa, Frequent pathway mutations of splicing machinery in myelodysplasia, Nature 478(7367) (2011) 64-9.

[9] B.B. Ganguly, N.N. Kadam, Mutations of myelodysplastic syndromes (MDS): An update, Mutation research. Reviews in mutation research 769 (2016) 47-62.

[10] H. Harada, Y. Harada, Recent advances in myelodysplastic syndromes: Molecular pathogenesis and its implications for targeted therapies, Cancer science 106(4) (2015) 32936.

[11] R. Itzykson, O. Kosmider, P. Fenaux, Somatic mutations and epigenetic abnormalities in myelodysplastic syndromes, Best practice \& research. Clinical haematology 26(4) (2013) 355-64. [12] P.L. Greenberg, R.M. Stone, A. Al-Kali, S.K. Barta, R. Bejar, J.M. Bennett, H. Carraway, C.M. De Castro, H.J. Deeg, A.E. DeZern, A.T. Fathi, O. Frankfurt, K. Gaensler, G. Garcia-Manero, E.A. Griffiths, D. Head, R. Horsfall, R.A. Johnson, M. Juckett, V.M. Klimek, R. Komrokji, L.A. Kujawski, L.J. Maness, M.R. O'Donnell, D.A. Pollyea, P.J. Shami, B.L. Stein, A.R. Walker, P. Westervelt, A. Zeidan, D.A. Shead, C. Smith, Myelodysplastic Syndromes, Version 2.2017, NCCN Clinical Practice Guidelines in Oncology, Journal of the National
Comprehensive Cancer Network : JNCCN 15(1) (2017) 60-87.

[13] L. Malcovati, M. Karimi, E.

Papaemmanuil, I. Ambaglio, M. Jadersten, M. Jansson, C. Elena, A. Galli, G. Walldin, M.G. Della Porta, K. Raaschou-Jensen, E. Travaglino, K. Kallenbach, D. Pietra, V. Ljungstrom, S. Conte, E. Boveri, R. Invernizzi, R. Rosenquist, P.J. Campbell, M. Cazzola, E. Hellstrom Lindberg, SF3B1 mutation identifies a distinct subset of myelodysplastic syndrome with ring sideroblasts, Blood 126(2) (2015) 233-41.

[14] K. Janusz, M. Del Rey, M. Abaigar, R. Collado, D. Ivars, M. Hernandez-Sanchez, A. Valiente, C. Robledo, R. Benito, M. DiezCampelo, F. Ramos, A. Kohlmann, C.D. Canizo, J.M. Hernandez-Rivas, A two-step approach for sequencing spliceosome-related genes as a complementary diagnostic assay in MDS patients with ringed sideroblasts, Leukemia research 56 (2017) 82-87.

[15] I. Martin, E. Such, B. Navarro, A. Vicente, M. Lopez-Pavia, M. Ibanez, M. Tormo, E. Villamon, I. Gomez-Segui, I. Luna, S. Oltra, L. Pedrola, M.A. Sanz, J. Cervera, G. Sanz, Negative impact on clinical outcome of the mutational co-occurrence of SF3B1 and DNMT3A in refractory anemia with ring sideroblasts (RARS), Leukemia \& lymphoma 58(7) (2017) 1686-1693.

[16] A.A. Mangaonkar, T.L. Lasho, C.M. Finke, N. Gangat, A. Al-Kali, M.A. Elliott, K.H. Begna, H. Alkhateeb, A.P. Wolanskyj-Spinner, C.A. Hanson, R.P. Ketterling, W.J. Hogan, A. Pardanani, M.R. Litzow, A. Tefferi, M.M. Patnaik, Prognostic interaction between bone marrow morphology and SF3B1 and ASXL1 mutations in myelodysplastic syndromes with ring sideroblasts, Blood cancer journal 8(2) (2018) 18.

[17] I. Martin, E. Such, B. Navarro, E. Villamon, A. Vicente, E. Mora, L. Pedrola, M. Ibanez, M. Lopez-Pavia, M. Tormo, A. Serrano, M.A. Sanz, J. Cervera, G. Sanz, Prognostic impact of gene mutations in myelodysplastic syndromes with ring sideroblasts, Blood cancer journal 7(12) (2017) 630.

[18] J. Schanz, H. Tuchler, F. Sole, M. Mallo, E. Luno, J. Cervera, I. Granada, B. Hildebrandt, M.L. Slovak, K. Ohyashiki, C. Steidl, C. 
Fonatsch, M. Pfeilstocker, T. Nosslinger, P. Valent, A. Giagounidis, C. Aul, M. Lubbert, R. Stauder, O. Krieger, G. Garcia-Manero, S. Faderl, S. Pierce, M.M. Le Beau, J.M. Bennett, P. Greenberg, U. Germing, D. Haase, New comprehensive cytogenetic scoring system for primary myelodysplastic syndromes (MDS) and oligoblastic acute myeloid leukemia after MDS derived from an international database merge, Journal of clinical oncology : official journal of the American Society of Clinical Oncology 30(8) (2012) 820-9.

[19] P.L. Greenberg, H. Tuechler, J. Schanz, G. Sanz, G. Garcia-Manero, F. Sole, J.M. Bennett, D. Bowen, P. Fenaux, F. Dreyfus, H. Kantarjian, A. Kuendgen, A. Levis, L. Malcovati, M. Cazzola, J. Cermak, C. Fonatsch, M.M. Le Beau, M.L. Slovak, O. Krieger, M. Luebbert, J. Maciejewski, S.M. Magalhaes, Y. Miyazaki, M. Pfeilstocker, M. Sekeres, W.R. Sperr, R. Stauder, S. Tauro, P. Valent, T. Vallespi, A.A. van de Loosdrecht, U. Germing, D. Haase, Revised international prognostic scoring system for myelodysplastic syndromes, Blood 120(12) (2012) 2454-65.

[20] G. Montalban-Bravo, G. Garcia-Manero, Myelodysplastic syndromes: 2018 update on diagnosis, risk-stratification and management, American journal of hematology 93(1) (2018) 129-147. [21] I. Triantafyllidis, A. Ciobanu, O. Stanca, A.R. Lupu, Prognostic factors in myelodysplastic syndromes, Maedica 7(4) (2012) 295-302.

[22] J. Boultwood, A. Pellagatti, A.N. McKenzie, J.S. Wainscoat, Advances in the 5qsyndrome, Blood 116(26) (2010) 5803-11. [23] A. Pellagatti, J. Boultwood, Recent Advances in the 5q-Syndrome, Mediterranean journal of hematology and infectious diseases 7(1) (2015) e2015037. [24] J.W. Vardiman, N.L. Harris, R.D. Brunning, The World Health Organization (WHO) classification of the myeloid neoplasms, Blood 100(7) (2002) 2292-302. [25] C.E. Swerdlow S.H., Harris N.L., Jaffe E.S., Pileri S.A., Stein H., Thiele J., Vardiman J.W., WHO Classification of Tumours of Haematopoietic and Lymphoid Tissues., (2008).
[26] C. Strupp, K. Nachtkamp, B. Hildebrandt, A. Giagounidis, R. Haas, N. Gattermann, J.M. Bennett, C. Aul, U. Germing, New proposals of the WHO working group (2016) for the diagnosis of myelodysplastic syndromes (MDS): Characteristics of refined MDS types, Leukemia research 57 (2017) 78-84.

[27] L. Malcovati, E. Papaemmanuil, D.T. Bowen, J. Boultwood, M.G. Della Porta, C. Pascutto, E. Travaglino, M.J. Groves, A.L. Godfrey, I. Ambaglio, A. Galli, M.C. Da Via, S. Conte, S. Tauro, N. Keenan, A. Hyslop, J. Hinton, L.J. Mudie, J.S. Wainscoat, P.A. Futreal, M.R. Stratton, P.J. Campbell, E. Hellstrom-Lindberg, M. Cazzola, C. Chronic Myeloid Disorders Working Group of the International Cancer Genome, M. of the Associazione Italiana per la Ricerca sul Cancro Gruppo Italiano Malattie, Clinical significance of SF3B1 mutations in myelodysplastic syndromes and myelodysplastic/myeloproliferative neoplasms, Blood 118(24) (2011) 6239-46. [28] E. Papaemmanuil, M. Cazzola, J. Boultwood, L. Malcovati, P. Vyas, D. Bowen, A. Pellagatti, J.S. Wainscoat, E. HellstromLindberg, C. Gambacorti-Passerini, A.L. Godfrey, I. Rapado, A. Cvejic, R. Rance, C. McGee, P. Ellis, L.J. Mudie, P.J. Stephens, S. McLaren, C.E. Massie, P.S. Tarpey, I. Varela, S. Nik-Zainal, H.R. Davies, A. Shlien, D. Jones, K. Raine, J. Hinton, A.P. Butler, J.W. Teague, E.J. Baxter, J. Score, A. Galli, M.G. Della Porta, E. Travaglino, M. Groves, S. Tauro, N.C. Munshi, K.C. Anderson, A. El-Naggar, A. Fischer, V. Mustonen, A.J. Warren, N.C. Cross, A.R. Green, P.A. Futreal, M.R. Stratton, P.J. Campbell, C. Chronic Myeloid Disorders Working Group of the International Cancer Genome, Somatic SF3B1 mutation in myelodysplasia with ring sideroblasts, The New England journal of medicine 365(15) (2011) 1384-95.

[29] M.M. Patnaik, T.L. Lasho, J.M. Hodnefield, R.A. Knudson, R.P. Ketterling, G. Garcia-Manero, D.P. Steensma, A. Pardanani, C.A. Hanson, A. Tefferi, SF3B1 mutations are prevalent in myelodysplastic syndromes with ring sideroblasts but do not hold independent prognostic value, Blood 119(2) (2012) 569-72. [30] R. Cui, R.P. Gale, Z. Xu, T. Qin, L. Fang, H. Zhang, L. Pan, Y. Zhang, Z. Xiao, Clinical 
importance of SF3B1 mutations in Chinese with myelodysplastic syndromes with ring sideroblasts, Leukemia research 36(11) (2012) 1428-33.

[31] F. Thol, S. Kade, C. Schlarmann, P. Loffeld, M. Morgan, J. Krauter, M.W. Wlodarski, B. Kolking, M. Wichmann, K. Gorlich, G. Gohring, G. Bug, O. Ottmann, C.M. Niemeyer, W.K. Hofmann, B. Schlegelberger, A. Ganser, M. Heuser, Frequency and prognostic impact of mutations in SRSF2, U2AF1, and ZRSR2 in patients with myelodysplastic syndromes, Blood 119(15) (2012) 3578-84.

[32] G. Montalban-Bravo, K. Takahashi, K. Patel, F. Wang, S. Xingzhi, G.M. Nogueras, X. Huang, A.A. Pierola, E. Jabbour, S. Colla, I. Ganan-Gomez, G. Borthakur, N. Daver, Z. Estrov, T. Kadia, N. Pemmaraju, F. Ravandi, C. Bueso-Ramos, A. Chamseddine, $M$.

Konopleva, J. Zhang, H. Kantarjian, A. Futreal, G. Garcia-Manero, Impact of the number of mutations in survival and response outcomes to hypomethylating agents in patients with myelodysplastic syndromes or myelodysplastic/myeloproliferative neoplasms, Oncotarget 9(11) (2018) 97149727.

[33] G. Genovese, A.K. Kahler, R.E. Handsaker, J. Lindberg, S.A. Rose, S.F. Bakhoum, K. Chambert, E. Mick, B.M. Neale, M. Fromer, S.M. Purcell, O. Svantesson, M. Landen, M. Hoglund, S. Lehmann, S.B. Gabriel, J.L. Moran, E.S. Lander, P.F. Sullivan, P. Sklar, H. Gronberg, C.M. Hultman, S.A. McCarroll, Clonal hematopoiesis and bloodcancer risk inferred from blood DNA sequence, The New England journal of medicine 371(26) (2014) 2477-87.

[34] S. Jaiswal, P. Fontanillas, J. Flannick, A. Manning, P.V. Grauman, B.G. Mar, R.C. Lindsley, C.H. Mermel, N. Burtt, A. Chavez, J.M. Higgins, V. Moltchanov, F.C. Kuo, M.J. Kluk, B. Henderson, L. Kinnunen, H.A. Koistinen, C. Ladenvall, G. Getz, A. Correa, B.F. Banahan, S. Gabriel, S. Kathiresan, H.M. Stringham, M.I. McCarthy, M. Boehnke, J. Tuomilehto, C. Haiman, L. Groop, G. Atzmon, J.G. Wilson, D. Neuberg, D. Altshuler, B.L. Ebert, Age-related clonal hematopoiesis associated with adverse outcomes, The New
England journal of medicine 371(26) (2014) 2488-98.

[35] S.M. Chan, R. Majeti, Role of DNMT3A, TET2, and IDH1/2 mutations in pre-leukemic stem cells in acute myeloid leukemia, International journal of hematology 98(6) (2013) 648-57. 


\section{Mutational status of mesenchymal stromal cells in patients with myelodysplastic syndromes patients}

Kamila Janusz ${ }^{1,2}$, Sandra Muntion ${ }^{2,3}$, Jesús María Hernández-Sánchez ${ }^{1,2}$, Marta Martín Izquierdo $^{1,2}$, María Hernández-Sánchez ${ }^{1,2}$, María Abáigar ${ }^{1,2}$, Cristina Robledo ${ }^{1,2}$, Félix López-Cadenas ${ }^{2,3}$, Mónica del Rey ${ }^{1,2}$, Juan Carlos Caballero ${ }^{2,3}$, Rocío Benito ${ }^{1,2}$, Alba Redondo Guijo ${ }^{2,3}$, Tamara Jimenez ${ }^{2,3}$, David Pescador ${ }^{4}$, Juan Blanco ${ }^{4}$, Fermín SánchezGuijo $^{2,3}$, Consuelo del Cañizo ${ }^{2,3}$, María Díez-Campelo ${ }^{2,3}$ and Jesús María Hernández$\operatorname{Rivas}^{1,2,3}$

${ }^{1}$ IBMCC, Centro de Investigación del Cáncer, Universidad de Salamanca-CSIC.

${ }^{2}$ IBSAL, Instituto de Investigación Biomédica de Salamanca.

${ }^{3}$ Hematología, Hospital Universitario de Salamanca.

${ }^{4}$ Traumatología, Hospital Universitario de Salamanca. 
Results - Chapter 3 


\title{
MUTATIONAL STATUS OF MESENCHYMAL STROMAL CELLS IN MYELODYSPLASTIC SYNDROMES PATIENTS
}

Kamila Janusz ${ }^{1,2}$, Sandra Muntion ${ }^{2,3}$, Jesús María Hernández-Sánchez ${ }^{1,2}$, Marta Martín Izquierdo d, ${ }^{1,2}$ María Hernández-Sánchez ${ }^{1,2}$, María Abáigar ${ }^{1,2}$, Cristina Robledo ${ }^{1,2}$, Félix LópezCadenas $^{2,3}$, Mónica del Rey ${ }^{1,2}$, Juan Carlos Caballero ${ }^{2,3}$, Rocío Benito ${ }^{1,2}$, Alba Redondo Guijo ${ }^{2,3}$, Tamara Jimenez ${ }^{2,3}$, David Pescador ${ }^{4}$, Juan Blanco ${ }^{4}$, Fermín Sánchez-Guijo ${ }^{2,3}$, Consuelo del Cañizo ${ }^{2,3}$, María Díez-Campelo ${ }^{2,3}$ and Jesús María Hernández-Rivas ${ }^{1,2,3}$

${ }^{1}$ IBMCC, Centro de Investigación del Cáncer, Universidad de Salamanca-CSIC.

${ }^{2}$ IBSAL, Instituto de Investigación Biomédica de Salamanca.

${ }^{3}$ Hematología, Hospital Universitario de Salamanca.

${ }^{4}$ Traumatología, Hospital Universitario de Salamanca.

\begin{abstract}
Mesenchymal stromal cells (MSC) represent a key component of the microenvironment. It has been shown that MSC cells derived from myelodysplastic syndromes (MDS) patients are functionally incorrect displaying chromosomal abnormalities, aberrant cytokine secretion or deregulation of gene expression profile. However, little is known about the mutational profile of MSC in MDS. Here, applying the targeted next generation sequencing we analyzed mutational profile of MSC of 58 MDS patients, and we compared it with the genetic alterations of their hematopoietic counterparts, evaluating as well their possible role in MDS pathogenesis. NGS analysis revealed that $60.3 \%$ of patients carried mutations in hematopoietic progenitor cells (HPC) while MSC alterations were presented in $13.8 \%$ MDS cases. Ninety-six mutations of 107 detected (89.7\%) were founded in HPC, affecting 40 genes. The genes most frequently mutated in HPC were TET2 (31\%), followed by SF3B1 (17.2\%), SRSF2 (13.8\%), TP53 (13.8) and DNMT3A, EZH2, RUNX1, STAG2 (10.3\% each). The remaining 11 of the 107 mutations were founded in MSC (10.3\%) and affected 10 genes without any specific mutational pattern. Six of ten genes affected (60\%) MSC were common with the mutated genes in HPC. Another 4 genes $(40 \%)$ were exclusive for MSC. MSC mutations were always different to their HPC counterpart as well to MSC mutations of other patients. Therefore our study demonstrated that MSC from MDS patients can harbor mutations in myeloidrelated genes, however they are occasional and do not coincide with mutations in HPC of the same patient.
\end{abstract}




\section{Introduction}

Myelodysplastic syndromes (MDS) are clonal disorders of hematopoietic progenitor cells with increased risk of for progression to acute myeloid leukaemia [1]. At the time of diagnosis, $40-70 \%$ of the patients harbor cytogenetic alterations, being the loss of the long arm of chromosome 5 the most frequent [2-4]. Moreover the use of last generation sequencing techniques applied to the study of MDS has allowed the identification of new mutations in a large number of genes constitutes an innovative diagnostic tool. Thus $80 \%$ of MDS patients have mutations in epigenetic regulatory genes (TET2, ASXL1, DNMT3A, IDH1,IDH2, EZH2), transcription factors (RUNX1, TP53, ETV6), signal transduction genes (NRAS, KRAS, JAK2, CBL) and splicing machinery (SF3B1, U2AF1, ZRSR2, SRSF2) [5-7]. These mutations, studied so far only in the clonal population, could be involved in the development of the disease. However few studies analyzed the presence of mutations in other bone marrow cells in the MDS.

Emerging research indicates that MDS is not solely a hematopoietic disease but rather affects the entire bone marrow microenvironment. Its altered functioning was demonstrated at cytogenetic and molecular level with changes in the expression of several genes in MDS patients, shedding a new light on MDS pathogenesis, and thereby increasing the interest in assessing mesenchymal stromal cells (MSC) involvement [8-11].

MSC represent a key component of BM microenvironment giving rise to different cell population including osteoblasts and adipocytes $[8,12,13]$. MSC represent a very low proportion of the total BM cells $(0.001 \%$ to $0.01 \%$ of mononuclear cells). However they are involved in all mechanisms regulating hematopoietic stem cells (HSC) as proliferation and differentiation [14, 15]. In 2006, the International Society for Cellular Therapy proposed the minimal definition criteria for MSC based on their plasticadherence, a specific immunophenotypic profile (CD73+, CD90+, CD105+; CD34-, CD45and CD14- or other hematopoietic markers) and the multilineage differentiation ability in vitro [16].

Despite several studies on the possible role of MSC in the physiopathology of MDS, their function in the development of these diseases remains unclear and brings some controversy. The presence of abnormalities of proliferation, differentiation, cell-cell interaction or cytogenetic profile in MSC of MDS patients has been showed [17-20]. In addition, some studies have demonstrated a normal cytogenetic profile and functioning of the MDS MSC, with a similar hematopoieticsupporting ability compared to normal MSC [21-23]. Nevertheless, few studies studied MSC from MDS patients at the molecular level, and this information may add knowledge in the involvement of MSC in patients with MDS [24-27].

The aim of this study was to analyze the mutational profile of MSC from 58 MDS patients, by applying Next Generation Sequencing (NGS), to compare it with the genetic alterations in the mononuclear cells (MNC) of the same patients and to evaluate its possible role in MDS.

\section{Materials and methods}

\section{Patients and samples}

The mutational profile of bone marrow (BM) mesenchymal stromal cells (MSC), taken until passage 3, and hematopoietic progenitor cells (HPC) from 58 MDS patients were analysed in the study. If possible peripheral blood (PB) samples, as control of polymorphism were analyzed. All patients 
were classified according to WHO 2008 criteria [28]. The most frequent groups were refractory cytopenia with multilineage dysplasia (RCMD) accounting for $48.3 \%$, followed by MDS with isolated del $5 q$ with the $25.9 \%$ of cases. The remaining $25.8 \%$ of patients included: refractory anemia with ring sideroblasts (RARS), refractory cytopenia with unilineage dysplasia (RCUD), refractory anemia with excess of blasts 1 (RAEB-1) and 2 (RAEB-2) and MDS unclassified (MDS-U), $(1.7 \%, 8.6 \%, 5.2 \%, 8.6 \%$ and $1.7 \%$, respectively). However RAEB-1 and RAEB-2 cases were included in the study (13.8\%) only $9.2 \%$ of cases were considerate as a high or very high risk according to IPSS-R. Samples from all patients were obtained at diagnosis or in an evolutionary sample without treatment and any significant clinical changes since diagnosis. All features of 58 MDS patients are present in Table 1. The study was approved by the Local Ethical Committee "Comité Ético de Investigación Clínica, Hospital Universitario de Salamanca" and, from each patient, written informed consent was obtained according to the guidelines of the Declaration of Helsinki.

\section{Isolation of the different cell populations and magnetic cell sorting enrichment}

Mononuclear cells (MNC) were isolated from BM of MDS patients on a density gradient centrifugation (Ficoll). Moreover CD34+ cells were sorted by magnetic labeling using the human CD34 MicroBead Kit according to the manufacturer's recommendations. In addition, and whenever possible, CD3+ cell population was purified from $\mathrm{PB}$ using the human CD3 MicroBead Kit followed the manufacturer's recommendations as above (Miltenyi Biotec $\mathrm{GmbH}$, BergischGladbach, Germany), and was used as germline, in order to discard any possible polymorphism.

\section{Isolation and expansion of MSC}

A portion of the BM MNC previously isolated

Table 1. The clinical features of 58 MDS patients.

\begin{tabular}{|c|c|c|c|c|c|}
\hline & $N=58$ & $\%$ & $\begin{array}{l}\text { Median } \\
\text { (range) }\end{array}$ & p10 & p90 \\
\hline \multicolumn{6}{|l|}{ Gender } \\
\hline Male & 27 & 47.4 & & & \\
\hline Female & 30 & 52.6 & & & \\
\hline Age & & & $74(44-88)$ & 60 & 85 \\
\hline \multicolumn{6}{|l|}{ WHO 2008} \\
\hline RARS & 1 & 1.7 & & & \\
\hline RCUD & 5 & 8.6 & & & \\
\hline RCMD & 28 & 48.3 & & & \\
\hline $\begin{array}{l}\text { MDS } \\
\text { del(5q) }\end{array}$ & 15 & 25.9 & & & \\
\hline MDS-U & 1 & 1.7 & & & \\
\hline RAEB-1 & 3 & 5.2 & & & \\
\hline RAEB-2 & 5 & 8.6 & & & \\
\hline $\begin{array}{l}\text { BM Blasts } \\
(\%)\end{array}$ & & & $1(0-15)$ & 0 & 9.6 \\
\hline \multicolumn{6}{|l|}{$\begin{array}{l}\text { Cytogeneti } \\
\text { c risk }\end{array}$} \\
\hline Very good & 2 & 3.6 & & & \\
\hline Good & 48 & 87.3 & & & \\
\hline $\begin{array}{l}\text { Intermedia } \\
\text { te }\end{array}$ & 1 & 1.8 & & & \\
\hline Poor & 4 & 7.3 & & & \\
\hline \multicolumn{6}{|l|}{ IPSS } \\
\hline Low & 26 & 50 & & & \\
\hline Int-1 & 20 & 38.5 & & & \\
\hline Int-2 & 6 & 11.5 & & & \\
\hline \multicolumn{6}{|l|}{ IPSS-R } \\
\hline Very Low & 12 & 22.6 & & & \\
\hline Low & 31 & 58.5 & & & \\
\hline Interm. & 5 & 9.4 & & & \\
\hline High & 4 & 7.5 & & & \\
\hline Very high & 1 & 1.9 & & & \\
\hline \multicolumn{6}{|l|}{ Status } \\
\hline Live & 35 & 60.3 & & & \\
\hline Death & 23 & 39.7 & & & \\
\hline $\mathrm{Hb}(\mathrm{g} / \mathrm{dL})$ & & & $9.9(6.7-15.3)$ & 8.2 & 12.2 \\
\hline $\begin{array}{l}\text { ANC } \\
\left(\times 10^{9} / L\right)\end{array}$ & & & $1.9(0.1-36)$ & 0.9 & 4.1 \\
\hline $\begin{array}{l}\text { Platelets } \\
\left(\times 10^{9} / \mathrm{L}\right)\end{array}$ & & & $146(10-628)$ & 37 & 359 \\
\hline
\end{tabular}

on a density gradient centrifugation (Ficoll) were counted and plated at a density of $1 \times 10^{6} \mathrm{cells} / \mathrm{cm}^{2}$ and expansion was carried out according to the previously described methods [20]. After the third passage, MSC were assessed in accordance with the minimal definition criteria proposed by the International Society for Cellular Therapy (ISCT)[16]. Viability studies were done by flow cytometry using APC H7 Annexin V DY634 (Immunostep \#ANXVDY, Salamanca, Spain).

\section{DNA isolation and WGA}

Genomic DNA from obtained samples was extracted using QIAamp DNA Mini Kit, AllPrep DNA/RNA Mini Kit (Qiagen, Valencia, CA, 
USA) or DNAzol ${ }^{\oplus}$ Reagent (Thermo Fisher Scientific, Waltham, MA USA) following the manufacturer's protocol. DNA quantity was assessed by dsDNA HS Qubit ${ }^{\circledR}$ Fluorometric Quantitation Assay Kit (Life Technologies, Carlsbad, CA). Whole genome amplification (WGA) was performed on limited genomic DNA (MSC) using REPLI-g Mini Kit following the manufacturer's instructions (QIAGEN).

\section{Next Generation Sequencing}

Mutational screening on genomic nonamplified DNA of BM MNC, BM CD34population and amplified DNA of MSC from passage 3 was performed. Therefore the customized myeloid panel of 117 genes previously related to MDS was applied (Supplementary Table S1). Next generation sequencing (NGS) was achieved on NextSeq sequencing platform (Illumina, San Diego, CA, USA) following Illumina's standard protocol as previously reported [29]. All reads were filtered accordingly to the previously reported criteria with a variant detection level $>1 \%$ [29].

\section{Validation of sequencing findings}

Validation of possible identified MSC mutations was performed on non-amplified DNA from cells taken until passage 1 where possible. In the rest of the samples nonamplified DNA from cells from passage 3 were used. To confirm HPC mutations DNA from the same MNC or CD34- sample as in the main NGS analyses was used. Possible polymorphisms were checked with DNA from PB samples if available. Validations were performed by Sanger sequencing or resequencing an independent PCR product with the Illumina system using a directed amplicon strategy (Nextera XT) as previously described, depending on the Variant Allele Frequency (VAF) [30, 31]

\section{Sequencing data analysis}

Sequencing data was analyzed by applying an in house informatic pipeline that uses different software tools to perform quality assessment, alignment and variant calling (Trimmomatic, FastQC, NGSQCToolkit, BWA, GATK, VarScan, SAMTools, ANNOVAR). Integrative Genomics Viewer (IGV, Broad Institute) was used for variants visual evaluation.

After analysis, only those variants with good quality ( $Q>30)$, supported by $\geq 100$ total and $\geq 10$ mutated reads, $V A F \geq 5 \%$, located in exonic or splicing regions and which generate an $A A$ change were considered. In addition, all the already reported polymorphisms (SNPs) (dbSNP144, 1000-genomes Project, ExAC, ESP-6500, when MAF $\geq 1 \%$ ) and sequencing artifacts (internal laboratory database) were discarded.

For variant interpretation and oncogenic potential evaluation COSMIC and ClinVar databases, SIFT, PolyPhen-2 and Mutation Taster predictors, among others, were used.

\section{Results}

\subsection{Molecular analyses}

Analysis of mutational profile of hematopoietic progenitor cells (HPC) and mesenchymal stromal cells (MSC) of the same patient revealed, that $60.3 \%$ of patients ( $n=35$ ) had mutations in HPC, meantime only 13.8\% ( $n=8)$ demonstrated MSC alterations. Four different groups of patients were identified: cases with mutations in both HPC and MSC $(3.5 \%, n=2)$, patients with mutations in MSC but not in their HPC counterpart $(10.3 \%, n=6)$, group with alterations only in HPC (56.9, n=33) and patients where neither HSC nor MSC were affected (29.3\%, $n=17)$, (Figure 1). 


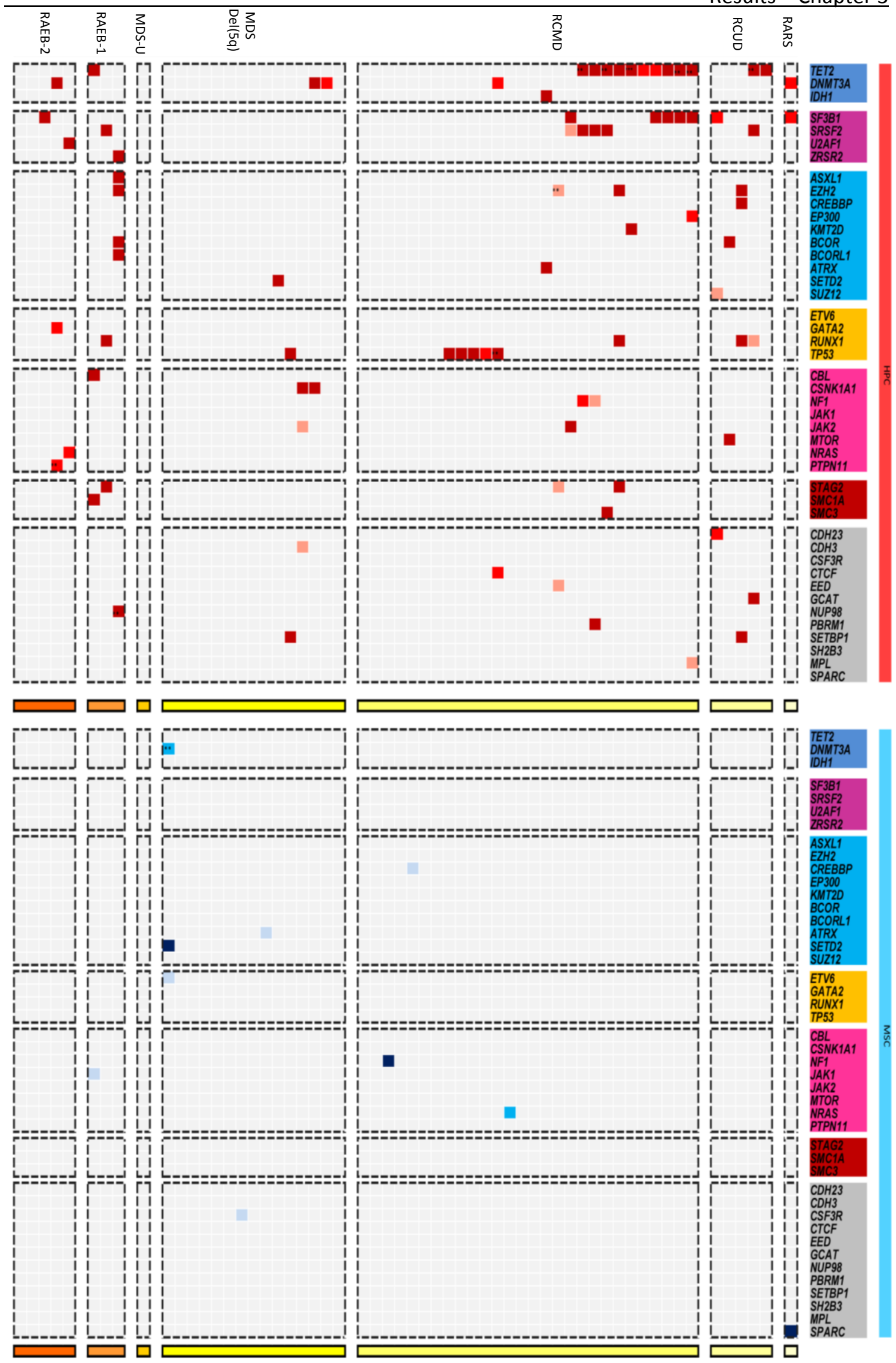

Figure 1. The comparison of mutational landscape in HPC and MSC of 58 patients. Each column represents one gene. Genes are grouped according to the function and represented by colors. Each file represents one patient. Patients are grouped according to WHO 2008 classification.

VAF: / $\geq 5<10 \% \quad$ / $\geq 10<20 \% \quad \square 20 \%$. Gene function: Dplicing, DNA methylation, chromatin modification, Transcription factors, [activated signaling, Cohesin complex, Others 
Using the personalize panel of 117 genes related to myeloid neoplasm, the total of 107 mutations among the 44 genes in MSC and HPC samples from 58 MDS patients were detected. The 96 mutations (89.7\%) belonged to HSC samples, affecting 40 genes. The genes most frequently mutated were TET2 (31\%), followed by SF3B1 (17.2\%), SRSF2 (13.8\%), TP53 (13.8) and DNMT3A, EZH2, RUNX1, STAG2 (10.3\% each) (Figure 2). The medium VAF for HPC mutations was $34.08 \%$. The remaining 11 out of the 107 mutations belonged to MSC, involving 10 genes with the medium VAF of $8.31 \%$. Six of ten genes affected (60\%) were common with HPC, other 4 (40\%) being exclusive for MSC (Figure 2). The median number of alteration per patient was 1 (0-7) in case of HPC and 0 (0-4) in MSC. Majority of mutations were missense as well in HPC (79.2\%, $n=76)$ as in MSC (81.8\%, $n=9)$. Deletions and insertions were present in both: HPC (10.4\%, $n=10$, each) and MSC (9.1\%, $n=1$, each).

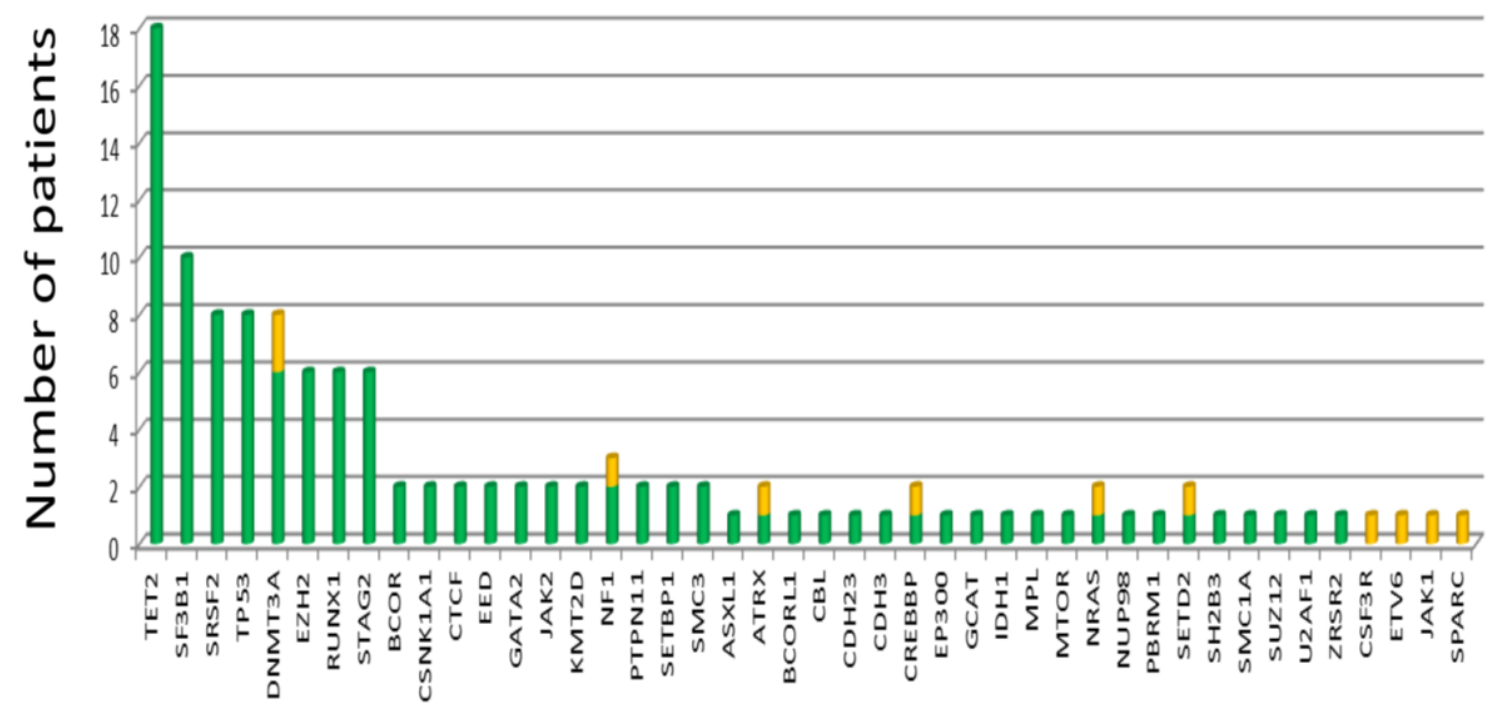

Figure 2. The forty-four mutated genes in fifty-eight MDS patients. The comparison of mutated genes frequency between HPC $\square$ and MSC .

The $51 \%$ of HPC mutations were previously reported, being $83.7 \%$ of them previously seen in haematological cancer. By contrast, all MSC mutations except ETV6 (p.R105G) have been not previously reported. It should be noted that we did not observe any specific mutational pattern in MSC.
The mutated MSC of each patient carried different to their hematopoietic counterpart as well to other MSC alterations (Figure 3). Interestingly all CRMD and MDS with isolated $\operatorname{del}(5 q)$ cases with MSC mutations did not present any HPC alteration (Figure 3). 


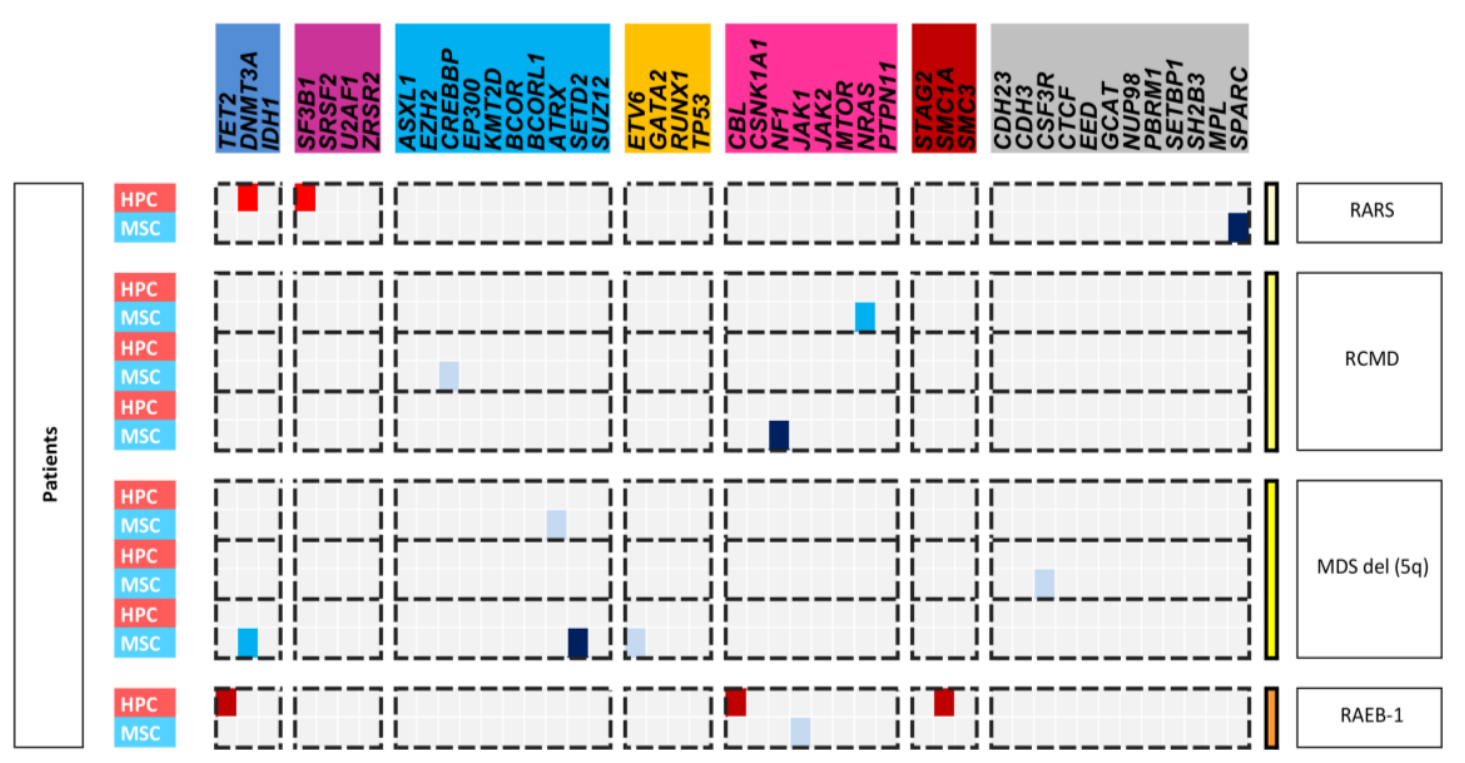

Figure 3. Paired analysis of eight MDS patients showing the presence of MSC mutations and their HPC counterpart. Each double file represents 1 patient. Each column represents one gene. Genes are grouped into the different functional group represented by colors (See Figure 1). VAF: $\geq 5<10 \%$ / $\geq 10<20 \%$ / $\geq 20 \%$.

\section{MSC mutations}

The sequencing of 58 MDS patients revealed 8 cases with MSC mutations, distributed in 1 RARS, 3 RCMD, 3 MDS with isolated del(5q) and 1 RAEB-1. Two cases had poor and remaining 6 patients had a good or very good IPSS-R cytogenetic risk, what was represented in the same manner in IPSS-R risk group. All the clinical and biological characteristics of MDS patients showing MSC mutations were similar to the group without these mutations. No differences between the two groups regarding WHO 2008 classification, IPSS-R cytogenetic risk or IPSS-R or status were observed (Tables $2 \& 3$ ).

Table 2. The comparison of median values of several clinical features between patients with wild type (wt) MSC and mutated (mut) MSC

\begin{tabular}{|c|cc||c|}
\cline { 2 - 4 } \multicolumn{1}{c|}{} & MSC wt & MSC mut & p value \\
\hline $\begin{array}{c}\text { Age } \\
\text { Hb } / \mathrm{dL})\end{array}$ & 74.5 & 74.5 & 0.703 \\
ANC & 9.9 & 10 & 0.743 \\
$\left(\times 10^{9} / \mathrm{L}\right)$ & 1.66 & 2.2 & 0.05 \\
$\begin{array}{c}\text { Platelets } \\
(\times 109 / \mathrm{L})\end{array}$ & 140 & 196 & 0.664 \\
\hline
\end{tabular}

Table 3. Association of presence of MSC mutations with clinical features (wt-wild type, mut-mutated).

\begin{tabular}{|c|c|c|c|}
\hline & MSCs wt (N) & MSCs mut (N) & $p$ value \\
\hline \multicolumn{4}{|l|}{ Gender } \\
\hline Male & 24 & 3 & \multirow{2}{*}{0.709} \\
\hline Female & 25 & 5 & \\
\hline \multicolumn{4}{|l|}{ Age } \\
\hline$<74$ & 22 & 4 & \multirow{2}{*}{1} \\
\hline$\geq 74$ & 26 & 4 & \\
\hline \multicolumn{4}{|l|}{ WHO 2008} \\
\hline RARS & 0 & 1 & \multirow{7}{*}{0.195} \\
\hline RCUD & 5 & 0 & \\
\hline RCMD & 25 & 3 & \\
\hline MDS del $(5 q)$ & 12 & 3 & \\
\hline MDS-U & 1 & 0 & \\
\hline RAEB-1 & 2 & 1 & \\
\hline RAEB-2 & 5 & 0 & \\
\hline \multicolumn{4}{|l|}{$\begin{array}{c}\text { Citigenetic } \\
\text { risk }\end{array}$} \\
\hline Very good & 1 & 1 & \multirow{4}{*}{0.150} \\
\hline Good & 43 & 5 & \\
\hline Interm. & 1 & 0 & \\
\hline Poor & 2 & 2 & \\
\hline \multicolumn{4}{|l|}{ IPSS-R } \\
\hline Very low & 10 & 2 & \multirow{5}{*}{0.695} \\
\hline Low & 27 & 4 & \\
\hline Int & 5 & 0 & \\
\hline High & 3 & 1 & \\
\hline Very high & 1 & 0 & \\
\hline \multicolumn{4}{|l|}{ Status } \\
\hline Live & 30 & 5 & \multirow{2}{*}{1} \\
\hline Death & 20 & 3 & \\
\hline
\end{tabular}


Furthermore the overall survival of In our study we included 58 untreated MDS MSC ${ }^{\text {mut }}$ patients and MSC wild type was patients. The major part of patients included, similar (Figure 4).

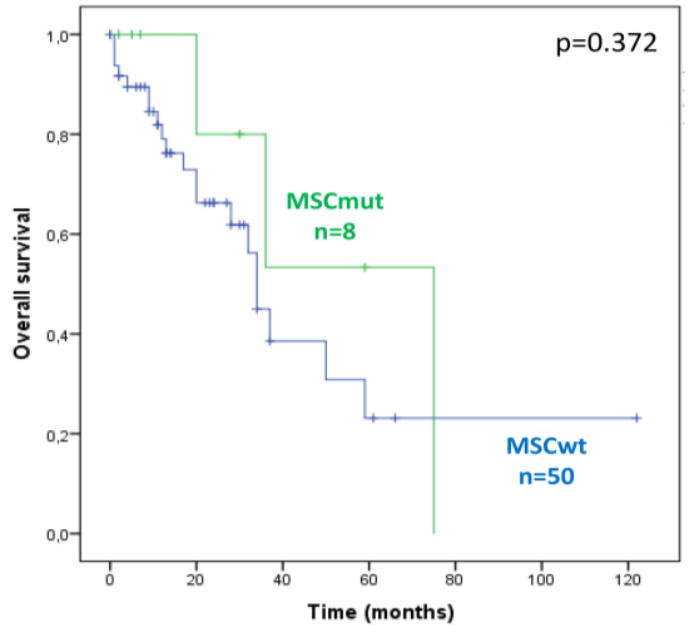

Figure 4. Overall survival of MDS patients showing MSC wild type (wt) and MSC mutated (mut).

\section{Discussion}

The pathogenesis of myelodysplastic syndrome patients (MDS) is complex, involving genetic abnormalities, immune alterations and microenviroment abnormalities. As far as it has been well known that the hematopoietic cells in this patients are defective and can carry mutations, little has been know about the molecular data in mesenchymal stromal cells that interact with them. Although nowadays MSC have been investigated and demonstrated some molecular imperfection that can have, more detailed knowledge and how exactly they contribute to MDS pathogenesis still remains understood. In this study we aimed to characterize the mutational profile of mesenchymal stromal cells from MDS patients and compare it with the genetic alteration of their hematological progenitors counterpart. Our study revealed that MSC from MDS patients do not carried the mutational profile characteristic for the HPC of MDS patients. were refractory cytopenia with multilineage dysplasia (RCMD) and MDS with isolated del(5q) and MDS very low or low IPSS-R risk. Bone marrow stromal niche being altered in MDS patient make in vitro culture quite complicated to obtain MSC, especially in high risk MDS or leukemia patients what influenced on define the study cohort [32, 33]. All MSC obtained samples were derived from passage 3 , as usually in previous studies, which guarantied purify without hematopoietic cells as well stability and enough amount of MSC [25, 34-36].

To analyze and to compare the mutational profile of MSC and HPC we used a focused panel of 117 genes related to myeloid neoplasms. Being a panel of genes focused on the analysis of hematopoietic cells, genes like DICER1, MMP1, JAG1 although related to MDS and LAM, were not included [9, 26, 34]. Moreover for the main aim of the study to compare the incidence of characteristic to HPC mutations in MSC was more accurate. Similar study, with target deep sequencing (50 genes) was implemented in analysis of 5 MDS patients by Azuma et al. [37]. In contrast, Fabiani or von der Heide conventional Sanger and Whole Exome Sequencing (WES) to mutational analysis in MSC of myeloid disorders were applied [27, 38]. Mutational analysis revealed that $60.3 \%$ of patients had at least one mutation in their HPC. Comparing this result to previously reported, we observed the smaller percentage of affected patients. These low frequency of genetic mutations could be related to the large number of patients with low-risk MDS, mainly del( $5 q)$, who show a small incidence of somatic mutations [6, 7]. However, the prevalence of genes most frequently mutated in HPC and the sizes of clones consisted with current results [5-7, 
39]. By contrast, the mutational analyses of MSC only showed $13 \%$ of mutations. Most likely, analyzes that cover a larger part of the genome would contribute to the detection of other than myeloid-related and characteristic for HPC genes involved in the functions of mesenchymal cells [27, 40, 41]. Azuma et al. detected MSC mutations in 3 of 5 MDS analysed patients, meantime Sanger sequencing in study by Fabiani et al. analyzing the specific and small regions of eight genes in 7 MDS patients, did not reveal any case with MSC mutation. However no mutations founded could be due to few genes analyzed and shallow sequencing technique $[31,37$, 38, 42]. We did not observe any specific mutational pattern in MSC. The mutated MSC of each patient carried different to their hematopoietic counterpart as well to other MSC alterations, with the quite low variant allele frequency (medium VAF of $8.3 \%$ ). However, analyses of MSC by Azuma et al. revealed patients with the same mutations in MSC as in their hematological counterpart with VAF around of $50 \%$, suggesting the germinal origin [37]. In HPC as well in MSC the main type of alterations were heterozygous missense mutations being the most common [43].

Based on these results we were able to identify 4 groups of patients. The most frequent group, probably most expected and already known in literature, were the patients with mutations in HPC and no in their MSC counterpart (56.9\%) flowed by the group of patients with HPC and MSC without any alterations (29.3\%). Two other groups revealed by our analysis were patients with mutations in both: MSC and HPC (3.5\%) and cases with MSC mutated and HPC wild type (10.3\%). The appearance of 4 different groups of patients supports the important controversy that exists about the implication of MSC in MDS pathogenesis. The group with defect HPC demonstrating the invasive functioning of hematopoietic cells and not the MSC that could initiate and support the MDS pathogenesis process, however accompanied by MSC mutations, although having a very low VAF in comparison to HPC alteration [21]. On the other hand, patients with mutations only in their MSC could support the studies where the MSC was seen as defected, supporting the malignant changes of HPC and MDS pathogenesis $[9,18$, 24]. Interestingly the RCMD and MDS with isolated del(5q) were the subtypes which all MSC mutated cases did not presented any HPC alteration what could indicate the differences in MDS pathogenesis in this patients and probably the differences in MSC involving capacity.

No clinical or overall survival differences were seen between the MSC mutated cases compared to those without MSC changes. However the very small number of MSC affected patients could be the reason.

In summary, the present study demonstrated that MSC from MDS patients can harbor mutations in myeloid-related genes, however they are occasional, with a low VAF frequency and different to their HPC counterparts. Further studies with more patients and wide genome region screening are still needed to confirm and get better know the molecular profile of MDS MSC patients. 


\section{References}

[1] N. Gangat, M.M. Patnaik, A. Tefferi, Myelodysplastic syndromes: Contemporary review and how we treat, American journal of hematology 91(1) (2016) 76-89.

[2] A.A. Geddes, D.T. Bowen, A. Jacobs, Clonal karyotype abnormalities and clinical progress in the myelodysplastic syndrome, British journal of haematology 76(2) (1990) 194-202.

[3] R.R. West, D.A. Stafford, A.D. White, D.T. Bowen, R.A. Padua, Cytogenetic abnormalities in the myelodysplastic syndromes and occupational or environmental exposure, Blood 95(6) (2000) 2093-7.

[4] F. Sole, B. Espinet, G.F. Sanz, J. Cervera, M.J. Calasanz, E. Luno, F. Prieto, I. Granada, J.M. Hernandez, J.C. Cigudosa, J.L. Diez, E. Bureo, M.L. Marques, E. Arranz, R. Rios, J.A. Martinez Climent, T. Vallespi, L. Florensa, S. Woessner, Incidence, characterization and prognostic significance of chromosomal abnormalities in 640 patients with primary myelodysplastic syndromes. Grupo Cooperativo Espanol de Citogenetica Hematologica, British journal of haematology 108(2) (2000) 346-56.

[5] R. Itzykson, O. Kosmider, P. Fenaux, Somatic mutations and epigenetic abnormalities in myelodysplastic syndromes, Best practice \& research. Clinical haematology 26(4) (2013) 35564.

[6] E. Papaemmanuil, M. Gerstung, L. Malcovati, S. Tauro, G. Gundem, P. Van Loo, C.J. Yoon, P. Ellis, D.C. Wedge, A. Pellagatti, A. Shlien, M.J. Groves, S.A. Forbes, K. Raine, J. Hinton, L.J. Mudie, S. McLaren, C. Hardy, C. Latimer, M.G. Della Porta, S. O'Meara, I. Ambaglio, A. Galli, A.P. Butler, G. Walldin, J.W. Teague, L. Quek, A. Sternberg, C. Gambacorti-Passerini, N.C. Cross, A.R. Green, J. Boultwood, P. Vyas, E. Hellstrom-Lindberg, D. Bowen, M. Cazzola, M.R. Stratton, P.J. Campbell, C. Chronic Myeloid Disorders Working Group of the International Cancer Genome, Clinical and biological implications of driver mutations in myelodysplastic syndromes, Blood 122(22) (2013) 3616-27; quiz 3699.

[7] T. Haferlach, Y. Nagata, V. Grossmann, Y. Okuno, U. Bacher, G. Nagae, S. Schnittger, M. Sanada, A. Kon, T. Alpermann, K. Yoshida, A. Roller, N. Nadarajah, Y. Shiraishi, Y. Shiozawa, K.
Chiba, H. Tanaka, H.P. Koeffler, H.U. Klein, M. Dugas, H. Aburatani, A. Kohlmann, S. Miyano, C. Haferlach, W. Kern, S. Ogawa, Landscape of genetic lesions in 944 patients with myelodysplastic syndromes, Leukemia 28(2) (2014) 241-7.

[8] E. Flores-Figueroa, R.M. Arana-Trejo, G. Gutierrez-Espindola, A. Perez-Cabrera, H. Mayani, Mesenchymal stem cells in myelodysplastic syndromes: phenotypic and cytogenetic characterization, Leukemia research 29(2) (2005) 215-24.

[9] S. Geyh, S. Oz, R.P. Cadeddu, J. Frobel, B. Bruckner, A. Kundgen, R. Fenk, I. Bruns, C. Zilkens, D. Hermsen, N. Gattermann, G. Kobbe, U. Germing, F. Lyko, R. Haas, T. Schroeder, Insufficient stromal support in MDS results from molecular and functional deficits of mesenchymal stromal cells, Leukemia 27(9) (2013) 1841-51.

[10] Y. Kim, D.W. Jekarl, J. Kim, A. Kwon, H. Choi, S. Lee, Y.J. Kim, H.J. Kim, Y. Kim, I.H. Oh, M. Kim, Genetic and epigenetic alterations of bone marrow stromal cells in myelodysplastic syndrome and acute myeloid leukemia patients, Stem cell research 14(2) (2015) 177-84.

[11] S. Chen, N.A. Zambetti, E.M. Bindels, K. Kenswill, A.M. Mylona, N.M. Adisty, R.M. Hoogenboezem, M.A. Sanders, E.M. Cremers, T.M. Westers, J.H. Jansen, A.A. van de Loosdrecht, M.H. Raaijmakers, Massive parallel RNA sequencing of highly purified mesenchymal elements in low-risk MDS reveals tissue-contextdependent activation of inflammatory programs, Leukemia 30(9) (2016) 1938-42.

[12] M.F. Pittenger, A.M. Mackay, S.C. Beck, R.K. Jaiswal, R. Douglas, J.D. Mosca, M.A. Moorman, D.W. Simonetti, S. Craig, D.R. Marshak, Multilineage potential of adult human mesenchymal stem cells, Science 284(5411) (1999) 143-7.

[13] C. Fehrer, G. Lepperdinger, Mesenchymal stem cell aging, Experimental gerontology 40(12) (2005) 926-30.

[14] M.K. Majumdar, M.A. Thiede, S.E. Haynesworth, S.P. Bruder, S.L. Gerson, Human marrow-derived mesenchymal stem cells (MSCs) express hematopoietic cytokines and support long-term hematopoiesis when differentiated toward stromal and osteogenic lineages, Journal 
of hematotherapy \& stem cell research 9(6) (2000) 841-8.

[15] N. Van Overstraeten-Schlogel, Y. Beguin, A. Gothot, Role of stromal-derived factor-1 in the hematopoietic-supporting activity of human mesenchymal stem cells, European journal of haematology 76(6) (2006) 488-93.

[16] M. Dominici, K. Le Blanc, I. Mueller, I. SlaperCortenbach, F. Marini, D. Krause, R. Deans, A. Keating, D. Prockop, E. Horwitz, Minimal criteria for defining multipotent mesenchymal stromal cells. The International Society for Cellular Therapy position statement, Cytotherapy 8(4) (2006) 315-7.

[17] G. Varga, J. Kiss, J. Varkonyi, V. Vas, P. Farkas, K. Paloczi, F. Uher, Inappropriate Notch activity and limited mesenchymal stem cell plasticity in the bone marrow of patients with myelodysplastic syndromes, Pathology oncology research : POR 13(4) (2007) 311-9.

[18] K. Pavlaki, C.G. Pontikoglou, A. Demetriadou, A.K. Batsali, A. Damianaki, E. Simantirakis, M. Kontakis, A. Galanopoulos, I. Kotsianidis, M.C. Kastrinaki, H.A. Papadaki, Impaired proliferative potential of bone marrow mesenchymal stromal cells in patients with myelodysplastic syndromes is associated with abnormal WNT signaling pathway, Stem cells and development 23(14) (2014) 1568-81.

[19] H.J. Deeg, C. Beckham, M.R. Loken, E. Bryant, M. Lesnikova, H.M. Shulman, T. Gooley, Negative regulators of hemopoiesis and stroma function in patients with myelodysplastic syndrome, Leukemia \& lymphoma 37(3-4) (2000) 405-14.

[20] O. Lopez-Villar, J.L. Garcia, F.M. SanchezGuijo, C. Robledo, E.M. Villaron, P. HernandezCampo, N. Lopez-Holgado, M. Diez-Campelo, M.V. Barbado, J.A. Perez-Simon, J.M. Hernandez-Rivas, J.F. San-Miguel, M.C. del Canizo, Both expanded and uncultured mesenchymal stem cells from MDS patients are genomically abnormal, showing a specific genetic profile for the $5 q$ - syndrome, Leukemia 23(4) (2009) 664-72.

[21] V. Soenen-Cornu, C. Tourino, M.L. Bonnet, M. Guillier, S. Flamant, R. Kotb, A. Bernheim, J.H. Bourhis, C. Preudhomme, P. Fenaux, A.G. Turhan, Mesenchymal cells generated from patients with myelodysplastic syndromes are devoid of chromosomal clonal markers and support short- and long-term hematopoiesis in vitro, Oncogene 24(15) (2005) 2441-8.

[22] M. Klaus, E. Stavroulaki, M.C. Kastrinaki, P. Fragioudaki, K. Giannikou, M. Psyllaki, C. Pontikoglou, D. Tsoukatou, C. Mamalaki, H.A. Papadaki, Reserves, functional, immunoregulatory, and cytogenetic properties of bone marrow mesenchymal stem cells in patients with myelodysplastic syndromes, Stem cells and development 19(7) (2010) 1043-54.

[23] E. Flores-Figueroa, J.J. Montesinos, P. FloresGuzman, G. Gutierrez-Espindola, R.M. AranaTrejo, S. Castillo-Medina, A. Perez-Cabrera, E. Hernandez-Estevez, L. Arriaga, H. Mayani, Functional analysis of myelodysplastic syndromesderived mesenchymal stem cells, Leukemia research 32(9) (2008) 1407-16.

[24] M.H. Raaijmakers, S. Mukherjee, S. Guo, S. Zhang, T. Kobayashi, J.A. Schoonmaker, B.L. Ebert, F. Al-Shahrour, R.P. Hasserjian, E.O. Scadden, Z. Aung, M. Matza, M. Merkenschlager, C. Lin, J.M. Rommens, D.T. Scadden, Bone progenitor dysfunction induces myelodysplasia and secondary leukaemia, Nature 464(7290) (2010) 852-7.

[25] O. Blau, C.D. Baldus, W.K. Hofmann, G. Thiel, F. Nolte, T. Burmeister, S. Turkmen, O. Benlasfer, E. Schumann, A. Sindram, M. Molkentin, S. Mundlos, U. Keilholz, E. Thiel, I.W. Blau, Mesenchymal stromal cells of myelodysplastic syndrome and acute myeloid leukemia patients have distinct genetic abnormalities compared with leukemic blasts, Blood 118(20) (2011) 558392.

[26] C. Santamaria, S. Muntion, B. Roson, B. Blanco, O. Lopez-Villar, S. Carrancio, F.M. SanchezGuijo, M. Diez-Campelo, S. Alvarez-Fernandez, M.E. Sarasquete, J. de las Rivas, M. Gonzalez, J.F. San Miguel, M.C. Del Canizo, Impaired expression of DICER, DROSHA, SBDS and some microRNAs in mesenchymal stromal cells from myelodysplastic syndrome patients, Haematologica 97(8) (2012) 1218-24.

[27] E.K. von der Heide, M. Neumann, S. Vosberg, A.R. James, M.P. Schroeder, J. Ortiz-Tanchez, K. Isaakidis, C. Schlee, M. Luther, K. Johrens, I. Anagnostopoulos, L.H. Mochmann, D. Nowak, W.K. Hofmann, P.A. Greif, C.D. Baldus, Molecular alterations in bone marrow mesenchymal stromal 
cells derived from acute myeloid leukemia patients, Leukemia 31(5) (2017) 1069-1078.

[28] J.W. Vardiman, J. Thiele, D.A. Arber, R.D. Brunning, M.J. Borowitz, A. Porwit, N.L. Harris, M.M. Le Beau, E. Hellstrom-Lindberg, A. Tefferi, C.D. Bloomfield, The 2008 revision of the World Health Organization (WHO) classification of myeloid neoplasms and acute leukemia: rationale and important changes, Blood 114(5) (2009) 93751.

[29] F. Ramos, C. Robledo, F.M. Izquierdo-Garcia, D. Suarez-Vilela, R. Benito, M. Fuertes, A. Insunza, E. Barragan, M. Del Rey, J.M. Garcia-Ruiz de Morales, M. Tormo, E. Salido, L. Zamora, C. Pedro, J. Sanchez-Del-Real, M. Diez-Campelo, C. Del Canizo, G.F. Sanz, J.M. Hernandez-Rivas, S. Spanish Group for Myelodysplastic, Bone marrow fibrosis in myelodysplastic syndromes: a prospective evaluation including mutational analysis, Oncotarget 7(21) (2016) 30492-503.

[30] J. Malcikova, K. Stano-Kozubik, B. Tichy, B. Kantorova, S. Pavlova, N. Tom, L. Radova, J. Smardova, F. Pardy, M. Doubek, Y. Brychtova, M. Mraz, K. Plevova, E. Diviskova, A. Oltova, J. Mayer, S. Pospisilova, M. Trbusek, Detailed analysis of therapy-driven clonal evolution of TP53 mutations in chronic lymphocytic leukemia, Leukemia 29(4) (2015) 877-85.

[31] A.C. Tsiatis, A. Norris-Kirby, R.G. Rich, M.J. Hafez, C.D. Gocke, J.R. Eshleman, K.M. Murphy, Comparison of Sanger sequencing, pyrosequencing, and melting curve analysis for the detection of KRAS mutations: diagnostic and clinical implications, The Journal of molecular diagnostics : JMD 12(4) (2010) 425-32.

[32] G. Corradi, C. Baldazzi, D. Ocadlikova, G. Marconi, S. Parisi, N. Testoni, C. Finelli, M. Cavo, A. Curti, M. Ciciarello, Mesenchymal stromal cells from myelodysplastic and acute myeloid leukemia patients display in vitro reduced proliferative potential and similar capacity to support leukemia cell survival, Stem cell research \& therapy 9(1) (2018) 271.

[33] Y. Pang, C. Deng, S. Geng, J. Weng, P. Lai, P. Liao, L. Zeng, Z. Lu, J. Zhang, X. Du, Premature exhaustion of mesenchymal stromal cells from myelodysplastic syndrome patients, American journal of translational research 9(7) (2017) 34623468.
[34] S. Zhao, Y. Zhao, J. Guo, C. Fei, Q. Zheng, X. Li, C. Chang, Downregulation of MMP1 in MDSderived mesenchymal stromal cells reduces the capacity to restrict MDS cell proliferation, Scientific reports 7 (2017) 43849.

[35] H. Ozdogan, B. Gur Dedeoglu, Y. Oztemur Islakoglu, A. Aydos, S. Kose, A. Atalay, Z.A. Yegin, F. Avcu, D. Uckan Cetinkaya, O. Ilhan, DICER1 gene and miRNA dysregulation in mesenchymal stem cells of patients with myelodysplastic syndrome and acute myeloblastic leukemia, Leukemia research 63 (2017) 62-71.

[36] S. Muntion, T.L. Ramos, M. Diez-Campelo, B. Roson, L.I. Sanchez-Abarca, I. MisiewiczKrzeminska, S. Preciado, M.E. Sarasquete, J. de Las Rivas, M. Gonzalez, F. Sanchez-Guijo, M.C. Del Canizo, Microvesicles from Mesenchymal Stromal Cells Are Involved in HPC-Microenvironment Crosstalk in Myelodysplastic Patients, PloS one 11(2) (2016) e0146722.

[37] K. Azuma, T. Umezu, S. Imanishi, M. Asano, S. Yoshizawa, S. Katagiri, K. Ohyashiki, J.H. Ohyashiki, Genetic variations of bone marrow mesenchymal stromal cells derived from acute leukemia and myelodysplastic syndrome by targeted deep sequencing, Leukemia research 62 (2017) 23-28.

[38] E. Fabiani, G. Falconi, L. Fianchi, F. Guidi, S. Bellesi, M.T. Voso, G. Leone, F. D'Alo, Mutational analysis of bone marrow mesenchymal stromal cells in myeloid malignancies, Experimental hematology 42(9) (2014) 731-3.

[39] J.A. Kennedy, B.L. Ebert, Clinical Implications of Genetic Mutations in Myelodysplastic Syndrome. Journal of clinical oncology : official journal of the American Society of Clinical Oncology 35(9) (2017) 968-974.

[40] A. Warr, C. Robert, D. Hume, A. Archibald, N. Deeb, M. Watson, Exome Sequencing: Current and Future Perspectives, G3 5(8) (2015) 1543-50.

[41] S. Stasik, C. Schuster, C. Ortlepp, U. Platzbecker, M. Bornhauser, J. Schetelig, G. Ehninger, G. Folprecht, C. Thiede, An optimized targeted Next-Generation Sequencing approach for sensitive detection of single nucleotide variants, Biomolecular detection and quantification 15 (2018) 6-12.

[42] C. Meldrum, M.A. Doyle, R.W. Tothill, Nextgeneration sequencing for cancer diagnostics: a practical perspective, The Clinical biochemist. 
Reviews / Australian Association of Clinical Biochemists 32(4) (2011) 177-95.

[43] A.S. Sperling, C.J. Gibson, B.L. Ebert, The genetics of myelodysplastic syndrome: from clonal haematopoiesis to secondary leukaemia, Nature reviews. Cancer 17(1) (2017) 5-19. 
Results - Chapter 3 
General discussion 
The achievement of the human genome mapping, in 2003, was a breakthrough in the history of genetic diseases. Since then the extensive development of the massive sequencing techniques (Target sequencing, Whole Exome Sequencing or Whole Genome Sequencing) and the Bioinformatics allowing for a very insightful molecular characterization of cancer.

MDS encompass a heterogeneous group of clonal and malignant myeloid disorders characterized by ineffective haematopoiesis, resulting in peripheral blood cytopenias and elevated risk of progression to acute myeloid leukemia [1-3, 147]. Integration of NGS techniques showed the mutational landscape of MDS patients, improving the better understanding of MDS. Thus the epigenetic regulators (TET2, ASXL1, DNMT3A, IDH1, $I D H 2, E Z H 2)$, transcription factors (ETV6, RUNX1, TP53), cohesins (STAG2, RAD21), signal transduction proteins ( $C B L, J A K 2, K R A S, N R A S)$, and genes related to the RNA splicing machinery (SF3B1, SRSF2, U2AF1, ZRSR2) were found to be frequently mutated and nowadays widely known $[37,38,58]$. However the clinical implementation of NGS in MDS is still challenging.

In 2016 the World Health Organization (WHO) published the revision of the previous classification (2008) of myeloid neoplasms and acute leukemia incorporating new clinical, prognostic, morphologic, immunophenotypic and genetic data discovered since the last classification [32]. In the case of myelodysplastic syndromes with ring sideroblasts (MDSRS) a significant genetic change was the incorporation of SF3B1 mutational analysis (being clearly related to the MDS-RS phenotype) in the diagnosis of MDS patients with the presence of $5-15 \%$ of ring sideroblasts (RS) [68]. SF3B1 is one of the genes regulating the splicing of RNA and contrary to other splicing genes as SRSF2 has been associated with a good prognosis in cases without excess of blasts $[72,148]$. The prevalence is particularly high, being $>80 \%$ in MDS-RS [40]. However, probably the exploration of a single mutation may not be enough to determine the real prognosis of patients with MDS. In a cohort of 122 MDS-RS patients (WHO2001/2008) we analyzed the presence of SF3B1 mutations combining the conventional Sanger sequencing followed by NGS strategy. Most of the mutations already reported are usually located at hot-spot locations of exons 14 and 15 $[72,73,148]$. Therefore the first step of the study (conventional sequencing) was focused on these regions. Sanger sequencing results revealed that most of MDS-RS patients 
(81.1\%, $\mathrm{n}=99$ ) carried mutations in SF3B1, being consistent with the previous studies [39, $72,136,149]$. Therefore the mutational analysis of hot-spot exons of this gene revealed information about clonality in almost all MDS-RS patients. Moreover, the NGS technique applied to the remaining 23 Sanger negative patients, revealed six additional patients showing SF3B1 mutations $(86.1 \%, \mathrm{n}=105)$. In the comparison with the typical detection variant allele frequency level of $15 \%$, as revealed by Sanger sequencing, one of the NGS advantages is the detection of lower levels of genetic variants, ensuring a more comprehensive coverage of the gene $[150,151]$. In addition the application of NGS in MDS-RS cohort allowed us to detect other splicing-related genes mutations (SRSF2, U2AF1 and ZRSR2) and the existence of rare double splicing gene mutations in 16 patients. In fact, ten patients presented double mutations, involving SF3B1 and SRSF2 in five cases, SF3B1 and U2AF1 in one and two distinct mutations in SF3B1 in the remaining four cases. The presence of concomitant mutations in splicing genes is an infrequent event in MDS-RS, and usually involves SF3B1 and SRSF2 [73, 76, 133]. Moreover, the overall survival of patients showing double splicing gene mutations showed a trend to a worse outcome. The presence of other gene mutations in splicing genes could modified the positive influence of SF3B1 mutations in the MDS patients and further studies in large series of patients must confirm this observation.

In MDS patients, several studies have demonstrated that mutations in TP53, EZH2, ETV6, RUNX1, SRSF2, DNMT3A and ASXI1 are predictors of poor overall survival $[46,58,136]$. The influence in the outcome of each mutation is well-defined. However, little is known about the concurrence of more than one mutation in the MDS outcome [137]. The presence of more than two mutations in the same MDS is observed in $40 \%$ of patients. At the same time $10 \%$ of patients presented 4 to 8 oncogenic point mutations affecting overall survival (OS) of these patients being the high number of mutations per patient related to a short survival [15]. However, the influence of additional mutations to SF3B1 has not been considered yet [152]. Therefore we analyzed the mutation co-occurrence of SF3B1 and other myeloid-related genes and we evaluated its prognostic value in 102 $S F 3 B 1^{\text {mut }}$ low/intermediate-risk MDS.

To carry out this project we used the customized panel of 117 genes previously related to MDS or other myeloid malignancies, which allowed for a wide and relatively fast analysis 
of large number of patients and the possibility of occurrence of other gene mutations. In the analysis, patients with the diagnosis of isolated 5q- or RAEB were excluded from the study to avoid any bias in the results $[37,38,153]$. The NGS analyses revealed that only 20 patients (19.3\%) carried SF3B1 as the unique mutation, supporting the need for more extensive sequencing studies in most of these patients. The SF3B1 as an unique mutation appeared as minority group as well in other studies, however in other MDS-RS series SF3B1 as a solely mutated gene was present in $40 \%$ of patients maybe because these studies analysed few genes or a different cut-off was accepted for the VAF assessment $[38,136]$. Moreover our NGS screening of co-existing SF3B1 mutations revealed the SF3B1 with $\geq 2$ additional mutations had a negative impact on the prognosis of patients as an independent prognostic factor. Therefore we confirmed in the present work the negative impact of the presence of mutations associated to SF3B1 in MDS.

The NGS analysis allowed us to assess the prevalence of additional mutated genes to SF3B1. The most frequently mutated genes were DNMT3A, TET2, ASXL1, CUX1 and EZH2 as previously reported $[37,38]$. Therefore the co-occurrence of gene mutations to SF3B1 was analysed. We did not confirm the results from other studies, showing additional mutations in either RUNX1 or DNMT3A genes are associated with a worse outcome [40]. However, our study revealed the negative impact on OS of patients displaying SF3B1 and SRSF2 and/or BCOR and/or IDH2 and/or NUP98 and/or STAG2 mutations. Nevertheless, due to small number of affected cases, further analysis and confirmation of these findings in a larger cohort of patients are needed. Therefore our results suggest that a complete NGS study in MDS SF3B1 ${ }^{\text {mut }}$ patients would be recommend for the better estimation of the evolution of the disease discarding the influence of additional mutations that could interfere in the good prognosis associated with SF3B1 mutations.

In 2014 NGS studies in healthy individuals revealed that around of $10-20 \%$ of elderly people ( $\geq 65$ years) carried somatic mutations in hematopoietic-related genes. The majority of the variants occurred in three genes: DNMT3A, TET2 and ASXL1. The Clonal Haematopoiesis of Indeterminate Potential (CHIP) in healthy people contributed to increase the risk to cardiovascular diseases $[134,154]$. In the current study, DNMT3A, TET2 and ASXL1 were seen as ones of most frequently mutated genes in MDS. No effect 
was seen in SF3B1 co-occurrence. However according to the previous reports, their existence could be crucial to initiate the clonal haematopoiesis that evolved into the MDS disease. This data demonstrate the importance and utility of NGS technique application not only in patients monitoring but also in healthy people, giving a chance for early detection of molecular changing (clonal hematopoiesis).

The last part of this thesis was focused in the use of NGS to characterize the mutational profile of mesenchymal stromal cells (MSC) from MDS patients and to compare it with the genetic alterations of their haematological progenitor counterpart. Emerging research indicates that the bone marrow microenvironment could play an essential role in MDS. Altered functioning of MSC was demonstrated at cytogenetic and molecular level with changes in the expression of several genes in MDS patients, shedding a new light on MDS pathogenesis, and thereby increasing the interest in assessing mesenchymal stromal cells involvement $[84,155]$. However, the functioning and the participation in MDS pathophysiology bring a lot of controversy and remains unclear [100, 144, 145, 156-158]. In fact only few studies have assessed MSC from MDS patients at the molecular level, and this information still remains controversial $[82,85,101,104,155]$. In our study we tried to reveal whether MSC from MDS patients harbor molecular alterations, and whether these potential abnormalities could be similar to those present in hematopoietic progenitor cells presented. The NGS analysis in 58 MDS patients revealed that gene mutations are more frequent in hematopoietic cells (HPC) than in mesenchymal stromal cells (MSC) confirming previous results in a short number of MDS patients [105], although some papers reported no mutations in MCS maybe because the low number of MDS patients analyzed. [104, 150, 151]. By contrast, the number of mutations in MSC seems to be higher in AML patients $[82,159,160]$. We did not observe any specific mutational pattern in MSC. The mutated MSC of each patient carried different to their hematopoietic counterpart as well to other MSC alterations, with a low variant allele frequency in accordance to previously published data in MDS patients [105]. Our study revealed four different groups of patients: cases with mutations in HPC and no in their MSC counterpart, patients with both HPC and MSC wild type, patients with mutations in MSCs and HPC, and those with mutations in MSC and no in HPC. The appearance of 4 different groups of patients supporting the controversy about the implication of MSCs in MDS 
pathogenesis $[90,101,144,157]$. These results demonstrated that MSC mutations are occasional and different to their HPC counterparts, and not support the common origin of the pathogenic clone in MSc and HPC. However more studies with more patients and wide genome region screening are still needed to confirm and get better know the molecular profile of MDS MSCs patients.

Taking together, the results provided in this PhD confirm the value of NGS in the clinical setting, providing detailed molecular information about the patients, facilitating the correct diagnosis and improving the risk stratification that could allowed to take the right treatment decision. However still further research with the new NGS techniques are needed to validate the clinical findings and to complement and enhance the molecular knowledge acquired so far. 
Concluding remarks 
1. The NGS sequencing can identify new mutations that are not detectable by conventional sequencing. All mutations detected by Sanger sequencing were identified by NGS. The presence of mutations in SRSF2, U2AF1 and ZRSR2 beyond SF3B1 suggest that any gene related to the spliceasome machinery could be mutated in the MDS-RS. In addition, patients who did not show any mutation in splicing genes did not have clinical or biological characteristics different from the rest of MDS-RS and could carry variations in other splicing genes not included in the study. The two-step approach for sequencing splicing-related genes is affordable and reveals mutations in almost all MDS-RS patients.

2. NGS analyses revealed that the vast majority of very low, low and intermediaterisk SF3B1 mutated MDS patients (80.4\%) carry at least 1 additional gene mutation. The existence of more than two additional mutations was associated with adverse clinical impact shortening the overall survival of very low, low and intermediate-risk MDS patients. The presence of additional SF3B1 mutations in SRSF2, IDH2, BCOR, NUP98 or STAG2 although do not change the clinical features, negatively affects the survival of these patients.

3. More than half of very low, low and intermediate-risk SF3B1 mutated MDS patients displayed Clonal Haematopoiesis of Indeterminate Potential (CHIP) mutations (DNMT3A, TET2 and/or ASXL1). Although no effect was seen in SF3B1 co-occurrence, their existence could be related to the evolution to the MDS.

4. The complete mutational study in patients with very low, low and intermediaterisk MDS and MDS with ring sideroblasts could allow to a better estimation of prognosis disease and could clarify the positive influence of SF3B1 isolated mutations in this subset of patients.

5. The analysis of the mutational profile of MSC from MDS patients revealed that $13.8 \%$ of cases harboured MSC alteration in myeloid-related genes. Any specific mutational pattern was seen. The MSC mutation of each MDS patient was always 
6. different to their hematopoietic counterpart as well as different to MSC alterations of other patients.

7. Mutational screening of MSC and their haematopoietic counterpart revealed four groups of MDS patients: cases with mutations in both HPC and MSC, patients with mutations in MSC but not in their HPC counterpart, group with alterations only in HPC and patients where neither HSC nor MSC were affected. The presence of heterogeneous groups of patients considering the mutations in the MSC supports the controversy about the implication of MSCs in MDS pathogenesis. 
References 
References 
[1] N. Gangat, M.M. Patnaik, A. Tefferi, Myelodysplastic syndromes: Contemporary review and how we treat, American journal of hematology 91(1) (2016) 76-89.

[2] S.D. Nimer, Myelodysplastic syndromes, Blood 111(10) (2008) 4841-51.

[3] G. Garcia-Manero, Myelodysplastic syndromes: 2015 Update on diagnosis, risk-stratification and management, American journal of hematology 90(9) (2015) 831-41.

[4] K.I. Mills, A. Kohlmann, P.M. Williams, L. Wieczorek, W.M. Liu, R. Li, W. Wei, D.T. Bowen, H. Loeffler, J.M. Hernandez, W.K. Hofmann, T. Haferlach, Microarray-based classifiers and prognosis models identify subgroups with distinct clinical outcomes and high risk of AML transformation of myelodysplastic syndrome, Blood 114(5) (2009) 1063-72.

[5] J. Flach, F. Dicker, S. Schnittger, S. Schindela, A. Kohlmann, T. Haferlach, W. Kern, C. Haferlach, An accumulation of cytogenetic and molecular genetic events characterizes the progression from MDS to secondary AML: an analysis of 38 paired samples analyzed by cytogenetics, molecular mutation analysis and SNP microarray profiling, Leukemia 25(4) (2011) 713-8.

[6] R. Liao, Y. Xu, M. Chen, X. Chen, X. Zhan, J. Sun, Molecular mechanism of microRNA involvement in genesis of myelodysplastic syndrome and its transformation to acute myeloid leukemia, Hematology 18(4) (2013) 191-7.

[7] X. Ma, M. Does, A. Raza, S.T. Mayne, Myelodysplastic syndromes: incidence and survival in the United States, Cancer 109(8) (2007) 1536-42.

[8] C. Aul, N. Gattermann, W. Schneider, Age-related incidence and other epidemiological aspects of myelodysplastic syndromes, British journal of haematology 82(2) (1992) 358-67.

[9] A. Radlund, T. Thiede, S. Hansen, M. Carlsson, L. Engquist, Incidence of myelodysplastic syndromes in a Swedish population, European journal of haematology 54(3) (1995) 153-6.

[10] M. Maynadie, C. Verret, P. Moskovtchenko, F. Mugneret, T. Petrella, D. Caillot, P.M. Carli, Epidemiological characteristics of myelodysplastic syndrome in a well-defined French population, British journal of cancer 74(2) (1996) 288-90.

[11] B. Chen, W.L. Zhao, J. Jin, Y.Q. Xue, X. Cheng, X.T. Chen, J. Cui, Z.M. Chen, Q. Cao, G. Yang, Y. Yao, H.L. Xia, J.H. Tong, J.M. Li, J. Chen, S.M. Xiong, Z.X. Shen, S. Waxman, Z. Chen, S.J. Chen, Clinical and cytogenetic features of 508 Chinese patients with myelodysplastic syndrome and comparison with those in Western countries, Leukemia 19(5) (2005) 767-75.

[12] C.R. Cogle, Incidence and Burden of the Myelodysplastic Syndromes, Current hematologic malignancy reports 10(3) (2015) 272-81.

[13] C. Aul, D.T. Bowen, Y. Yoshida, Pathogenesis, etiology and epidemiology of myelodysplastic syndromes, Haematologica 83(1) (1998) 71-86.

[14] D.T. Bowen, Occupational and environmental etiology of MDS, Best practice \& research. Clinical haematology 26(4) (2013) 319-26.

[15] S.A. Bannon, C.D. DiNardo, Hereditary Predispositions to Myelodysplastic Syndrome, International journal of molecular sciences 17(6) (2016).

[16] G. Garcia-Manero, Myelodysplastic syndromes: 2014 update on diagnosis, risk-stratification, and management, American journal of hematology 89(1) (2014) 97-108.

[17] P.L. Greenberg, H. Tuechler, J. Schanz, G. Sanz, G. Garcia-Manero, F. Sole, J.M. Bennett, D. Bowen, P. Fenaux, F. Dreyfus, H. Kantarjian, A. Kuendgen, A. Levis, L. Malcovati, M. Cazzola, J. Cermak, C. Fonatsch, M.M. Le Beau, M.L. Slovak, O. Krieger, M. Luebbert, J. Maciejewski, S.M. Magalhaes, Y. Miyazaki, M. Pfeilstocker, M. Sekeres, W.R. Sperr, R. Stauder, S. Tauro, P. Valent, T. Vallespi, A.A. van de Loosdrecht, U. Germing, D. Haase, Cytopenia levels for aiding establishment of the diagnosis of myelodysplastic syndromes, Blood 128(16) (2016) 2096-2097.

[18] D.P. Steensma, Myelodysplastic Syndromes: Diagnosis and Treatment, Mayo Clinic proceedings 90(7) (2015) 969-83.

[19] M.G. Della Porta, L. Malcovati, R. Invernizzi, E. Travaglino, C. Pascutto, M. Maffioli, A. Galli, S. Boggi, D. Pietra, L. Vanelli, C. Marseglia, S. Levi, P. Arosio, M. Lazzarino, M. Cazzola, Flow cytometry evaluation of erythroid dysplasia in patients with myelodysplastic syndrome, Leukemia 20(4) (2006) 549-55. 
[20] A. Mazzone, C. Porta, G. Fossati, D. Gritti, I. Mazzucchelli, G. Ricevuti, Granulocyte dysplasia and dysfunction, and CD11/CD18 defects in myelodysplastic syndromes, Leukemia \& lymphoma 23(3-4) (1996) 267-75.

[21] G. Feng, R.P. Gale, W. Cui, W. Cai, G. Huang, Z. Xu, T. Qin, Y. Zhang, B. Li, L. Fang, H. Zhang, L. Pan, N. Hu, S. Qu, J. Wang, Y. Cui, Z. Xiao, A systematic classification of megakaryocytic dysplasia and its impact on prognosis for patients with myelodysplastic syndromes, Experimental hematology \& oncology 5 (2015) 12.

[22] O.K. Weinberg, R.P. Hasserjian, The current approach to the diagnosis of myelodysplastic syndromes(), Seminars in hematology 56(1) (2019) 15-21.

[23] G. Gupta, R. Singh, D.S. Kotasthane, V.D. Kotasthane, Myelodysplastic syndromes/neoplasms: recent classification system based on World Health Organization Classification of Tumors International Agency for Research on Cancer for Hematopoietic and Lymphoid Tissues, Journal of blood medicine 1 (2010) 171-82.

[24] R. Bejar, Myelodysplastic Syndromes Diagnosis: What Is the Role of Molecular Testing?, Current hematologic malignancy reports 10(3) (2015) 282-91.

[25] E.J. Duncavage, B. Tandon, The utility of next-generation sequencing in diagnosis and monitoring of acute myeloid leukemia and myelodysplastic syndromes, International journal of laboratory hematology 37 Suppl 1 (2015) 115-21.

[26] L. Ades, R. Itzykson, P. Fenaux, Myelodysplastic syndromes, Lancet 383(9936) (2014) 2239-52.

[27] C.D. DiNardo, G. Garcia-Manero, S. Pierce, A. Nazha, C. Bueso-Ramos, E. Jabbour, F. Ravandi, J. Cortes, H. Kantarjian, Interactions and relevance of blast percentage and treatment strategy among younger and older patients with acute myeloid leukemia (AML) and myelodysplastic syndrome (MDS), American journal of hematology 91(2) (2016) 227-32.

[28] J.M. Bennett, A comparative review of classification systems in myelodysplastic syndromes (MDS), Seminars in oncology 32(4 Suppl 5) (2005) S3-10.

[29] T. Nosslinger, R. Reisner, E. Koller, H. Gruner, H. Tuchler, H. Nowotny, E. Pittermann, M. Pfeilstocker, Myelodysplastic syndromes, from French-American-British to World Health Organization: comparison of classifications on 431 unselected patients from a single institution, Blood 98(10) (2001) 2935-41.

[30] J.W. Vardiman, N.L. Harris, R.D. Brunning, The World Health Organization (WHO) classification of the myeloid neoplasms, Blood 100(7) (2002) 2292-302.

[31] J.W. Vardiman, J. Thiele, D.A. Arber, R.D. Brunning, M.J. Borowitz, A. Porwit, N.L. Harris, M.M. Le Beau, E. Hellstrom-Lindberg, A. Tefferi, C.D. Bloomfield, The 2008 revision of the World Health Organization (WHO) classification of myeloid neoplasms and acute leukemia: rationale and important changes, Blood 114(5) (2009) 937-51.

[32] D.A. Arber, A. Orazi, R. Hasserjian, J. Thiele, M.J. Borowitz, M.M. Le Beau, C.D. Bloomfield, M. Cazzola, J.W. Vardiman, The 2016 revision to the World Health Organization classification of myeloid neoplasms and acute leukemia, Blood 127(20) (2016) 2391-405.

[33] P. Greenberg, C. Cox, M.M. LeBeau, P. Fenaux, P. Morel, G. Sanz, M. Sanz, T. Vallespi, T. Hamblin, D. Oscier, K. Ohyashiki, K. Toyama, C. Aul, G. Mufti, J. Bennett, International scoring system for evaluating prognosis in myelodysplastic syndromes, Blood 89(6) (1997) 2079-88.

[34] G. Montalban-Bravo, G. Garcia-Manero, Myelodysplastic syndromes: 2018 update on diagnosis, risk-stratification and management, American journal of hematology 93(1) (2018) 129147.

[35] P.L. Greenberg, H. Tuechler, J. Schanz, G. Sanz, G. Garcia-Manero, F. Sole, J.M. Bennett, D. Bowen, P. Fenaux, F. Dreyfus, H. Kantarjian, A. Kuendgen, A. Levis, L. Malcovati, M. Cazzola, J. Cermak, C. Fonatsch, M.M. Le Beau, M.L. Slovak, O. Krieger, M. Luebbert, J. Maciejewski, S.M. Magalhaes, Y. Miyazaki, M. Pfeilstocker, M. Sekeres, W.R. Sperr, R. Stauder, S. Tauro, P. Valent, T. Vallespi, A.A. van de Loosdrecht, U. Germing, D. Haase, Revised international prognostic scoring system for myelodysplastic syndromes, Blood 120(12) (2012) 2454-65.

[36] C. International Human Genome Sequencing, Finishing the euchromatic sequence of the human genome, Nature 431(7011) (2004) 931-45. 
[37] E. Papaemmanuil, M. Gerstung, L. Malcovati, S. Tauro, G. Gundem, P. Van Loo, C.J. Yoon, P. Ellis, D.C. Wedge, A. Pellagatti, A. Shlien, M.J. Groves, S.A. Forbes, K. Raine, J. Hinton, L.J. Mudie, S. McLaren, C. Hardy, C. Latimer, M.G. Della Porta, S. O'Meara, I. Ambaglio, A. Galli, A.P. Butler, G. Walldin, J.W. Teague, L. Quek, A. Sternberg, C. Gambacorti-Passerini, N.C. Cross, A.R. Green, J. Boultwood, P. Vyas, E. Hellstrom-Lindberg, D. Bowen, M. Cazzola, M.R. Stratton, P.J. Campbell, C. Chronic Myeloid Disorders Working Group of the International Cancer Genome, Clinical and biological implications of driver mutations in myelodysplastic syndromes, Blood 122(22) (2013) 3616-27; quiz 3699.

[38] T. Haferlach, Y. Nagata, V. Grossmann, Y. Okuno, U. Bacher, G. Nagae, S. Schnittger, M. Sanada, A. Kon, T. Alpermann, K. Yoshida, A. Roller, N. Nadarajah, Y. Shiraishi, Y. Shiozawa, K. Chiba, H. Tanaka, H.P. Koeffler, H.U. Klein, M. Dugas, H. Aburatani, A. Kohlmann, S. Miyano, C. Haferlach, W. Kern, S. Ogawa, Landscape of genetic lesions in 944 patients with myelodysplastic syndromes, Leukemia 28(2) (2014) 241-7.

[39] E. Papaemmanuil, M. Cazzola, J. Boultwood, L. Malcovati, P. Vyas, D. Bowen, A. Pellagatti, J.S. Wainscoat, E. Hellstrom-Lindberg, C. Gambacorti-Passerini, A.L. Godfrey, I. Rapado, A. Cvejic, R. Rance, C. McGee, P. Ellis, L.J. Mudie, P.J. Stephens, S. McLaren, C.E. Massie, P.S. Tarpey, I. Varela, S. Nik-Zainal, H.R. Davies, A. Shlien, D. Jones, K. Raine, J. Hinton, A.P. Butler, J.W. Teague, E.J. Baxter, J. Score, A. Galli, M.G. Della Porta, E. Travaglino, M. Groves, S. Tauro, N.C. Munshi, K.C. Anderson, A. El-Naggar, A. Fischer, V. Mustonen, A.J. Warren, N.C. Cross, A.R. Green, P.A. Futreal, M.R. Stratton, P.J. Campbell, C. Chronic Myeloid Disorders Working Group of the International Cancer Genome, Somatic SF3B1 mutation in myelodysplasia with ring sideroblasts, The New England journal of medicine 365(15) (2011) 1384-95.

[40] L. Malcovati, M. Karimi, E. Papaemmanuil, I. Ambaglio, M. Jadersten, M. Jansson, C. Elena, A. Galli, G. Walldin, M.G. Della Porta, K. Raaschou-Jensen, E. Travaglino, K. Kallenbach, D. Pietra, V. Ljungstrom, S. Conte, E. Boveri, R. Invernizzi, R. Rosenquist, P.J. Campbell, M. Cazzola, E. Hellstrom Lindberg, SF3B1 mutation identifies a distinct subset of myelodysplastic syndrome with ring sideroblasts, Blood 126(2) (2015) 233-41.

[41] X. Zheng, Z. Zhan, D. Naren, J. Li, T. Yan, Y. Gong, Prognostic value of SRSF2 mutations in patients with de novo myelodysplastic syndromes: A meta-analysis, PloS one 12(9) (2017) e0185053.

[42] M.E. Lin, H.A. Hou, C.H. Tsai, S.J. Wu, Y.Y. Kuo, M.H. Tseng, M.C. Liu, C.W. Liu, W.C. Chou, C.Y. Chen, J.L. Tang, M. Yao, C.C. Li, S.Y. Huang, B.S. Ko, S.C. Hsu, C.T. Lin, H.F. Tien, Dynamics of DNMT3A mutation and prognostic relevance in patients with primary myelodysplastic syndrome, Clinical epigenetics 10 (2018) 42.

[43] A.A. Mangaonkar, N. Gangat, A. Al-Kali, M.A. Elliott, K.H. Begna, C.A. Hanson, R.P. Ketterling, A.P. Wolanskyj-Spinner, W.J. Hogan, M.R. Litzow, M.M. Patnaik, Prognostic impact of ASXL1 mutations in patients with myelodysplastic syndromes and multilineage dysplasia with or without ring sideroblasts, Leukemia research 71 (2018) 60-62.

[44] N. Gangat, M. Mudireddy, T.L. Lasho, C.M. Finke, M. Nicolosi, N. Szuber, M.M. Patnaik, A. Pardanani, C.A. Hanson, R.P. Ketterling, A. Tefferi, Mutations and prognosis in myelodysplastic syndromes: karyotype-adjusted analysis of targeted sequencing in 300 consecutive cases and development of a genetic risk model, American journal of hematology 93(5) (2018) 691-697.

[45] D. Haase, K.E. Stevenson, D. Neuberg, J.P. Maciejewski, A. Nazha, M.A. Sekeres, B.L. Ebert, G. Garcia-Manero, C. Haferlach, T. Haferlach, W. Kern, S. Ogawa, Y. Nagata, K. Yoshida, T.A. Graubert, M.J. Walter, A.F. List, R.S. Komrokji, E. Padron, D. Sallman, E. Papaemmanuil, P.J. Campbell, M.R. Savona, A. Seegmiller, L. Ades, P. Fenaux, L.Y. Shih, D. Bowen, M.J. Groves, S. Tauro, M. Fontenay, O. Kosmider, M. Bar-Natan, D. Steensma, R. Stone, M. Heuser, F. Thol, M. Cazzola, L. Malcovati, A. Karsan, C. Ganster, E. Hellstrom-Lindberg, J. Boultwood, A. Pellagatti, V. Santini, L. Quek, P. Vyas, H. Tuchler, P.L. Greenberg, R. Bejar, M.D.S.M.P.C. International Working Group for, TP53 mutation status divides myelodysplastic syndromes with complex karyotypes into distinct prognostic subgroups, Leukemia (2019). 
[46] H.A. Hou, C.H. Tsai, C.C. Lin, W.C. Chou, Y.Y. Kuo, C.Y. Liu, M.H. Tseng, Y.L. Peng, M.C. Liu, C.W. Liu, X.W. Liao, L.I. Lin, M. Yao, J.L. Tang, H.F. Tien, Incorporation of mutations in five genes in the revised International Prognostic Scoring System can improve risk stratification in the patients with myelodysplastic syndrome, Blood cancer journal 8(4) (2018) 39.

[47] Q. Song, M. Peng, Y. Chu, S. Huang, Techniques for detecting chromosomal aberrations in Myelodysplastic syndromes, Oncotarget (2017).

[48] M.F. Zahid, U.A. Malik, M. Sohail, I.N. Hassan, S. Ali, M.H.S. Shaukat, Cytogenetic Abnormalities in Myelodysplastic Syndromes: An Overview, International journal of hematologyoncology and stem cell research 11(3) (2017) 231-239.

[49] E. Ciabatti, A. Valetto, V. Bertini, M.I. Ferreri, A. Guazzelli, S. Grassi, F. Guerrini, I. Petrini, M.R. Metelli, M.A. Caligo, S. Rossi, S. Galimberti, Myelodysplastic syndromes: advantages of a combined cytogenetic and molecular diagnostic workup, Oncotarget (2017).

[50] D. Haase, U. Germing, J. Schanz, M. Pfeilstocker, T. Nosslinger, B. Hildebrandt, A. Kundgen, M. Lubbert, R. Kunzmann, A.A. Giagounidis, C. Aul, L. Trumper, O. Krieger, R. Stauder, T.H. Muller, F. Wimazal, P. Valent, C. Fonatsch, C. Steidl, New insights into the prognostic impact of the karyotype in MDS and correlation with subtypes: evidence from a core dataset of 2124 patients, Blood 110(13) (2007) 4385-95.

[51] M. Wall, Recurrent Cytogenetic Abnormalities in Myelodysplastic Syndromes, Methods in molecular biology 1541 (2017) 209-222.

[52] V. Adema, R. Bejar, What lies beyond del(5q) in myelodysplastic syndrome?, Haematologica 98(12) (2013) 1819-21.

[53] F. Sole, B. Espinet, G.F. Sanz, J. Cervera, M.J. Calasanz, E. Luno, F. Prieto, I. Granada, J.M. Hernandez, J.C. Cigudosa, J.L. Diez, E. Bureo, M.L. Marques, E. Arranz, R. Rios, J.A. Martinez Climent, T. Vallespi, L. Florensa, S. Woessner, Incidence, characterization and prognostic significance of chromosomal abnormalities in 640 patients with primary myelodysplastic syndromes. Grupo Cooperativo Espanol de Citogenetica Hematologica, British journal of haematology 108(2) (2000) 346-56.

[54] D. Haase, Cytogenetic features in myelodysplastic syndromes, Annals of hematology 87(7) (2008) 515-26.

[55] J. Schanz, H. Tuchler, F. Sole, M. Mallo, E. Luno, J. Cervera, I. Granada, B. Hildebrandt, M.L. Slovak, K. Ohyashiki, C. Steidl, C. Fonatsch, M. Pfeilstocker, T. Nosslinger, P. Valent, A. Giagounidis, C. Aul, M. Lubbert, R. Stauder, O. Krieger, G. Garcia-Manero, S. Faderl, S. Pierce, M.M. Le Beau, J.M. Bennett, P. Greenberg, U. Germing, D. Haase, New comprehensive cytogenetic scoring system for primary myelodysplastic syndromes (MDS) and oligoblastic acute myeloid leukemia after MDS derived from an international database merge, Journal of clinical oncology : official journal of the American Society of Clinical Oncology 30(8) (2012) 820-9.

[56] H.J. Deeg, B.L. Scott, M. Fang, H.M. Shulman, B. Gyurkocza, D. Myerson, J.M. Pagel, U. Platzbecker, A. Ramakrishnan, J.P. Radich, B.M. Sandmaier, M. Sorror, D.L. Stirewalt, W.A. Wilson, R. Storb, F.R. Appelbaum, T. Gooley, Five-group cytogenetic risk classification, monosomal karyotype, and outcome after hematopoietic cell transplantation for MDS or acute leukemia evolving from MDS, Blood 120(7) (2012) 1398-408.

[57] R. Itzykson, O. Kosmider, P. Fenaux, Somatic mutations and epigenetic abnormalities in myelodysplastic syndromes, Best practice \& research. Clinical haematology 26(4) (2013) 355-64.

[58] R. Bejar, K. Stevenson, O. Abdel-Wahab, N. Galili, B. Nilsson, G. Garcia-Manero, H. Kantarjian, A. Raza, R.L. Levine, D. Neuberg, B.L. Ebert, Clinical effect of point mutations in myelodysplastic syndromes, The New England journal of medicine 364(26) (2011) 2496-506.

[59] J.A. Kennedy, B.L. Ebert, Clinical Implications of Genetic Mutations in Myelodysplastic Syndrome, Journal of clinical oncology : official journal of the American Society of Clinical Oncology 35(9) (2017) 968-974.

[60] P.L. Greenberg, R.M. Stone, A. Al-Kali, S.K. Barta, R. Bejar, J.M. Bennett, H. Carraway, C.M. De Castro, H.J. Deeg, A.E. DeZern, A.T. Fathi, O. Frankfurt, K. Gaensler, G. Garcia-Manero, E.A. Griffiths, D. Head, R. Horsfall, R.A. Johnson, M. Juckett, V.M. Klimek, R. Komrokji, L.A. Kujawski, 
L.J. Maness, M.R. O'Donnell, D.A. Pollyea, P.J. Shami, B.L. Stein, A.R. Walker, P. Westervelt, A. Zeidan, D.A. Shead, C. Smith, Myelodysplastic Syndromes, Version 2.2017, NCCN Clinical Practice Guidelines in Oncology, Journal of the National Comprehensive Cancer Network : JNCCN 15(1) (2017) 60-87.

[61] K. Janusz, M. Del Rey, M. Abaigar, R. Collado, D. Ivars, M. Hernandez-Sanchez, A. Valiente, C. Robledo, R. Benito, M. Diez-Campelo, F. Ramos, A. Kohlmann, C.D. Canizo, J.M. Hernandez-Rivas, A two-step approach for sequencing spliceosome-related genes as a complementary diagnostic assay in MDS patients with ringed sideroblasts, Leukemia research 56 (2017) 82-87.

[62] P. Joshi, S. Halene, O. Abdel-Wahab, How do messenger RNA splicing alterations drive myelodysplasia?, Blood 129(18) (2017) 2465-2470.

[63] A.G. Matera, Z. Wang, A day in the life of the spliceosome, Nature reviews. Molecular cell biology 15(2) (2014) 108-21.

[64] J. Chen, W.A. Weiss, Alternative splicing in cancer: implications for biology and therapy, Oncogene 34(1) (2015) 1-14.

[65] Y. Lee, D.C. Rio, Mechanisms and Regulation of Alternative Pre-mRNA Splicing, Annual review of biochemistry 84 (2015) 291-323.

[66] H. Dolatshad, A. Pellagatti, F.G. Liberante, M. Llorian, E. Repapi, V. Steeples, S. Roy, L. Scifo, R.N. Armstrong, J. Shaw, B.H. Yip, S. Killick, R. Kusec, S. Taylor, K.I. Mills, K.I. Savage, C.W. Smith, J. Boultwood, Cryptic splicing events in the iron transporter ABCB7 and other key target genes in SF3B1-mutant myelodysplastic syndromes, Leukemia 30(12) (2016) 2322-2331.

[67] J. Qiu, B. Zhou, F. Thol, Y. Zhou, L. Chen, C. Shao, C. DeBoever, J. Hou, H. Li, A. Chaturvedi, A. Ganser, R. Bejar, D.E. Zhang, X.D. Fu, M. Heuser, Distinct splicing signatures affect converged pathways in myelodysplastic syndrome patients carrying mutations in different splicing regulators, Rna 22(10) (2016) 1535-49.

[68] F. Damm, F. Thol, O. Kosmider, S. Kade, P. Loffeld, F. Dreyfus, A. Stamatoullas-Bastard, A. Tanguy-Schmidt, O. Beyne-Rauzy, S. de Botton, A. Guerci-Bresler, G. Gohring, B. Schlegelberger, A. Ganser, O.A. Bernard, M. Fontenay, M. Heuser, SF3B1 mutations in myelodysplastic syndromes: clinical associations and prognostic implications, Leukemia 26(5) (2012) 1137-40.

[69] V. Visconte, H. Makishima, A. Jankowska, H. Szpurka, F. Traina, A. Jerez, C. O'Keefe, H.J. Rogers, M.A. Sekeres, J.P. Maciejewski, R.V. Tiu, SF3B1, a splicing factor is frequently mutated in refractory anemia with ring sideroblasts, Leukemia 26(3) (2012) 542-5.

[70] R. Bejar, Splicing Factor Mutations in Cancer, Advances in experimental medicine and biology 907 (2016) 215-28.

[71] S. Bonnal, L. Vigevani, J. Valcarcel, The spliceosome as a target of novel antitumour drugs, Nature reviews. Drug discovery 11(11) (2012) 847-59.

[72] R. Cui, R.P. Gale, Z. Xu, T. Qin, L. Fang, H. Zhang, L. Pan, Y. Zhang, Z. Xiao, Clinical importance of SF3B1 mutations in Chinese with myelodysplastic syndromes with ring sideroblasts, Leukemia research 36(11) (2012) 1428-33.

[73] K. Yoshida, M. Sanada, Y. Shiraishi, D. Nowak, Y. Nagata, R. Yamamoto, Y. Sato, A. SatoOtsubo, A. Kon, M. Nagasaki, G. Chalkidis, Y. Suzuki, M. Shiosaka, R. Kawahata, T. Yamaguchi, M. Otsu, N. Obara, M. Sakata-Yanagimoto, K. Ishiyama, H. Mori, F. Nolte, W.K. Hofmann, S. Miyawaki, S. Sugano, C. Haferlach, H.P. Koeffler, L.Y. Shih, T. Haferlach, S. Chiba, H. Nakauchi, S. Miyano, S. Ogawa, Frequent pathway mutations of splicing machinery in myelodysplasia, Nature 478(7367) (2011) 64-9.

[74] J.L. Jenkins, C.L. Kielkopf, Splicing Factor Mutations in Myelodysplasias: Insights from Spliceosome Structures, Trends in genetics : TIG 33(5) (2017) 336-348.

[75] T. Okeyo-Owuor, B.S. White, R. Chatrikhi, D.R. Mohan, S. Kim, M. Griffith, L. Ding, S. KetkarKulkarni, J. Hundal, K.M. Laird, C.L. Kielkopf, T.J. Ley, M.J. Walter, T.A. Graubert, U2AF1 mutations alter sequence specificity of pre-mRNA binding and splicing, Leukemia 29(4) (2015) 909-17.

[76] F. Thol, S. Kade, C. Schlarmann, P. Loffeld, M. Morgan, J. Krauter, M.W. Wlodarski, B. Kolking, M. Wichmann, K. Gorlich, G. Gohring, G. Bug, O. Ottmann, C.M. Niemeyer, W.K. Hofmann, B. 
Schlegelberger, A. Ganser, M. Heuser, Frequency and prognostic impact of mutations in SRSF2, U2AF1, and ZRSR2 in patients with myelodysplastic syndromes, Blood 119(15) (2012) 3578-84.

[77] S.J. Wu, Y.Y. Kuo, H.A. Hou, L.Y. Li, M.H. Tseng, C.F. Huang, F.Y. Lee, M.C. Liu, C.W. Liu, C.T. Lin, C.Y. Chen, W.C. Chou, M. Yao, S.Y. Huang, B.S. Ko, J.L. Tang, W. Tsay, H.F. Tien, The clinical implication of SRSF2 mutation in patients with myelodysplastic syndrome and its stability during disease evolution, Blood 120(15) (2012) 3106-11.

[78] J. Zhang, Y.K. Lieu, A.M. Ali, A. Penson, K.S. Reggio, R. Rabadan, A. Raza, S. Mukherjee, J.L. Manley, Disease-associated mutation in SRSF2 misregulates splicing by altering RNA-binding affinities, Proceedings of the National Academy of Sciences of the United States of America 112(34) (2015) E4726-34.

[79] P.E. Boulais, P.S. Frenette, Making sense of hematopoietic stem cell niches, Blood 125(17) (2015) 2621-9.

[80] R. Schofield, The relationship between the spleen colony-forming cell and the haemopoietic stem cell, Blood cells 4(1-2) (1978) 7-25.

[81] C.R. Cogle, N. Saki, E. Khodadi, J. Li, M. Shahjahani, S. Azizidoost, Bone marrow niche in the myelodysplastic syndromes, Leukemia research 39(10) (2015) 1020-7.

[82] E.K. von der Heide, M. Neumann, S. Vosberg, A.R. James, M.P. Schroeder, J. Ortiz-Tanchez, K. Isaakidis, C. Schlee, M. Luther, K. Johrens, I. Anagnostopoulos, L.H. Mochmann, D. Nowak, W.K. Hofmann, P.A. Greif, C.D. Baldus, Molecular alterations in bone marrow mesenchymal stromal cells derived from acute myeloid leukemia patients, Leukemia 31(5) (2017) 1069-1078.

[83] S.J. Morrison, D.T. Scadden, The bone marrow niche for haematopoietic stem cells, Nature 505(7483) (2014) 327-34.

[84] E. Flores-Figueroa, R.M. Arana-Trejo, G. Gutierrez-Espindola, A. Perez-Cabrera, H. Mayani, Mesenchymal stem cells in myelodysplastic syndromes: phenotypic and cytogenetic characterization, Leukemia research 29(2) (2005) 215-24.

[85] O. Blau, C.D. Baldus, W.K. Hofmann, G. Thiel, F. Nolte, T. Burmeister, S. Turkmen, O. Benlasfer, E. Schumann, A. Sindram, M. Molkentin, S. Mundlos, U. Keilholz, E. Thiel, I.W. Blau, Mesenchymal stromal cells of myelodysplastic syndrome and acute myeloid leukemia patients have distinct genetic abnormalities compared with leukemic blasts, Blood 118(20) (2011) 5583-92. [86] A.J. Rathnayake, H.W. Goonasekera, V.H. Dissanayake, Phenotypic and Cytogenetic Characterization of Mesenchymal Stromal Cells in De Novo Myelodysplastic Syndromes, Analytical cellular pathology 2016 (2016) 8012716.

[87] F. Dazzi, R. Ramasamy, S. Glennie, S.P. Jones, I. Roberts, The role of mesenchymal stem cells in haemopoiesis, Blood reviews 20(3) (2006) 161-71.

[88] M. Dominici, K. Le Blanc, I. Mueller, I. Slaper-Cortenbach, F. Marini, D. Krause, R. Deans, A. Keating, D. Prockop, E. Horwitz, Minimal criteria for defining multipotent mesenchymal stromal cells. The International Society for Cellular Therapy position statement, Cytotherapy 8(4) (2006) 315-7.

[89] M.F. Pittenger, A.M. Mackay, S.C. Beck, R.K. Jaiswal, R. Douglas, J.D. Mosca, M.A. Moorman, D.W. Simonetti, S. Craig, D.R. Marshak, Multilineage potential of adult human mesenchymal stem cells, Science 284(5411) (1999) 143-7.

[90] S. Geyh, S. Oz, R.P. Cadeddu, J. Frobel, B. Bruckner, A. Kundgen, R. Fenk, I. Bruns, C. Zilkens, D. Hermsen, N. Gattermann, G. Kobbe, U. Germing, F. Lyko, R. Haas, T. Schroeder, Insufficient stromal support in MDS results from molecular and functional deficits of mesenchymal stromal cells, Leukemia 27(9) (2013) 1841-51.

[91] F. Gao, S.M. Chiu, D.A. Motan, Z. Zhang, L. Chen, H.L. Ji, H.F. Tse, Q.L. Fu, Q. Lian, Mesenchymal stem cells and immunomodulation: current status and future prospects, Cell death \& disease 7 (2016) e2062.

[92] M. Lisovsky, V.G. Savchenko, Defect of stromal microenvironment in long term bone marrow cultures of patients with acute and chronic myelogenous leukemias, Leukemia \& lymphoma 19(12) (1995) 145-52. 
[93] U. Duhrsen, G. Knieling, W. Beecken, S. Neumann, D.K. Hossfeld, Chimaeric cultures of human marrow stroma and murine leukaemia cells: evidence for abnormalities in the haemopoietic microenvironment in myeloid malignancies and other infiltrating marrow disorders, British journal of haematology 90(3) (1995) 502-11.

[94] Y. Kim, D.W. Jekarl, J. Kim, A. Kwon, H. Choi, S. Lee, Y.J. Kim, H.J. Kim, Y. Kim, I.H. Oh, M. Kim, Genetic and epigenetic alterations of bone marrow stromal cells in myelodysplastic syndrome and acute myeloid leukemia patients, Stem cell research 14(2) (2015) 177-84.

[95] S. Chen, N.A. Zambetti, E.M. Bindels, K. Kenswill, A.M. Mylona, N.M. Adisty, R.M. Hoogenboezem, M.A. Sanders, E.M. Cremers, T.M. Westers, J.H. Jansen, A.A. van de Loosdrecht, M.H. Raaijmakers, Massive parallel RNA sequencing of highly purified mesenchymal elements in low-risk MDS reveals tissue-context-dependent activation of inflammatory programs, Leukemia 30(9) (2016) 1938-42.

[96] S. Zhao, Y. Zhao, J. Guo, C. Fei, Q. Zheng, X. Li, C. Chang, Downregulation of MMP1 in MDSderived mesenchymal stromal cells reduces the capacity to restrict MDS cell proliferation, Scientific reports 7 (2017) 43849.

[97] N. Awaya, Rupter, K., Bryant, E., et al., Marrow stromal cells are not derived from the malignant clone in myelodysplastic syndromes (MDS).

, Blood 98(Suppl 1) (2001) 1487a.

[98] V. Soenen, Korb, R., Bonnet, M. L., et al., Mesenchymal cells (MC) from patients with myelodysplastic syndromes (MDS) are devoid of cytogenetic abnormalities and support short- and long-term hematopoiesis in vitro., Blood 98(Suppl 1) (2001) 3041a.

[99] O. Blau, W.K. Hofmann, C.D. Baldus, G. Thiel, V. Serbent, E. Schumann, E. Thiel, I.W. Blau, Chromosomal aberrations in bone marrow mesenchymal stroma cells from patients with myelodysplastic syndrome and acute myeloblastic leukemia, Experimental hematology 35(2) (2007) 221-9.

[100] O. Lopez-Villar, J.L. Garcia, F.M. Sanchez-Guijo, C. Robledo, E.M. Villaron, P. HernandezCampo, N. Lopez-Holgado, M. Diez-Campelo, M.V. Barbado, J.A. Perez-Simon, J.M. HernandezRivas, J.F. San-Miguel, M.C. del Canizo, Both expanded and uncultured mesenchymal stem cells from MDS patients are genomically abnormal, showing a specific genetic profile for the $5 q$ syndrome, Leukemia 23(4) (2009) 664-72.

[101] M.H. Raaijmakers, S. Mukherjee, S. Guo, S. Zhang, T. Kobayashi, J.A. Schoonmaker, B.L. Ebert, F. Al-Shahrour, R.P. Hasserjian, E.O. Scadden, Z. Aung, M. Matza, M. Merkenschlager, C. Lin, J.M. Rommens, D.T. Scadden, Bone progenitor dysfunction induces myelodysplasia and secondary leukaemia, Nature 464(7290) (2010) 852-7.

[102] A. Kode, J.S. Manavalan, I. Mosialou, G. Bhagat, C.V. Rathinam, N. Luo, H. Khiabanian, A. Lee, V.V. Murty, R. Friedman, A. Brum, D. Park, N. Galili, S. Mukherjee, J. Teruya-Feldstein, A. Raza, R. Rabadan, E. Berman, S. Kousteni, Leukaemogenesis induced by an activating beta-catenin mutation in osteoblasts, Nature 506(7487) (2014) 240-4.

[103] A. Stoddart, J. Wang, C. Hu, A.A. Fernald, E.M. Davis, J.X. Cheng, M.M. Le Beau, Inhibition of WNT signaling in the bone marrow niche prevents the development of MDS in the Apcdel/+ MDS mouse model, Blood 129(22) (2017) 2959-2970.

[104] E. Fabiani, G. Falconi, L. Fianchi, F. Guidi, S. Bellesi, M.T. Voso, G. Leone, F. D'Alo, Mutational analysis of bone marrow mesenchymal stromal cells in myeloid malignancies, Experimental hematology 42(9) (2014) 731-3.

[105] K. Azuma, T. Umezu, S. Imanishi, M. Asano, S. Yoshizawa, S. Katagiri, K. Ohyashiki, J.H. Ohyashiki, Genetic variations of bone marrow mesenchymal stromal cells derived from acute leukemia and myelodysplastic syndrome by targeted deep sequencing, Leukemia research 62 (2017) 23-28.

[106] R.W. Holley, J. Apgar, G.A. Everett, J.T. Madison, M. Marquisee, S.H. Merrill, J.R. Penswick, A. Zamir, Structure of a Ribonucleic Acid, Science 147(3664) (1965) 1462-5. 
[107] F. Sanger, G.G. Brownlee, B.G. Barrell, A two-dimensional fractionation procedure for radioactive nucleotides, Journal of molecular biology 13(2) (1965) 373-98.

[108] W. Min Jou, G. Haegeman, M. Ysebaert, W. Fiers, Nucleotide sequence of the gene coding for the bacteriophage MS2 coat protein, Nature 237(5350) (1972) 82-8.

[109] W. Fiers, R. Contreras, F. Duerinck, G. Haegeman, D. Iserentant, J. Merregaert, W. Min Jou, F. Molemans, A. Raeymaekers, A. Van den Berghe, G. Volckaert, M. Ysebaert, Complete nucleotide sequence of bacteriophage MS2 RNA: primary and secondary structure of the replicase gene, Nature 260(5551) (1976) 500-7.

[110] F. Sanger, A.R. Coulson, A rapid method for determining sequences in DNA by primed synthesis with DNA polymerase, Journal of molecular biology 94(3) (1975) 441-8.

[111] A.M. Maxam, W. Gilbert, A new method for sequencing DNA, Proceedings of the National Academy of Sciences of the United States of America 74(2) (1977) 560-4.

[112] E.S. Lander, Initial impact of the sequencing of the human genome, Nature 470(7333) (2011) 187-97.

[113] T.J. Ley, E.R. Mardis, L. Ding, B. Fulton, M.D. McLellan, K. Chen, D. Dooling, B.H. DunfordShore, S. McGrath, M. Hickenbotham, L. Cook, R. Abbott, D.E. Larson, D.C. Koboldt, C. Pohl, S. Smith, A. Hawkins, S. Abbott, D. Locke, L.W. Hillier, T. Miner, L. Fulton, V. Magrini, T. Wylie, J. Glasscock, J. Conyers, N. Sander, X. Shi, J.R. Osborne, P. Minx, D. Gordon, A. Chinwalla, Y. Zhao, R.E. Ries, J.E. Payton, P. Westervelt, M.H. Tomasson, M. Watson, J. Baty, J. Ivanovich, S. Heath, W.D. Shannon, R. Nagarajan, M.J. Walter, D.C. Link, T.A. Graubert, J.F. DiPersio, R.K. Wilson, DNA sequencing of a cytogenetically normal acute myeloid leukaemia genome, Nature 456(7218) (2008) 66-72.

[114] T. Fujiwara, N. Fukuhara, R. Funayama, N. Nariai, M. Kamata, T. Nagashima, K. Kojima, Y. Onishi, Y. Sasahara, K. Ishizawa, M. Nagasaki, K. Nakayama, H. Harigae, Identification of acquired mutations by whole-genome sequencing in GATA-2 deficiency evolving into myelodysplasia and acute leukemia, Annals of hematology 93(9) (2014) 1515-22.

[115] X.J. Yan, J. Xu, Z.H. Gu, C.M. Pan, G. Lu, Y. Shen, J.Y. Shi, Y.M. Zhu, L. Tang, X.W. Zhang, W.X. Liang, J.Q. Mi, H.D. Song, K.Q. Li, Z. Chen, S.J. Chen, Exome sequencing identifies somatic mutations of DNA methyltransferase gene DNMT3A in acute monocytic leukemia, Nature genetics 43(4) (2011) 309-15.

[116] M. Ruffalo, H. Husseinzadeh, H. Makishima, B. Przychodzen, M. Ashkar, M. Koyuturk, J.P. Maciejewski, T. LaFramboise, Whole-exome sequencing enhances prognostic classification of myeloid malignancies, Journal of biomedical informatics 58 (2015) 104-113.

[117] C.A. Cargo, N. Rowbotham, P.A. Evans, S.L. Barrans, D.T. Bowen, S. Crouch, A.S. Jack, Targeted sequencing identifies patients with preclinical MDS at high risk of disease progression, Blood 126(21) (2015) 2362-5.

[118] X. Liang, S. Vacher, A. Boulai, V. Bernard, S. Baulande, M. Bohec, I. Bieche, F. Lerebours, C. Callens, Targeted next-generation sequencing identifies clinically relevant somatic mutations in a large cohort of inflammatory breast cancer, Breast cancer research : BCR 20(1) (2018) 88.

[119] J.C. Thompson, S.S. Yee, A.B. Troxel, S.L. Savitch, R. Fan, D. Balli, D.B. Lieberman, J.D. Morrissette, T.L. Evans, J. Bauml, C. Aggarwal, J.A. Kosteva, E. Alley, C. Ciunci, R.B. Cohen, S. Bagley, S. Stonehouse-Lee, V.E. Sherry, E. Gilbert, C. Langer, A. Vachani, E.L. Carpenter, Detection of Therapeutically Targetable Driver and Resistance Mutations in Lung Cancer Patients by NextGeneration Sequencing of Cell-Free Circulating Tumor DNA, Clinical cancer research : an official journal of the American Association for Cancer Research 22(23) (2016) 5772-5782.

[120] S. Behjati, P.S. Tarpey, What is next generation sequencing?, Archives of disease in childhood. Education and practice edition 98(6) (2013) 236-8.

[121] S. Goodwin, J.D. McPherson, W.R. McCombie, Coming of age: ten years of next-generation sequencing technologies, Nature reviews. Genetics 17(6) (2016) 333-51.

[122] L. Liu, Y. Li, S. Li, N. Hu, Y. He, R. Pong, D. Lin, L. Lu, M. Law, Comparison of next-generation sequencing systems, Journal of biomedicine \& biotechnology 2012 (2012) 251364. 
[123] M.A. Quail, M. Smith, P. Coupland, T.D. Otto, S.R. Harris, T.R. Connor, A. Bertoni, H.P. Swerdlow, Y. Gu, A tale of three next generation sequencing platforms: comparison of Ion Torrent, Pacific Biosciences and Illumina MiSeq sequencers, BMC genomics 13 (2012) 341.

[124] L. Mamanova, A.J. Coffey, C.E. Scott, I. Kozarewa, E.H. Turner, A. Kumar, E. Howard, J. Shendure, D.J. Turner, Target-enrichment strategies for next-generation sequencing, Nature methods 7(2) (2010) 111-8.

[125] E.R. Mardis, Next-generation DNA sequencing methods, Annual review of genomics and human genetics 9 (2008) 387-402.

[126] M. Margulies, M. Egholm, W.E. Altman, S. Attiya, J.S. Bader, L.A. Bemben, J. Berka, M.S. Braverman, Y.J. Chen, Z. Chen, S.B. Dewell, L. Du, J.M. Fierro, X.V. Gomes, B.C. Godwin, W. He, S. Helgesen, C.H. Ho, G.P. Irzyk, S.C. Jando, M.L. Alenquer, T.P. Jarvie, K.B. Jirage, J.B. Kim, J.R. Knight, J.R. Lanza, J.H. Leamon, S.M. Lefkowitz, M. Lei, J. Li, K.L. Lohman, H. Lu, V.B. Makhijani, K.E. McDade, M.P. McKenna, E.W. Myers, E. Nickerson, J.R. Nobile, R. Plant, B.P. Puc, M.T. Ronan, G.T. Roth, G.J. Sarkis, J.F. Simons, J.W. Simpson, M. Srinivasan, K.R. Tartaro, A. Tomasz, K.A. Vogt, G.A. Volkmer, S.H. Wang, Y. Wang, M.P. Weiner, P. Yu, R.F. Begley, J.M. Rothberg, Genome sequencing in microfabricated high-density picolitre reactors, Nature 437(7057) (2005) 376-80.

[127] J.M. Rothberg, J.H. Leamon, The development and impact of 454 sequencing, Nature biotechnology 26(10) (2008) 1117-24.

[128] D.C. Koboldt, K.M. Steinberg, D.E. Larson, R.K. Wilson, E.R. Mardis, The next-generation sequencing revolution and its impact on genomics, Cell 155(1) (2013) 27-38.

[129] Z. Shi, T. Qin, Z. Xu, B. Li, H. Huang, H. Zhang, L. Fang, L. Pan, N. Hu, S. Qu, G. Huang, R.P. Gale, Z. Xiao, Prognostic mutations in persons with isolated neutropenia myelodysplastic syndrome, Leukemia \& lymphoma (2019) 1-3.

[130] S. Jeromin, S. Weissmann, C. Haferlach, F. Dicker, K. Bayer, V. Grossmann, T. Alpermann, A. Roller, A. Kohlmann, T. Haferlach, W. Kern, S. Schnittger, SF3B1 mutations correlated to cytogenetics and mutations in NOTCH1, FBXW7, MYD88, XPO1 and TP53 in 1160 untreated CLL patients, Leukemia 28(1) (2014) 108-17.

[131] L. Malcovati, M.G. Della Porta, D. Pietra, E. Boveri, A. Pellagatti, A. Galli, E. Travaglino, A. Brisci, E. Rumi, F. Passamonti, R. Invernizzi, L. Cremonesi, J. Boultwood, J.S. Wainscoat, E. Hellstrom-Lindberg, M. Cazzola, Molecular and clinical features of refractory anemia with ringed sideroblasts associated with marked thrombocytosis, Blood 114(17) (2009) 3538-45.

[132] L. Malcovati, E. Papaemmanuil, D.T. Bowen, J. Boultwood, M.G. Della Porta, C. Pascutto, E. Travaglino, M.J. Groves, A.L. Godfrey, I. Ambaglio, A. Galli, M.C. Da Via, S. Conte, S. Tauro, N. Keenan, A. Hyslop, J. Hinton, L.J. Mudie, J.S. Wainscoat, P.A. Futreal, M.R. Stratton, P.J. Campbell, E. Hellstrom-Lindberg, M. Cazzola, C. Chronic Myeloid Disorders Working Group of the International Cancer Genome, M. of the Associazione Italiana per la Ricerca sul Cancro Gruppo Italiano Malattie, Clinical significance of SF3B1 mutations in myelodysplastic syndromes and myelodysplastic/myeloproliferative neoplasms, Blood 118(24) (2011) 6239-46.

[133] E.M. Je, N.J. Yoo, Y.J. Kim, M.S. Kim, S.H. Lee, Mutational analysis of splicing machinery genes SF3B1, U2AF1 and SRSF2 in myelodysplasia and other common tumors, International journal of cancer 133(1) (2013) 260-5.

[134] G. Genovese, A.K. Kahler, R.E. Handsaker, J. Lindberg, S.A. Rose, S.F. Bakhoum, K. Chambert, E. Mick, B.M. Neale, M. Fromer, S.M. Purcell, O. Svantesson, M. Landen, M. Hoglund, S. Lehmann, S.B. Gabriel, J.L. Moran, E.S. Lander, P.F. Sullivan, P. Sklar, H. Gronberg, C.M. Hultman, S.A. McCarroll, Clonal hematopoiesis and blood-cancer risk inferred from blood DNA sequence, The New England journal of medicine 371(26) (2014) 2477-87.

[135] V. Visconte, H.J. Rogers, J. Singh, J. Barnard, M. Bupathi, F. Traina, J. McMahon, H. Makishima, H. Szpurka, A. Jankowska, A. Jerez, M.A. Sekeres, Y. Saunthararajah, A.S. Advani, E. Copelan, H. Koseki, K. Isono, R.A. Padgett, S. Osman, K. Koide, C. O'Keefe, J.P. Maciejewski, R.V. Tiu, SF3B1 haploinsufficiency leads to formation of ring sideroblasts in myelodysplastic syndromes, Blood 120(16) (2012) 3173-86. 
[136] I. Martin, E. Such, B. Navarro, E. Villamon, A. Vicente, E. Mora, L. Pedrola, M. Ibanez, M. Lopez-Pavia, M. Tormo, A. Serrano, M.A. Sanz, J. Cervera, G. Sanz, Prognostic impact of gene mutations in myelodysplastic syndromes with ring sideroblasts, Blood cancer journal 7(12) (2017) 630.

[137] I. Martin, E. Such, B. Navarro, A. Vicente, M. Lopez-Pavia, M. Ibanez, M. Tormo, E. Villamon, I. Gomez-Segui, I. Luna, S. Oltra, L. Pedrola, M.A. Sanz, J. Cervera, G. Sanz, Negative impact on clinical outcome of the mutational co-occurrence of SF3B1 and DNMT3A in refractory anemia with ring sideroblasts (RARS), Leukemia \& lymphoma 58(7) (2017) 1686-1693.

[138] E. Kouvidi, A. Stratigi, A. Batsali, I. Mavroudi, S. Mastrodemou, M. Ximeri, H.A. Papadaki, C.G. Pontikoglou, Cytogenetic evaluation of mesenchymal stem/stromal cells from patients with myelodysplastic syndromes at different time-points during ex vivo expansion, Leukemia research 43 (2016) 24-32.

[139] S.D. Mundle, P. Venugopal, J.D. Cartlidge, D.V. Pandav, L. Broady-Robinson, S. Gezer, E.L. Robin, S.R. Rifkin, M. Klein, D.E. Alston, B.M. Hernandez, D. Rosi, S. Alvi, V.T. Shetty, S.A. Gregory, A. Raza, Indication of an involvement of interleukin-1 beta converting enzyme-like protease in intramedullary apoptotic cell death in the bone marrow of patients with myelodysplastic syndromes, Blood 88(7) (1996) 2640-7.

[140] N.A. Zambetti, Z. Ping, S. Chen, K.J.G. Kenswil, M.A. Mylona, M.A. Sanders, R.M. Hoogenboezem, E.M.J. Bindels, M.N. Adisty, P.M.H. Van Strien, C.S. van der Leije, T.M. Westers, E.M.P. Cremers, C. Milanese, P.G. Mastroberardino, J. van Leeuwen, B.C.J. van der Eerden, I.P. Touw, T.W. Kuijpers, R. Kanaar, A.A. van de Loosdrecht, T. Vogl, M. Raaijmakers, Mesenchymal Inflammation Drives Genotoxic Stress in Hematopoietic Stem Cells and Predicts Disease Evolution in Human Pre-leukemia, Cell stem cell 19(5) (2016) 613-627.

[141] M.K. Majumdar, M.A. Thiede, S.E. Haynesworth, S.P. Bruder, S.L. Gerson, Human marrowderived mesenchymal stem cells (MSCs) express hematopoietic cytokines and support long-term hematopoiesis when differentiated toward stromal and osteogenic lineages, Journal of hematotherapy \& stem cell research 9(6) (2000) 841-8.

[142] N. Van Overstraeten-Schlogel, Y. Beguin, A. Gothot, Role of stromal-derived factor-1 in the hematopoietic-supporting activity of human mesenchymal stem cells, European journal of haematology 76(6) (2006) 488-93.

[143] Z.G. Zhao, W. Xu, H.P. Yu, B.L. Fang, S.H. Wu, F. Li, W.M. Li, Q.B. Li, Z.C. Chen, P. Zou, Functional characteristics of mesenchymal stem cells derived from bone marrow of patients with myelodysplastic syndromes, Cancer letters 317(2) (2012) 136-43.

[144] V. Soenen-Cornu, C. Tourino, M.L. Bonnet, M. Guillier, S. Flamant, R. Kotb, A. Bernheim, J.H. Bourhis, C. Preudhomme, P. Fenaux, A.G. Turhan, Mesenchymal cells generated from patients with myelodysplastic syndromes are devoid of chromosomal clonal markers and support shortand long-term hematopoiesis in vitro, Oncogene 24(15) (2005) 2441-8.

[145] M. Klaus, E. Stavroulaki, M.C. Kastrinaki, P. Fragioudaki, K. Giannikou, M. Psyllaki, C. Pontikoglou, D. Tsoukatou, C. Mamalaki, H.A. Papadaki, Reserves, functional, immunoregulatory, and cytogenetic properties of bone marrow mesenchymal stem cells in patients with myelodysplastic syndromes, Stem cells and development 19(7) (2010) 1043-54.

[146] Q. Han, Z. Sun, L. Liu, B. Chen, Y. Cao, K. Li, R.C. Zhao, Impairment in immuno-modulatory function of Flk1(+)CD31(-)CD34(-) MSCs from MDS-RA patients, Leukemia research 31(11) (2007) 1469-78.

[147] R.M. Shallis, R. Ahmad, A.M. Zeidan, The genetic and molecular pathogenesis of myelodysplastic syndromes, European journal of haematology 101(3) (2018) 260-271.

[148] H. Makishima, V. Visconte, H. Sakaguchi, A.M. Jankowska, S. Abu Kar, A. Jerez, B. Przychodzen, M. Bupathi, K. Guinta, M.G. Afable, M.A. Sekeres, R.A. Padgett, R.V. Tiu, J.P. Maciejewski, Mutations in the spliceosome machinery, a novel and ubiquitous pathway in leukemogenesis, Blood 119(14) (2012) 3203-10.

[149] C.C. Lin, H.A. Hou, W.C. Chou, Y.Y. Kuo, S.J. Wu, C.Y. Liu, C.Y. Chen, M.H. Tseng, C.F. Huang, F.Y. Lee, M.C. Liu, C.W. Liu, J.L. Tang, M. Yao, S.Y. Huang, S.C. Hsu, B.S. Ko, W. Tsay, Y.C. Chen, H.F. 
Tien, SF3B1 mutations in patients with myelodysplastic syndromes: the mutation is stable during disease evolution, American journal of hematology 89(8) (2014) E109-15.

[150] A.C. Tsiatis, A. Norris-Kirby, R.G. Rich, M.J. Hafez, C.D. Gocke, J.R. Eshleman, K.M. Murphy, Comparison of Sanger sequencing, pyrosequencing, and melting curve analysis for the detection of KRAS mutations: diagnostic and clinical implications, The Journal of molecular diagnostics : JMD 12(4) (2010) 425-32.

[151] C. Meldrum, M.A. Doyle, R.W. Tothill, Next-generation sequencing for cancer diagnostics: a practical perspective, The Clinical biochemist. Reviews / Australian Association of Clinical Biochemists 32(4) (2011) 177-95.

[152] G. Montalban-Bravo, K. Takahashi, K. Patel, F. Wang, S. Xingzhi, G.M. Nogueras, X. Huang, A.A. Pierola, E. Jabbour, S. Colla, I. Ganan-Gomez, G. Borthakur, N. Daver, Z. Estrov, T. Kadia, N. Pemmaraju, F. Ravandi, C. Bueso-Ramos, A. Chamseddine, M. Konopleva, J. Zhang, H. Kantarjian, A. Futreal, G. Garcia-Manero, Impact of the number of mutations in survival and response outcomes to hypomethylating agents in patients with myelodysplastic syndromes or myelodysplastic/myeloproliferative neoplasms, Oncotarget 9(11) (2018) 9714-9727.

[153] I. Triantafyllidis, A. Ciobanu, O. Stanca, A.R. Lupu, Prognostic factors in myelodysplastic syndromes, Maedica 7(4) (2012) 295-302.

[154] S. Jaiswal, P. Fontanillas, J. Flannick, A. Manning, P.V. Grauman, B.G. Mar, R.C. Lindsley, C.H. Mermel, N. Burtt, A. Chavez, J.M. Higgins, V. Moltchanov, F.C. Kuo, M.J. Kluk, B. Henderson, L. Kinnunen, H.A. Koistinen, C. Ladenvall, G. Getz, A. Correa, B.F. Banahan, S. Gabriel, S. Kathiresan, H.M. Stringham, M.I. McCarthy, M. Boehnke, J. Tuomilehto, C. Haiman, L. Groop, G. Atzmon, J.G. Wilson, D. Neuberg, D. Altshuler, B.L. Ebert, Age-related clonal hematopoiesis associated with adverse outcomes, The New England journal of medicine 371(26) (2014) 2488-98.

[155] C. Santamaria, S. Muntion, B. Roson, B. Blanco, O. Lopez-Villar, S. Carrancio, F.M. SanchezGuijo, M. Diez-Campelo, S. Alvarez-Fernandez, M.E. Sarasquete, J. de las Rivas, M. Gonzalez, J.F. San Miguel, M.C. Del Canizo, Impaired expression of DICER, DROSHA, SBDS and some microRNAs in mesenchymal stromal cells from myelodysplastic syndrome patients, Haematologica 97(8) (2012) 1218-24.

[156] G. Varga, J. Kiss, J. Varkonyi, V. Vas, P. Farkas, K. Paloczi, F. Uher, Inappropriate Notch activity and limited mesenchymal stem cell plasticity in the bone marrow of patients with myelodysplastic syndromes, Pathology oncology research : POR 13(4) (2007) 311-9.

[157] K. Pavlaki, C.G. Pontikoglou, A. Demetriadou, A.K. Batsali, A. Damianaki, E. Simantirakis, M. Kontakis, A. Galanopoulos, I. Kotsianidis, M.C. Kastrinaki, H.A. Papadaki, Impaired proliferative potential of bone marrow mesenchymal stromal cells in patients with myelodysplastic syndromes is associated with abnormal WNT signaling pathway, Stem cells and development 23(14) (2014) 1568-81.

[158] E. Flores-Figueroa, J.J. Montesinos, P. Flores-Guzman, G. Gutierrez-Espindola, R.M. AranaTrejo, S. Castillo-Medina, A. Perez-Cabrera, E. Hernandez-Estevez, L. Arriaga, H. Mayani, Functional analysis of myelodysplastic syndromes-derived mesenchymal stem cells, Leukemia research 32(9) (2008) 1407-16.

[159] A. Warr, C. Robert, D. Hume, A. Archibald, N. Deeb, M. Watson, Exome Sequencing: Current and Future Perspectives, G3 5(8) (2015) 1543-50.

[160] S. Stasik, C. Schuster, C. Ortlepp, U. Platzbecker, M. Bornhauser, J. Schetelig, G. Ehninger, G. Folprecht, C. Thiede, An optimized targeted Next-Generation Sequencing approach for sensitive detection of single nucleotide variants, Biomolecular detection and quantification 15 (2018) 6-12. 
References 
Supplementary Appendix 


\section{A two-step approach for sequencing spliceosome-related genes as a complementary diagnostic assay in MDS patients with ringed sideroblasts}

Kamila Janusz ${ }^{1,2^{*}}$, Mónica del Rey ${ }^{1,2^{*}}$, María Abáigar ${ }^{1,2}$, Rosa Collado ${ }^{3}$, David Ivars ${ }^{3}$, María Hernández ${ }^{1,2}$, Alberto Valiente ${ }^{4}$, Cristina Robledo ${ }^{1,2}$, Rocío Benito ${ }^{1,2}$, María DíezCampelo $^{2,5}$, Fernando Ramos ${ }^{6}$, Alexander Kohlmann ${ }^{7}$, Consuelo del Cañizo ${ }^{2,5}$ and Jesús María Hernández-Rivas ${ }^{1,2,5}$

Supplementary Table S1. Clinical features of 122 MDS-RS patients

\begin{tabular}{|c|c|c|}
\hline WHO subtype & $\%$ & median [range] \\
\hline RARS & 55 & \\
\hline RCMD-RS & 45 & \\
\hline Age (years) & & 77 [29-95] \\
\hline \multicolumn{3}{|l|}{ Sex } \\
\hline Male & 33.7 & \\
\hline Female & 66.3 & \\
\hline \multicolumn{3}{|l|}{ Karyotype } \\
\hline Normal & 65.8 & \\
\hline No mitosis & 13.7 & \\
\hline Abnormal & 20.5 & \\
\hline Hb level (g/dL) & & $9.7[5.4-13]$ \\
\hline WBC count $\left(\times 10^{9} / L\right)$ & & $5.8[1.1-19.5]$ \\
\hline Neutrophil count $\left(\times 10^{9} / \mathrm{L}\right)$ & & $3[0.3-15]$ \\
\hline Platelet count $\left(\times 10^{9} / \mathrm{L}\right)$ & & $264[3.6-1018]$ \\
\hline Bone marrow blasts (\%) & & $0.8[0-4]$ \\
\hline Monocytes / $\mathrm{mm}^{3}$ & & $400[100-80000]$ \\
\hline
\end{tabular}

Supplementary Table S2. Primer sequences designed for SF3B1 Sanger sequencing

\begin{tabular}{|c|c|c|}
\hline $\begin{array}{c}\text { SF3B1 } \\
\text { Oligonucleotide } \\
\left(\mathbf{5}^{\prime} \rightarrow \mathbf{3}^{\prime} \mathbf{)}\right.\end{array}$ & Exon $\mathbf{1 4}$ & Exon $\mathbf{1 5}$ \\
\hline Forward & CCAACTCATGACTGTCCTTTCTT & TTGGGGCATAGTTAAAACCTG \\
\hline Reverse & GGGCAACATAGTAAGACCCTGT & AAATCAAAAGGTAATTGGTGGA \\
\hline Annealing temperature & $59.9^{\circ} \mathrm{C}$ & $57.1^{\circ} \mathrm{C}$ \\
\hline
\end{tabular}


Supplementary Table S3. Information on primer-pair sequences for Spliceosome-related genes by using 454 amplicon deep sequencing

\begin{tabular}{|c|c|c|c|c|}
\hline Gene & $\begin{array}{c}\text { Exon/ } \\
\text { Amplicon }\end{array}$ & Forward Sequence $\left(5^{\prime}\right.$-> 3') & Reverse Sequence (5' -> 3') & Length \\
\hline \multirow{7}{*}{$S F 3 B 1$} & 10 & GTGCAAATATTGTTCATTATGCTGT & TGTTAAGGGAAGTTGAAATGTTATGA & 345 \\
\hline & 11 & TCATAACATTTCAACTTCCCTTAACA & ACATGGCCAGGTGCAGAG & 331 \\
\hline & 12 & TGGAAAATCTTCTTTGAGTAATTTG & GTGCAAAGGAAAAGGTCTAGGA & 364 \\
\hline & 13 & TCTTAAACAGTTCGTCCCTTGA & GTAGCCAGACCAGCAGCCTA & 360 \\
\hline & 14 & CCAACTCATGACTGTCCTTTCT & CATAGTAAGACCCTGTCTCCTAAAGA & 369 \\
\hline & 15 & TGAGAGAATCTGGATGATATTGTGT & TTCAAGAAAGCAGCCAAACC & 336 \\
\hline & 16 & GCAACTCCTTATGGTATCGAATC & GAACCATGAAACATATCCAGTTTACA & 369 \\
\hline \multirow{8}{*}{ U2AF1 } & 1 & GCGTCGGCAGCAGTGTC & CCAAGGCCGGAGAAAGC & 353 \\
\hline & 2 & GCTGCTGACATATTCCATGTG & AACAAGGAGTGGTGGTCTCAG & 357 \\
\hline & 3 & ACTGAAGCACTTGCCAGAGG & TTAACACACGGTGGGAGTTCA & 331 \\
\hline & 4 & GGTTAACATGTTCTAACCAGCAAG & GTGGTCTCCCAGGTTGTCAC & 323 \\
\hline & 5 & GAGGTGAGAGAACTGAACTCTGTG & CACACTAAGCGGCTGCAC & 354 \\
\hline & 6 & GGCAAAATCTTGGACTATCTTGA & CGAACTGTGCTCAGTCACGTC & 360 \\
\hline & 7 & AGTGAGGAGTGGCCAGTGAC & GGTGAATATTCTTCTCCAAAGAGG & 359 \\
\hline & 8 & TGAAATCAGGGTGTGTCTCAGT & TCAACTACAACACTTTCTAGCAGACAT & 360 \\
\hline \multirow{12}{*}{ ZRSR2 } & 1 & TGAGCAGGGTTCTGGAAGAC & GCACCAGGAAGGAATGGAG & 337 \\
\hline & 2 & GCGGATGGAGAAGAACTGTC & TCAAGTTAGGGCTGGAGTGG & 362 \\
\hline & 3 & TTGTGTTGTACCAAAGAAGGTTG & GACTGGTACTGGTTAGTAAAGGTTG & 326 \\
\hline & 4 & TTTGCTCTCGTGTGTGTGTG & GAGATGGAGTTCCGCTCTTG & 330 \\
\hline & 5 & TGTGCGCTGTATGTGAAATG & GACCCGAAGAAGAGCATCAG & 330 \\
\hline & 6 & AGCCTGGGTGACAGAGTGAG & CCACGAAACTAACATTACTGGAA & 346 \\
\hline & 7 & GCGTAGTCTTGATTGCCTGTTCCAA & СTCTCCCAAAAGGGGAACTC & 343 \\
\hline & 8 & CCACCATGCCTGGTCTAAAG & TGTGTCCCAGCTCTCTTGTG & 375 \\
\hline & 9 & GGGAATGTTAGCCTGGACAA & GAACACGCCATTGCACTCTA & 340 \\
\hline & 10 & TCAGTGAACTTGGTGGTCCT & AAGCTATGCCTCACCACTTGA & 326 \\
\hline & 11.1 & AGTGCTGTTTCATCACTGTGC & CCTCTCCCGACTCTTTGATG & 343 \\
\hline & 11.2 & GGGAATCCGAGAGGAAAAGT & AACCCATCTGCGTTCATAGC & 357 \\
\hline \multirow{4}{*}{ SRSF2 } & 1.1 & CGCCCAGTTGTTACTCAGGT & GTCGTGAAAGCGAACGAAG & 368 \\
\hline & 1.2 & CAAGGTGGACAACCTGACCT & CCTCAGCCCCGTTTACCT & 331 \\
\hline & 1.3 & CCCGGACTCACACCACAG & CCAGGCCGCCATTATCTC & 339 \\
\hline & 2 & CGCTGCCTGGAATTAACC & TCGGATTCCCAGACATTACC & 376 \\
\hline
\end{tabular}

Length, including sequence-specific primer 
Supplementary Table S4. SF3B1 mutations not detected by Sanger sequencing, identified by NGS

\begin{tabular}{cccc} 
Case number & MDS subtype & Amino acid change & VAF by NGS \\
\hline 1 & RARS & p.Gly740Glu & $45 \%$ \\
\hline 2 & RARS & p.Gly742Asp & $37 \%$ \\
\hline 3 & RARS & p.Lys666Asn & $10 \%$ \\
\hline 4 & RARS & p.Lys748Glu & $35 \%$ \\
\hline 5 & RCMD-RS & p.Arg625Leu & $23 \%$ \\
\hline 6 & RCMD-RS & p.His662Gln & $18 \%$
\end{tabular}

RARS: refractory anemia with ring sideroblasts; RCMD-RS: refractory cytopenia with multilineage dysplasia and ring sideroblasts. 
Supplementary Table S5. Comparison of hematological data of MDS-RS patients with respect to the number of splicing genes mutations.

\begin{tabular}{lrrr}
\hline Characteristic & $\begin{array}{c}\text { 1 mutation } \\
\text { (mean/median*) }\end{array}$ & $\begin{array}{c}\text { 2 mutations } \\
\text { (mean/median*) }\end{array}$ & P value \\
\hline Hb level $(\mathrm{g} / \mathrm{dL})$ & 9.7 & 9.6 & 0.827 \\
Neutrophil count $\left(\times 10^{9} / \mathrm{L}\right)$ & $3.0^{*}$ & $3.1^{*}$ & 0.522 \\
Platelet count $\left(\times 10^{9} / \mathrm{L}\right)$ & 288.6 & 283.8 & 0.926 \\
WBC count $\left(\times 10^{9} / \mathrm{L}\right)$ & 6.3 & 7.3 & 0.423 \\
Monocytes $/ \mathrm{mm}^{3}$ & 460 & 522 & 0.658 \\
\hline
\end{tabular}

$\mathrm{Hb}$ : hemoglobin; WBC: white blood cells

Supplementary Table S6. Comparison of hematological data of MDS-RS patients with respect to the presence of splicing gene mutations.

\begin{tabular}{lrrr}
\hline Characteristic & $\begin{array}{c}\text { Not mutated } \\
\text { (mean/median*) }\end{array}$ & $\begin{array}{c}\text { Mutated } \\
\text { (mean/median*) }\end{array}$ & P value \\
\hline Hb level $(\mathrm{g} / \mathrm{dL})$ & 9.1 & 9.7 & 0.284 \\
Neutrophil count $\left(\times 10^{9} / \mathrm{L}\right)$ & $1.1^{*}$ & $3.0^{*}$ & 0.438 \\
Platelet count $\left(\times 10^{9} / \mathrm{L}\right)$ & $227^{*}$ & $266^{*}$ & 0.270 \\
WBC count $\left(\times 10^{9} / \mathrm{L}\right)$ & $6.5^{*}$ & $5.8^{*}$ & 0.968 \\
Monocytes $/ \mathrm{mm}^{3}$ & 317 & 465 & 0.284 \\
\hline
\end{tabular}

Hb: hemoglobin; WBC: white blood cells 
Supplementary Figure S1. Overall survival of MDS-RS patients with respect to mutations in SF3B1 and the other splicing genes analyzed (A), the presence of SF3B1 single mutation vs. double mutations (B), and the presence of concomitant mutations vs. wild type (WT) (C).

A

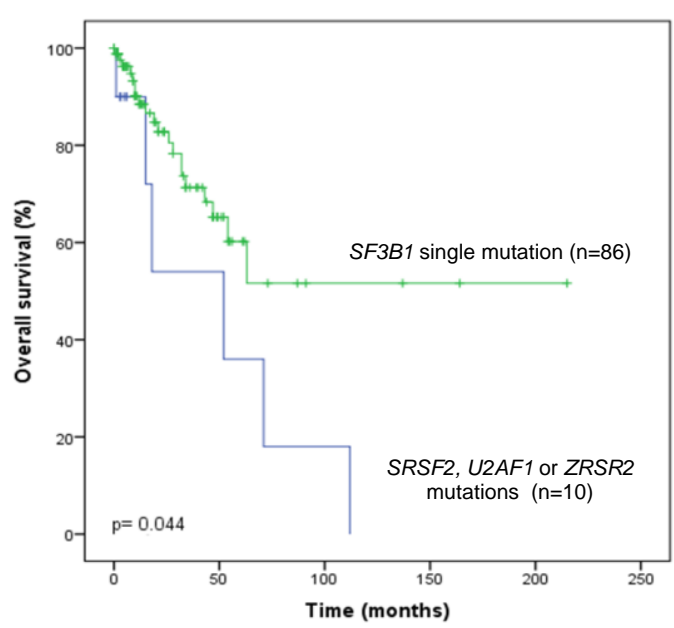

C

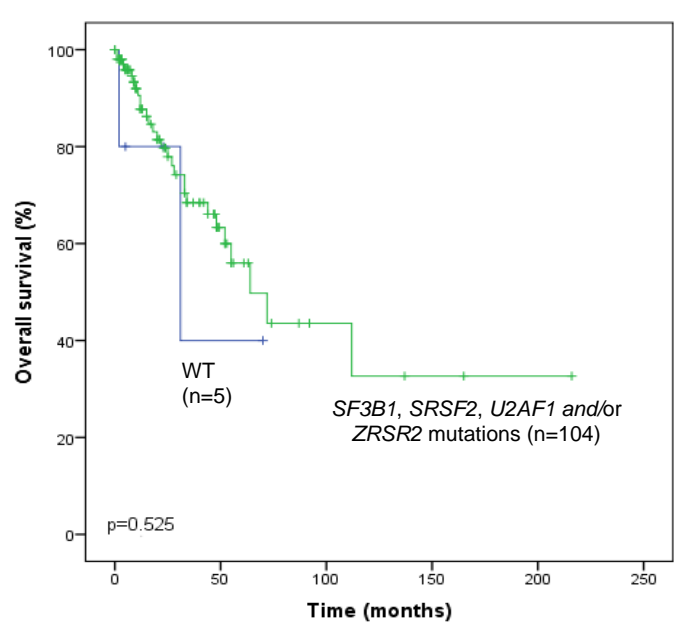

B

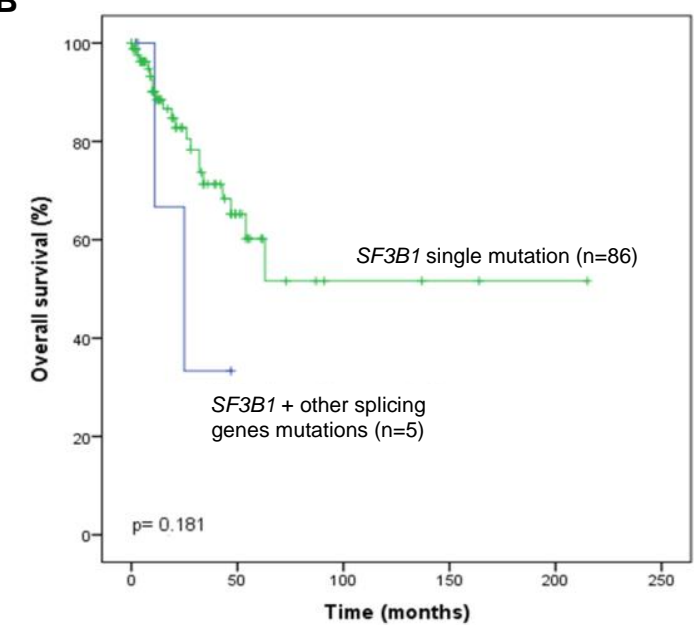




\section{Clincal, biological and prognostic implication of SF3B1 co- occurrence mutations in very low/low and intermediate-risk MDS patients}

Kamila Janusz ${ }^{1}$, Marta Martín Izquierdo ${ }^{1}$, Félix López Cadenas ${ }^{2}$, Fernando Ramos ${ }^{3}$, Jesús María Hernández Sánchez ${ }^{1}$, Eva Lumbreras ${ }^{1}$, Cristina Robledo $^{1}$, Javier Sánchez del Real ${ }^{3}$, Rosa Collado ${ }^{4}$, Teresa Bernal ${ }^{5}$, Carme Pedro $^{6}$, Andrés Insunza $^{7}$, Raquel de Paz ${ }^{8}$, Blanca Xicoy $^{9}$, Eduardo Salido ${ }^{10}$, Joaquín Sánchez García ${ }^{11}$, Sandra Santos Mínguez ${ }^{1}$, Cristina Miguel García ${ }^{1}$, Ana María Simón Muñoz ${ }^{1}$, Jesús María Hernández Rivas ${ }^{1,2}$, María Abáigar ${ }^{1}$, María Díez Campelo

Supplementary Figure 1. Summary of in-house sequencing pipeline algorithm used for base calls of somatic mutations.

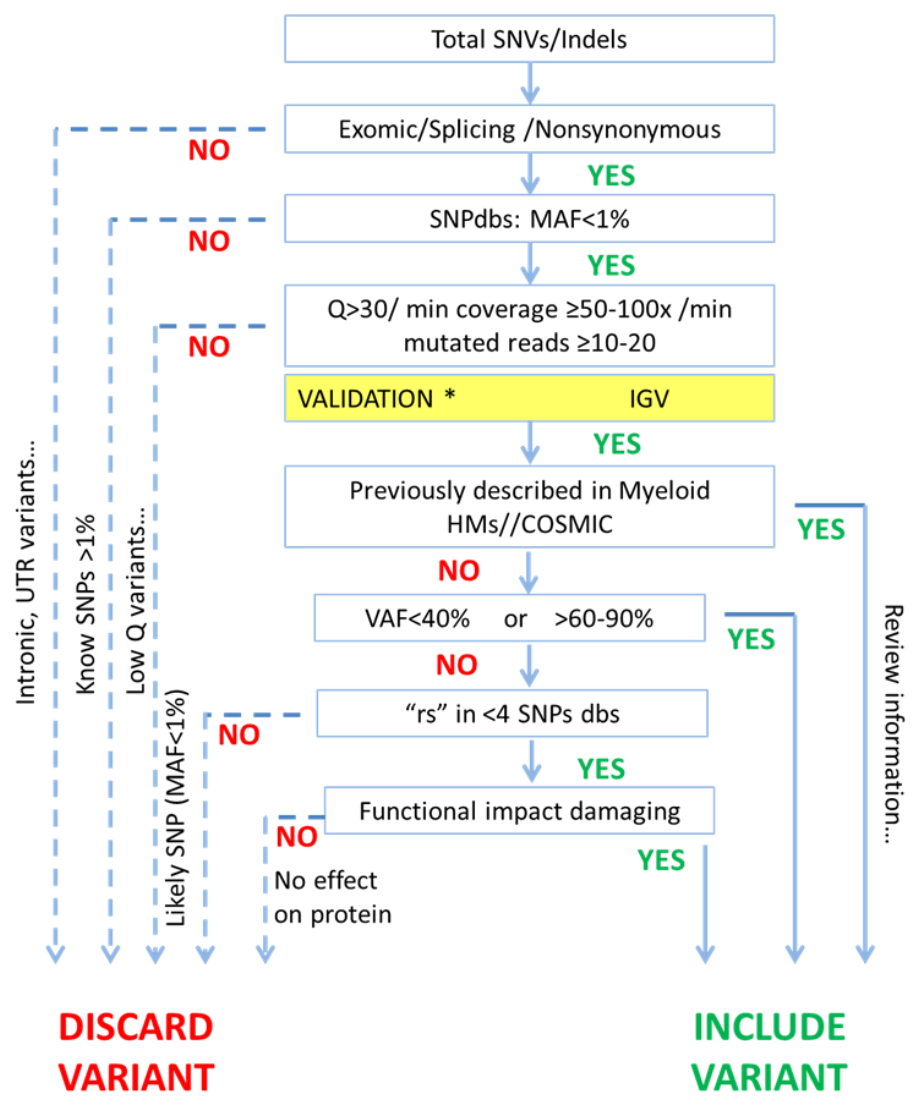


Supplementary Table S1. Customized panel of 117 myeloid-related genes applied in the study.

\begin{tabular}{|c|c|c|c|c|c|c|c|}
\hline$A B L 1$ & $C B L C$ & $E E D$ & HRAS & MECOM & PHF19 & SF1 & TET2 \\
\hline$A E B P 2$ & CD177 & $E G F R$ & $I D H 1$ & KMT2A & PHF6 & SF3A1 & TGM2 \\
\hline ARID2 & $\mathrm{CDH} 13$ & EIF2AK2 & $\mathrm{IDH} 2$ & KMT2D & PHLPP1 & $S F 3 B 1$ & TIMM50 \\
\hline$A S X L 1$ & $\mathrm{CDH} 23$ & ENG & $I K Z F 1$ & $M P L$ & PTEN & $S F P Q$ & TNFAIP3 \\
\hline ATRX & $\mathrm{CDH} 3$ & $E P 300$ & IL3 & MTOR & PTPN1 & $S H 2 B 3$ & TP53 \\
\hline$B C A S 1$ & CDK2 & ETV6 & IRF1 & $N F 1$ & PTPN11 & SMC1A & TYK2 \\
\hline$B C O R$ & CDKN2A & $E Z H 2$ & $J A K 1$ & NOTCH1 & RAD21 & SMC3 & U2AF1 \\
\hline BCORL1 & CEBPA & FBXW7 & $J A K 2$ & NPM1 & RARA & SPARC & UMODL1 \\
\hline$B C R$ & CREBBP & FLT3 & $J A K 3$ & NRAS & RET & SRSF2 & USB1 \\
\hline BMI1 & CSF3R & G3BP1 & JARID2 & NR2F6 & RPS14 & STAG1 & WASF3 \\
\hline BRAF & CSNK1A1 & GATA1 & $J K A M P$ & NTRK1 & RUNX1 & STAG2 & WT1 \\
\hline CALR & CTCF & GATA2 & KDM6A & NUP98 & SALL4 & SUZ12 & ZRSR2 \\
\hline$C B F B$ & CTNNA1 & GCAT & KIT & PBRM1 & $S B D S$ & $T C L 1 B$ & \\
\hline$C B L$ & CUX1 & GNAS & KRAS & PDGFRA & SETBP1 & TERC & \\
\hline CBLB & DNMT3A & GNB1 & LUC7L2 & PDGFRB & SETD2 & TERT & \\
\hline
\end{tabular}

Supplementary Table S2. Comparison of clinical features (median values) between patients with SF3B1mut isolated vs. SF3B1 with 1,2,3,4 and 5 additional mutations.

\begin{tabular}{|c|c|c|c|c|c|c|c|}
\hline & SF3B1 isolated & $S F 3 B 1+1$ & $S F 3 B 1+2$ & $S F 3 B 1+3$ & $S F 3 B 1+4$ & $S F 3 B 1+5$ & p \\
\hline Age & 76 & 75.8 & 76.6 & 79.5 & 76 & 78.2 & 0.885 \\
\hline Blasts (\%) & 0.3 & 0.5 & 1 & 0.6 & 1.4 & 0.8 & 0.035 \\
\hline RS (\%) & 46 & 40 & 40 & 27.5 & 68 & 36.5 & 0.217 \\
\hline $\mathrm{Hb}(\mathrm{g} / \mathrm{dL})$ & 10 & 9.3 & 10.2 & 9.6 & 8.6 & 10.3 & 0.134 \\
\hline Platelets (x10 $/ \mathrm{L})$ & 248 & 258 & 234 & 256 & 247 & 245 & 0.983 \\
\hline $\operatorname{ANC}\left(\times 10^{9} / L\right)$ & 2.9 & 3 & 3.2 & 2.6 & 1.9 & 1.9 & 0.284 \\
\hline
\end{tabular}




\section{Mutational status of mesenchymal stromal cells in myelodysplastic syndromes patients}

Kamila Janusz ${ }^{1,2}$, Sandra Muntion ${ }^{2,3}$, Jesús María Hernández-Sánchez ${ }^{1,2}$, Marta Martín Izquierdo ${ }^{1,2}$, María Hernández-Sánchez ${ }^{1,2}$, María Abáigar ${ }^{1,2}$, Cristina Robledo ${ }^{1,2}$, Félix López-Cadenas ${ }^{2,3}$, Mónica del Rey ${ }^{1,2}$, Juan Carlos Caballero ${ }^{2,3}$, Rocío Benito ${ }^{1,2}$, Alba Redondo Guijo ${ }^{2,3}$, Tamara Jimenez ${ }^{2,3}$, David Pescador ${ }^{4}$, Juan Blanco ${ }^{4}$, Fermín SánchezGuijo $^{2,3}$, Consuelo del Cañizo ${ }^{2,3}$, María Díez-Campelo ${ }^{2,3}$ and Jesús María HernándezRivas $^{1,2,3}$

Supplementary Table S1. Customized panel of 117 myeloid-related genes applied in the study.

\begin{tabular}{|c|c|c|c|c|c|c|c|}
\hline$A B L 1$ & $C B L C$ & EED & HRAS & MECOM & PHF19 & SF1 & TET2 \\
\hline$A E B P 2$ & CD177 & EGFR & $I D H 1$ & KMT2A & PHF6 & SF3A1 & TGM2 \\
\hline$A R I D 2$ & $\mathrm{CDH} 13$ & EIF2AK2 & $\mathrm{IDH} 2$ & KMT2D & PHLPP1 & SF3B1 & TIMM50 \\
\hline$A S X L 1$ & $\mathrm{CDH} 23$ & ENG & IKZF1 & $M P L$ & PTEN & SFPQ & TNFAIP3 \\
\hline ATRX & $\mathrm{CDH} 3$ & EP300 & IL3 & MTOR & PTPN1 & $\mathrm{SH} 2 \mathrm{~B} 3$ & TP53 \\
\hline BCAS1 & $C D K 2$ & ETV6 & IRF1 & $N F 1$ & PTPN11 & SMC1A & TYK2 \\
\hline$B C O R$ & CDKN2A & $E Z H 2$ & $J A K 1$ & NOTCH1 & RAD21 & SMC3 & U2AF1 \\
\hline BCORL1 & CEBPA & $F B X W 7$ & JAK2 & NPM1 & RARA & SPARC & UMODL1 \\
\hline$B C R$ & CREBBP & FLT3 & $J A K 3$ & NRAS & RET & SRSF2 & USB1 \\
\hline BMI1 & CSF3R & G3BP1 & JARID2 & NR2F6 & RPS14 & STAG1 & WASF3 \\
\hline BRAF & CSNK1A1 & GATA1 & $J K A M P$ & NTRK1 & RUNX1 & STAG2 & WT1 \\
\hline CALR & CTCF & GATA2 & $K D M 6 A$ & NUP98 & SALL4 & SUZ12 & ZRSR2 \\
\hline$C B F B$ & CTNNA1 & GCAT & KIT & PBRM1 & $S B D S$ & $T C L 1 B$ & \\
\hline$C B L$ & cuX1 & GNAS & KRAS & PDGFRA & SETBP1 & TERC & \\
\hline CBLB & DNMT3A & GNB1 & LUC7L2 & PDGFRB & SETD2 & TERT & \\
\hline
\end{tabular}




\section{List of Tables \& Figures}

\section{Introduction}

Table 1. WHO 2008 classification of MDS

Table 2. WHO 2016 classification of MDS

Table 3. A comparison between the International Prognostic Scoring System (IPSS) and the Revised International Prognostic Scoring System (IPSS-R)

Figure 1. Incidence of chromosome abnormalities in MDS

Figure 2. Frequency of driven mutations according to the MDS subtype

Figure 3. Representation of the spliceosome and splicing process, including the implication of the different snRNP in order to produce a mature mRNA

Figure 4. Distribution of SF3B1 mutations

Figure 5. Mesenchymal stromal and hematopoietic cells and their niche

Figure 6. Workflow of amplicon-based NGS by 454 system

Figure 7. Generation of DNA cluster by bridge amplification and sequencing by synthesis with the Miseq platform of Illumina

Results - Chapter1. A two-step approach for sequencing spliceosome-related genes as a complementary diagnostic assay in MDS patients with ringed sideroblasts

Table 1. SRSF2, U2AF1 and ZRSR2 gene mutations in MDS- RS

Figure 1. Distribution of missense mutations in SF3B1 in MDS-RS

Figure 2. Location of novel mutations identified in spliceosome-related genes in patients with MDS-RS 
Results - Chapter 2. Clincal, biological and prognostic implication of SF3B1 cooccurrence mutations in very low/low and intermediate-risk MDS patients

Table 1. Clinical features of 102 MDS patients

Table 2. Comparison of median values between patients with vs. without co-ocurrence SF3B1 mutation with CHIPs genes mutations

Figure 1. One hundred and seven SF3B1 mutations distributed in 102 patients according to WHO 2008 MDS subtypes

Figure 2. Frequency of mutations in fifty one genes co-ocurring with SF3B1 in 102 very low/low/intermediate-risk MDS patients

Figure 3. Mutational landscape of 102 MDS

Figure 4. Overall survival of MDS SF3B1 mut patients regarding the number of concomitants mutations, SRSF2mut co-ocurrence, IDH2mut co-ocurrence, BCORmut co-ocurrence, NUP98mut co-ocurrence, STAG2mut co-ocurrence

Figure 5. Overall survival of MDS SF3B1mut patients regarding to CHIPs gene coocurrence: TET2mut, DNMT3Amut, ASXL1mut

Results - Chapter 3. Mutational status of mesenchymal stromal cells in myelodysplastic syndromes patients

Table 1. The clinical features of 58 MDS patients

Table 2. The comparison of median values of several clinical features between patients with wild type MSC and mutated MSC

Table 3. Association of presence of MSC mutation with clinical features

Figure 1. The comparison of mutational landscape in HPC and MSC of 58 MDS patients 
Figure 2. The forty-four mutated genes in fifty-eight patients with MDS.

The comparison of mutated genes frequency between HPC and MSC

Figure 3. Paired analysis of eight patients with MDS showing the presence of MSC mutations and their HPC counterpart

Figure 4. Overall survival of MDS patients showing MSC wild type and MSC mutated

\section{Supplementary Appendix - Chapter 1}

Supplementary Table S1. Clinical features of 122 MDS-RS patients

Supplementary Table S2. Primer sequences designed for SF3B1 Sanger sequencing

Supplementary Table S3. Information on primer-pair sequences for Spliceosome-related genes by using 454 amplicon deep sequencing

Supplementary Table S4. SF3B1 mutations not detected by Sanger sequencing, identified by NGS

Supplementary Table S5. Comparison of hematological data of MDS-RS patients with respect to the number of splicing genes mutations

Supplementary Table S6. Comparison of hematological data of MDS-RS patients with respect to the presence of splicing gene mutations

Supplementary Figure S1. Overall survival of MDS-RS patients with respect to mutations in SF3B1 and the other splicing genes analyzed, the presence of SF3B1 single mutation vs. double mutations, and the presence of concomitant mutations vs. wild type (WT) 


\section{Supplementary Appendix - Chapter 2}

Supplementary Table S1. Customized panel of 117 myeloid-related genes applied in the study

Supplementary Table S2. Comparison of clinical features (median values) between patients with SF3B1mut isolated vs. SF3B1 with 1,2,3,4 and 5 additional mutations

Supplementary Figure 1. Summary of in-house sequencing pipeline algorithm used for base calls of somatic mutations

\section{Supplementary Appendix - Chapter 3}

Supplementary Table S1. Customized panel of 117 myeloid-related genes applied in the study 